\title{
Key Residential Building Equipment Technologies for Control and Grid Support - PART I (Residential)
}

\section{August 2011}

Prepared by

M. Starke

O. Onar

B. Devault

Oak Ridge National Laboratory 


\title{
TABLE OF CONTENTS
}

\begin{abstract}
Page
\end{abstract}

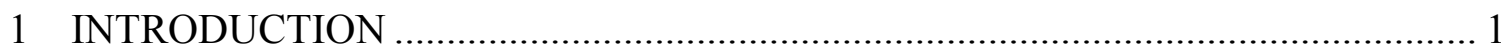

2 DEMAND RESPONSE: ANCILLARY SERVICES, LOAD SHEDDING, AND

LOAD FACTOR

2.1 Demand Response Programs …………............................................................. 3

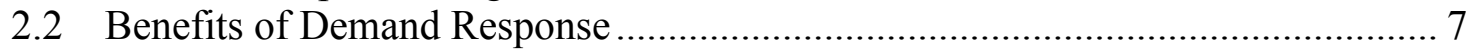

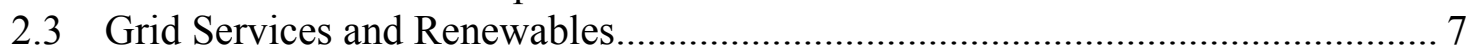

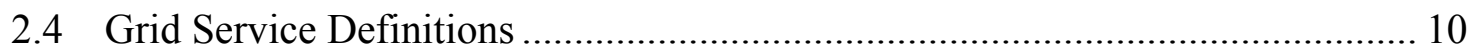

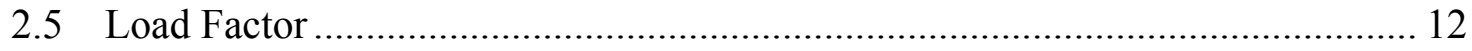

3 RESIDENTIAL LOAD CONTROL AND ONSITE-GENERATION_........................ 14

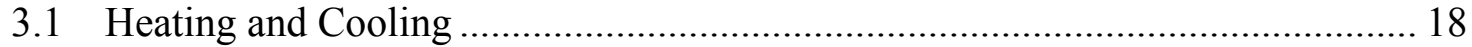

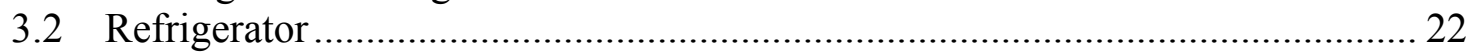

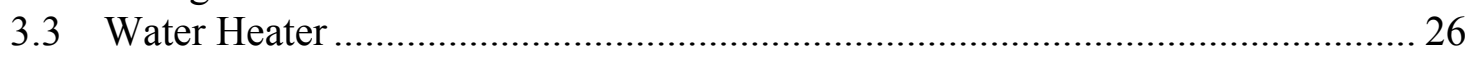

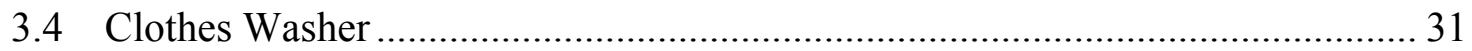

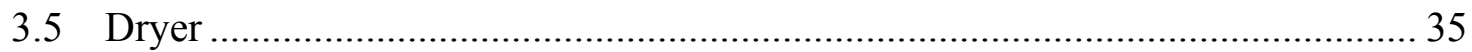

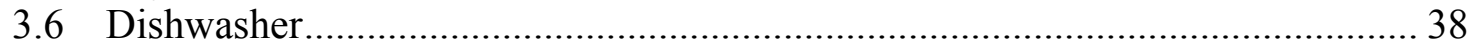

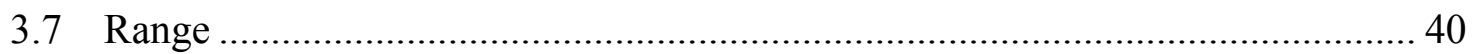

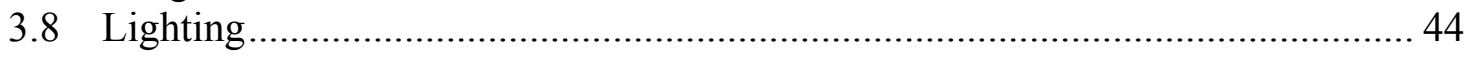

3.9 Computers/Electronics ............................................................................. 49

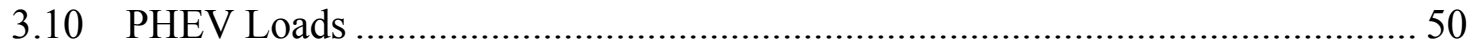

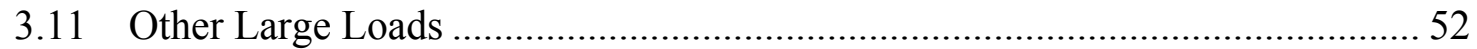

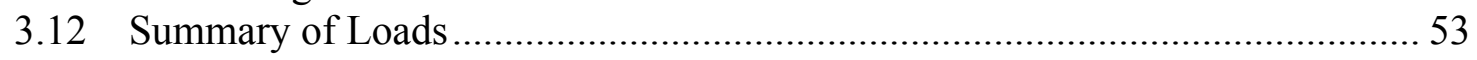

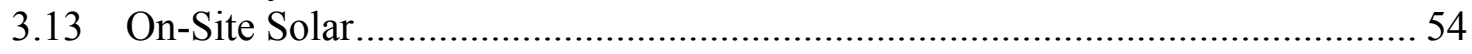

3.14 Demand Response Expectation.................................................................. 57

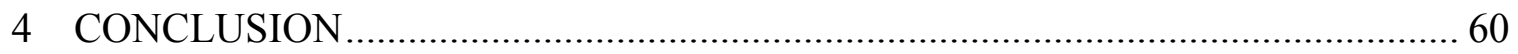

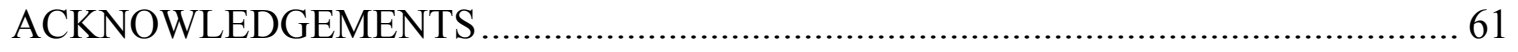

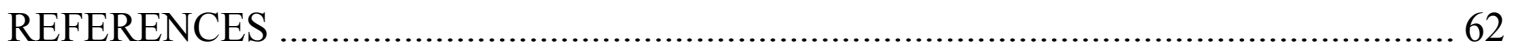




\section{LIST OF FIGURES}

Figure Page

Figure 2.1 Regional Transmission Organizations [6] .................................................... 4

Figure 2.2 ISO Demand Response Framework. ………................................................ 7

Figure 2.3 January 2010 PJM Load Profile .................................................................. 9

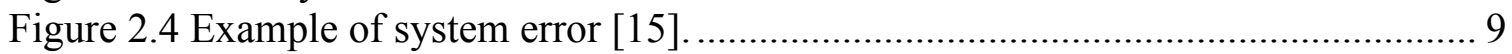

Figure 2.5 January 2010 Wind Generation Profile in PJM [15] .................................... 10

Figure 2.6. Grid services operations [1] .............................................................. 12

Figure 2.7 Adjustment of Load Factor.......................................................................... 13

Figure 3.1. Electrical energy consumption by sector [18] ........................................... 14

Figure 3.2. Annual energy consumption by sector between 1999-2009 [18] ................. 15

Figure 3.3. Residential load breakdown by electrical energy consumption [18].............. 16

Figure 3.4 Hourly usage for CC1 type home for 2010 (including all loads)................... 17

Figure 3.5 Simplified diagram of a vapor compression air-conditioning cycle operating

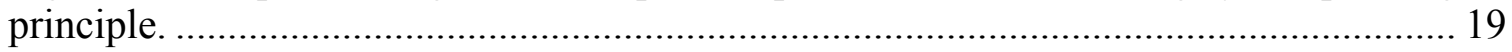

Figure 3.6 Hourly heating and cooling consumption for CC1 type home for 2010 ........ 19

Figure 3.7 Winter consumption example for HVAC in 2010 ....................................... 20

Figure 3.8 Summer consumption example of HVAC for 2010 ...................................... 20

Figure 3.9. Indoor/Outdoor temperature and comfort relationship [24]........................ 21

Figure 3.10 Humidity versus operating temperature acceptable operating range. [24] ... 22

Figure 3.11 Refrigerator cooling and heating loop schematic ........................................ 23

Figure 3.12 Hourly refrigerator usage for CC1 type home for 2010 .............................. 24

Figure 3.13 Refrigerator characteristic profile.......................................................... 24

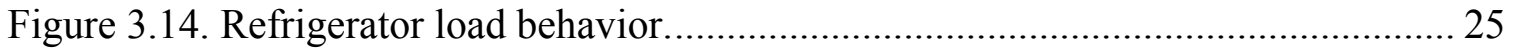

Figure 3.15 Relay control system for compressor control........................................... 25

Figure 3.16 Electrical schematic of a conventional water heater. ................................... 27

Figure 3.17. Hourly water heater usage for CC1 type home for 2010 ............................ 28

Figure 3.18. Water heater profile (6/01/2010) .............................................................. 28

Figure 3.19. Water heater performance behavior. .................................................... 29

Figure 3.20 Water heater with 120-240V position switch for load reduction .................. 29

Figure 3.21 Water heater with switchable heating elements; (a) series elements with

parallel by-pass switches, (b) parallel elements with series switches............................... 30

Figure 3.22 Clothes washer electrical schematic ......................................................... 32

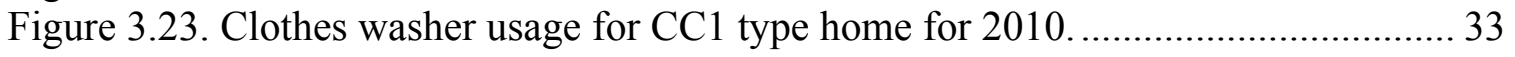

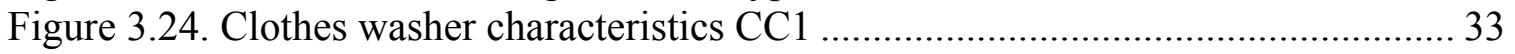

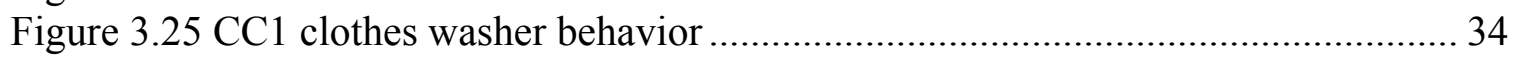

Figure 3.26 Clothes washer behavior behavior for Atlanta homes................................... 34

Figure 3.27 Dryer electrical schematic …………………........................................ 35

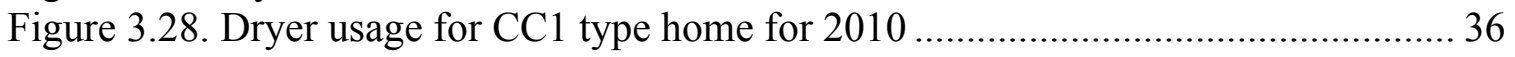

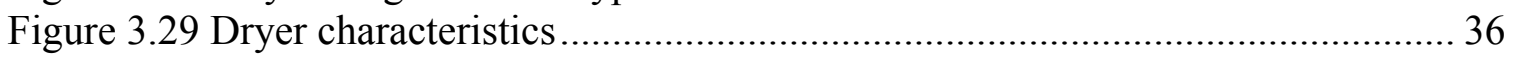

Figure 3.30 Dryer behavior for $\mathrm{CC} 1$ homes .................................................................. 37

Figure 3.31 Dryer behavior for Atlanta homes.............................................................. 37

Figure 3.32. Dishwasher usage for CC1 type home for 2010 ....................................... 38

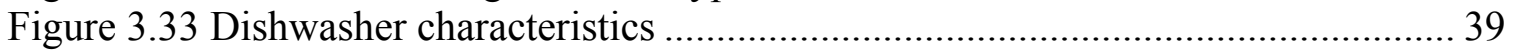

Figure 3.34 Dishwasher performance for $\mathrm{CC} 1$ homes................................................... 39 
Figure 3.35 Dishwasher performance for Atlanta homes............................................... 40

Figure 3.36. Electrical schematic of a range............................................................... 40

Figure 3.37. Electrical layout of an oven with bake and broil heating elements............. 41

Figure 3.38. Range usage for $\mathrm{CC} 1$ type home for 2010 ............................................. 41

Figure 3.39 Range characteristics .......................................................................... 42

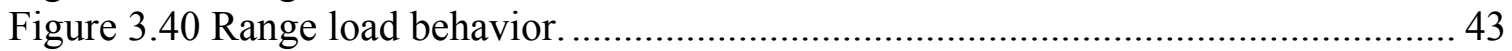

Figure 3.41 Cooktop heating element set to lower heating. ............................................. 44

Figure 3.42 Cooktop heating element set to higher heating. …………………............... 44

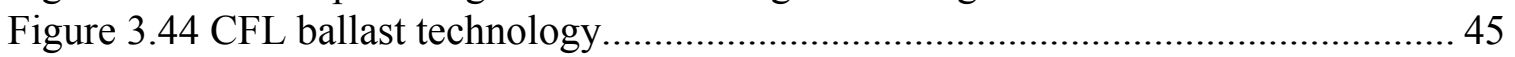

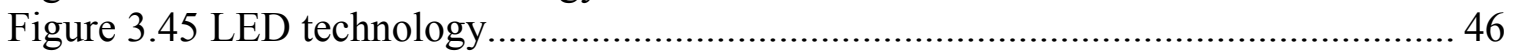

Figure 3.46. Lighting usage for $\mathrm{CC} 1$ type home for 2010.......................................... 47

Figure 3.47 Power and Light Characteristics of Typical Dimming Ballast [48]............. 48

Figure 3.48 Simplified diagram of a computer power supply. ....................................... 50

Figure 3.49 A PHEV or EV connected to the grid. ....................................................... 51

Figure 3.50 Hourly energy generation of PV panels at CC3 home and global solar

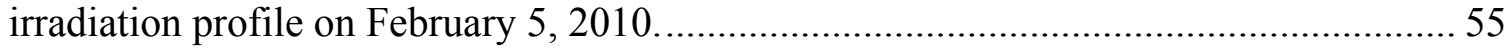

Figure 3.51 Hourly energy generation of PV panels at CC3 home and global solar

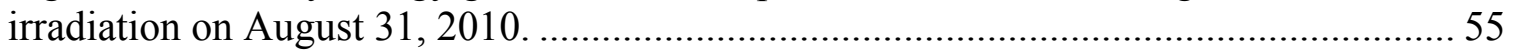

Figure 3.52 PV Characteristic curves. ...................................................................... 56

Figure $3.53 \mathrm{~A}$ solar energy system with maximum power point tracking........................ 57

Figure 3.54 Peak demand reduction potential estimated by Brattle [63] ......................... 59 


\section{LIST OF TABLES}

Table

Page

Table 2.1 Demand response characteristics for various markets across the U.S. [5]-[14] . 5

Table 3.1. Legionella growth range with water temperature [39] 31

Table 3.2. Clothes washer usage in millions of U.S. homes, EIA 2005 [40] ................... 32

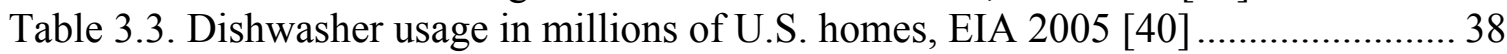

Table 3.4. Range usage in millions of U.S. homes, EIA 2005 [40] ............................... 42

Table 3.5 Millions of U.S. homes using lighting in summer; 2005 EIA data [65]......... 47

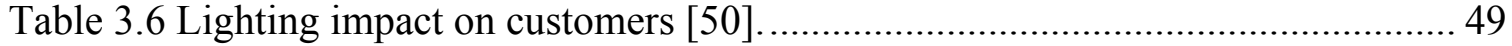

Table 3.7 Battery specifications of Chevy Volt, Nissan Leaf, and Toyota Prius. ........... 52

Table 3.8 Specifications of the Coulomb Tech Vehicle Chargers [60] ............................ 52

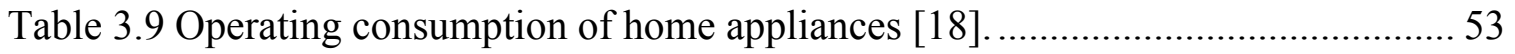

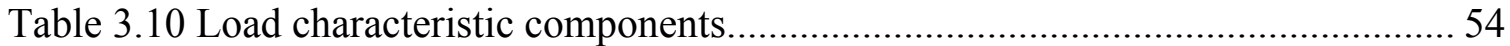

Table 3.11 Assumptions on demand response study by Brattle [63] ............................ 58 


\section{ACRONYMS}

$\begin{array}{ll}\text { AC } & \text { Alternating current } \\ \text { CC1 } & \text { Campbell Creek house 1 } \\ \text { CC2 } & \text { Campbell Creek house 2 } \\ \text { CC3 } & \text { Campbell Creek house 3 } \\ \text { CFL } & \text { Compact fluorescent light } \\ \text { CLR } & \text { Controllable load resource } \\ \text { CSP } & \text { Curtailment service provider } \\ \text { DADRP } & \text { Day ahead demand reduction program } \\ \text { DALRP } & \text { Day ahead load response program (DALRP) } \\ \text { DC } & \text { Direct current } \\ \text { DRR } & \text { Demand response resource type } \\ \text { DSASP } & \text { Demand Side Ancillary Services Program } \\ \text { EDR } & \text { Emergency demand response } \\ \text { EDRP } & \text { Emergency demand response program } \\ \text { EILS } & \text { Emergency interruptible load service } \\ \text { EMS } & \text { Energy management system } \\ \text { ERCOT } & \text { Electric Reliability Council of Texas } \\ \text { EV } & \text { Electric vehicle } \\ \text { FDA } & \text { Food and Drug Administration } \\ \text { ISO } & \text { Independent system operator } \\ \text { ISO-NE } & \text { New England Independent System Operator } \\ \text { LaaR } & \text { Load Acting as a Resource } \\ \text { LED } & \text { Light emitting diode } \\ \text { LSE } & \text { Load serving entity } \\ \text { NYISO } & \text { New York Independent System Operator } \\ \text { OP } & \text { On Peak Seasonal Resources } \\ \text { OSHA } & \text { Occupational Safety and Health Administration } \\ \text { PHEV } & \text { Plug-in electric vehicle } \\ \text { PJM } & \text { Pennsylvania-New Jersey-Maryland Interconnection } \\ \text { PV } & \text { Photovoltaic (solar cells) } \\ \text { RTDRP } & \text { Real Time Demand Response Program } \\ \text { RTPRP } & \text { Real Time Price Response Program } \\ \text { SPP } & \text { Southwest Power Pool } \\ \text { VDDR } & \text { Variable Dispatch Demand Response } \\ & \end{array}$




\section{INTRODUCTION}

Electrical energy consumption of the residential sector is a crucial area of research that has in the past primarily focused on increasing the efficiency of household devices such as water heaters, dishwashers, air conditioners, and clothes washer and dryer units. However, the focus of this research is shifting as objectives such as developing the smart grid and ensuring that the power system remains reliable come to the fore, along with the increasing need to reduce energy use and costs. Load research has started to focus on mechanisms to support the power system through demand reduction and/or reliability services.

The power system relies on matching generation and load, and day-ahead and real-time energy markets capture most of this need. However, a separate set of grid services exist to address the discrepancies in load and generation arising from contingencies and operational mismatches, and to ensure that the transmission system is available for delivery of power from generation to load. Currently, these grid services are mostly provided by generation resources. The addition of renewable resources with their inherent variability can complicate the issue of power system reliability and lead to the increased need for grid services. Using load as a resource, through demand response programs, can fill the additional need for flexible resources and even reduce costly energy peaks. Loads have been shown to have response that is equal to or better than generation in some cases [1]. Furthermore, price-incentivized demand response programs have been shown to reduce the peak energy requirements, thereby affecting the wholesale market efficiency and overall energy prices [2], [3].

The residential sector is not only the largest consumer of electrical energy in the United States, but also has the highest potential to provide demand reduction and power system support, as technological advancements in load control, sensor technologies, and communication are made. The prevailing loads based on the largest electrical energy consumers in the residential sector are space heating and cooling, washer and dryer, water heating, lighting, computers and electronics, dishwasher and range, and refrigeration. As the largest loads, these loads provide the highest potential for delivering demand response and reliability services.

Many residential loads have inherent flexibility that is related to the purpose of the load. Depending on the load type, electric power consumption levels can either be ramped, changed in a step-change fashion, or completely removed. Loads with only on-off capability (such as clothes washers and dryers) provide less flexibility than resources that can be ramped or step-changed. Add-on devices may be able to provide extra demand response capabilities. Still, operating residential loads effectively requires awareness of the delicate balance of occupants' health and comfort and electrical energy consumption.

This report is Phase I of a series of reports aimed at identifying gaps in automated home energy management systems for incorporation of building appliances, vehicles, and 
renewable adoption into a smart grid, specifically with the intent of examining demand response and load factor control for power system support. The objective is to capture existing gaps in load control, energy management systems, and sensor technology with consideration of PHEV and renewable technologies to establish areas of research for the Department of Energy. In this report, 1) data is collected and examined from state of the art homes to characterize the primary residential loads as well as PHEVs and photovoltaic for potential adoption into energy management control strategies; and 2) demand response rules and requirements across the various demand response programs are examined for potential participation of residential loads. This report will be followed by a Phase II report aimed at identifying the current state of technology of energy management systems, sensors, and communication technologies for demand response and load factor control applications for the residential sector. The purpose is to cover the gaps that exist in the information captured by the sensors for energy management system to be able to provide demand response and load factor control. The vision is the development of an energy management system or other controlling enterprise hardware and software that is not only able to control loads, PHEVs, and renewable generation for demand response and load factor control, but also to do so with consumer comforts in mind and in an optimal fashion.

This report is divided into four sections. The Introduction describes the intention of this report and the importance of the research. The second section, Demand Response: Ancillary Services and Load Reduction, examines the benefits of demand response, the need for ancillary services, types of services that exist under the various Independent System Operators, and requirements for participation. The third section, Residential Load Control and On-Site Generation, covers the energy consumption by sector, the various loads found in residential settings, primary consumers, and characteristic consumption behavior along with design, expectations of the impact of future loads, and the controllability of the loads. The section also and provides an estimate of available demand. The last section is the Conclusion. 


\section{DEMAND RESPONSE: ANCILLARY SERVICES, LOAD SHEDDING, AND LOAD FACTOR}

In 2006, The Department of Energy released a document describing the benefits of demand response programs in electricity markets. The document defined demand response as [4]: "Changes in electric usage by end-use customers from their normal consumption patterns in response to changes in the price of electricity over time, or to incentive payments designed to induce lower electricity use at times of high wholesale market prices or when system reliability is jeopardized." The programs related to demand response vary based on regions, independent system operator ISO (ISO) market, and utility, but often can be classified as emergency or economic programs. At a high level, emergency demand response programs provide demand reduction or grid support during contingencies. The economic demand response programs utilize load reduction resources to reduce demand when energy prices are high.

In the United States, utilities are regulated to varying degrees, and each type of utility has associated demand response programs. In the Southeast, TVA and Southern Company (among others) are regulated and do not provide open access to the management, bidding, and selling of generation. However, demand response programs are still available. In other areas of the country, ISOs manage the sale and delivery of power from generation to smaller utility servicing entities and must purchase reliability. Here the servicing entities procure the reliability and demand reduction mechanisms to sell to the ISOs.

There are a number of ISOs across the United States. In the Northeast, PJM, NYISO, and New England ISO control the transactions. Their territories cover much of the east and go as far north as Maine and as far south as Virginia and North Carolina. In the middle portion of the United States, Midwest ISO, SPP, and ERCOT manage the transactions of power. Their combined territories go as far north as Canada and south to Texas. In California, CALISO plays the primary role of the ISO. Figure 2.1 shows the areas that each ISO manages.

In this section of the report the objective is to describe the various demand response programs that exist across the ISOs, the importance of grid services, and the existing types of grid services.

\subsection{Demand Response Programs}

Existing demand response programs can typically be classified as economic and emergency programs, each with dedicated communication and control strategies. Emergency demand response programs primarily represent a commitment to reduce load or only consume electricity up to certain level when the power system needs assistance. This is to ensure the reliability of the power system under supply shortages or expected emergency operation conditions [5]-[7]. 


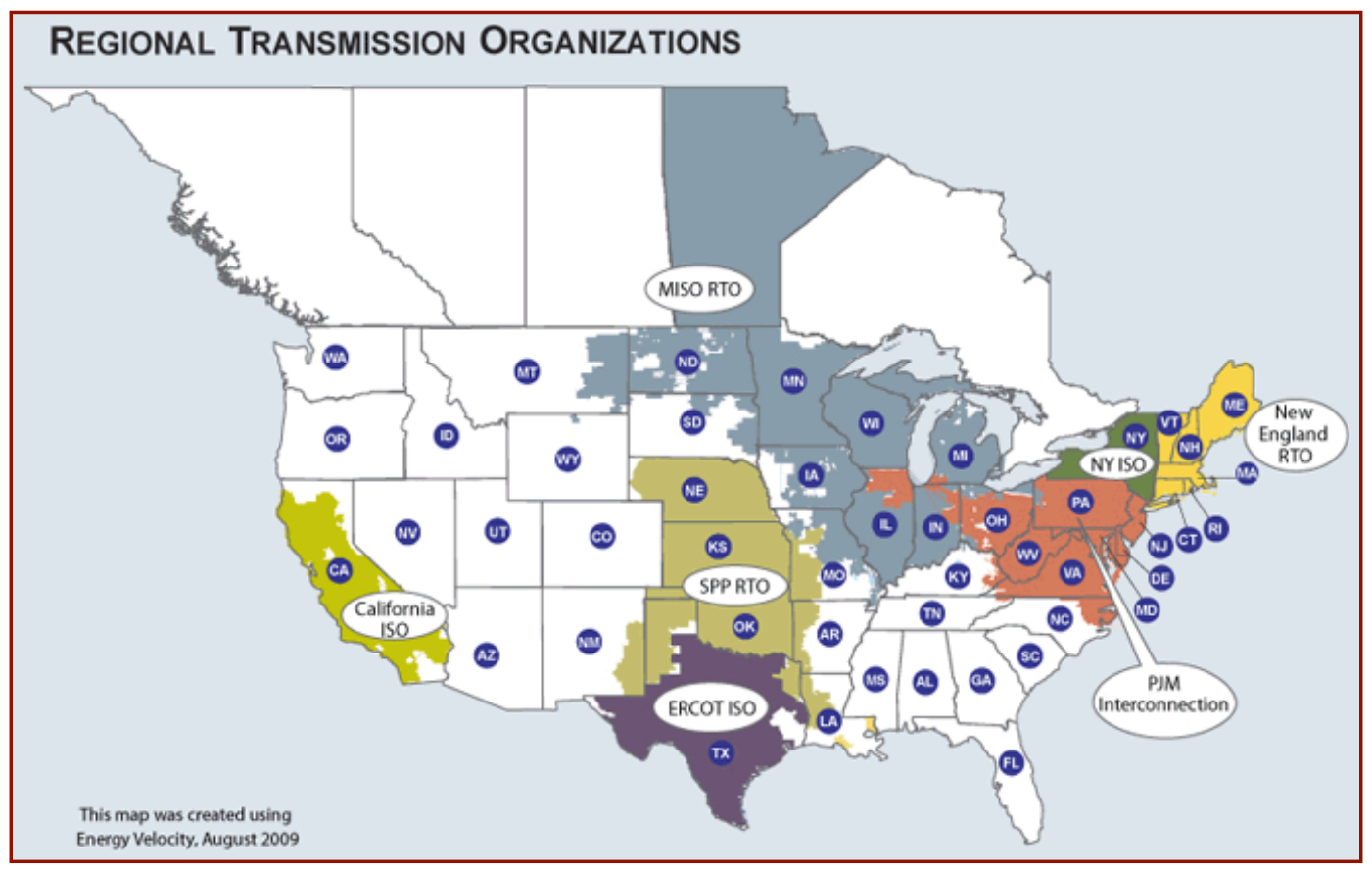

Figure 2.1 Regional Transmission Organizations [6].

The economic demand response programs utilize resources to deal with periods when energy supply and demand curves becomes inelastic, or a small change in energy demand leads to a large change in price. Studies from Brattle [3] and others have shown that demand response programs can have significant impact on lowering the cost of energy. Economic programs often utilize two mechanisms to reduce energy cost: (1) let the customer decide and respond to an energy price or (2) request reduction of energy when market prices reach certain levels. Economic demand response programs also often encompass loads delivering grid services.

A set of the demand response programs for each ISO are listed below:

NYISO (New York Independent System Operator):

- $\quad$ Emergency Demand Response Program (EDRP)

- Installed Capacity (ICAP) SCR

- Day Ahead Demand Reduction Program (DADRP)

- Demand Side Ancillary Services Program (DSASP)

PJM (Pennsylvania-New Jersey-Maryland Interconnection)

- Economic

- Emergency

ISO-NE (New England Independent System Operator):

- $\quad$ Real Time Demand Response Program (RTDRP)

- Day-Ahead Load Response Program (DALRP)

- Real Time Price Response Program ( Energy)

- On Peak Seasonal Resources (OP and SP)

Midwest ISO: 
- Emergency Demand Response (EDR)

- Demand Response Resource Type I (DRR-I)

- Demand Response Resource Type II (DRR-II)

ERCOT (Electric Reliability Council of Texas):

- Emergency Interruptible Load Service (EILS)

- Load Acting as a Resource (LaaR)

- Controllable Load Resource (CLR)

SPP (Southwest Power Pool):

- Variable Dispatch Demand Response (VDDR)

Each of the demand response programs has specific rules and requirements for participation. Table 2.1 lists minimum participation levels, whether aggregated loads are accepted, required response times, interruption periods, whether a resource receives advance notification, and metering requirements for the ISO demand response programs.

Table 2.1 Demand response characteristics for various markets across the U.S. [5]-[14]

\begin{tabular}{|c|c|c|c|c|c|c|}
\hline & $\begin{array}{l}\text { Minimum } \\
\text { Participation }\end{array}$ & $\begin{array}{l}\text { Agg. } \\
\text { Allow? }\end{array}$ & $\begin{array}{l}\text { Required } \\
\text { Response Time }\end{array}$ & $\begin{array}{l}\text { Interruption } \\
\text { Period }\end{array}$ & $\begin{array}{l}\text { Advance } \\
\text { Notification }\end{array}$ & Metering Requirements \\
\hline \multicolumn{7}{|l|}{ NYISO } \\
\hline $\begin{array}{l}\text { DADRP } \\
\text { (Energy) }\end{array}$ & $\begin{array}{l}1 \mathrm{MW} \\
(2 \mathrm{MW})^{1}\end{array}$ & Yes & None & As scheduled & $\begin{array}{l}\text { Day ahead by } \\
11 \text { AM ( } 2 \text { hours } \\
\text { notice in day) }\end{array}$ & $\begin{array}{l}\text { Not Monitored } \\
\text { (Hourly } \\
\text { Interval metering of } \\
\text { event) }\end{array}$ \\
\hline $\begin{array}{l}\text { DSASP } \\
\text { (Reserve) }\end{array}$ & $1 \mathrm{MW}$ & No & $\begin{array}{l}10 \text { to } 30 \\
\text { Minutes } \\
\text { (Mandatory) }\end{array}$ & As scheduled & Day ahead by $11 \mathrm{am}$ & $\begin{array}{l}\text { Telemetry } \\
\text { (6-seconds ) }\end{array}$ \\
\hline $\begin{array}{l}\text { DSASP } \\
\text { (Regulation) }\end{array}$ & $1 \mathrm{MW}$ & No & $\begin{array}{l}\text { Continuous } \\
\text { (Mandatory) }\end{array}$ & As scheduled & Day ahead by $11 \mathrm{am}$ & Telemetry(6-seconds ) \\
\hline $\begin{array}{l}\text { EDRP } \\
\text { (Energy) }\end{array}$ & $\begin{array}{l}100 \mathrm{~kW} \\
(500 \mathrm{~kW})^{2}\end{array}$ & Yes & $\begin{array}{l}2 \text { hours } \\
\text { (Voluntary) }\end{array}$ & $\begin{array}{l}4 \text { Hours } \\
\text { min }\end{array}$ & $\begin{array}{l}\text { Day ahead 11am } \\
\text { (no notice in day) }\end{array}$ & $\begin{array}{l}\text { Not Monitored/Hourly } \\
\text { Interval metering of } \\
\text { event. }\end{array}$ \\
\hline $\begin{array}{l}\text { ICAP SCR } \\
\text { (Energy/Capacity) }\end{array}$ & $\begin{array}{l}100 \mathrm{~kW} \\
<100 \mathrm{MW}\end{array}$ & Yes & $\begin{array}{l}2 \text { hours } \\
\text { (Mandatory) }\end{array}$ & 4 Hours min & $\begin{array}{l}\text { Day ahead when } \\
\text { possible ( } 2 \text { hours } \\
\text { notice in day) }\end{array}$ & $\begin{array}{l}\text { Not Monitored/Hourly } \\
\text { Interval metering of } \\
\text { event. }\end{array}$ \\
\hline \multicolumn{7}{|l|}{ PJM } \\
\hline $\begin{array}{l}\text { Economic } \\
\text { (Energy) }\end{array}$ & $100 \mathrm{~kW}$ & Yes & $\begin{array}{l}\text { None } \\
\text { (Voluntary) }\end{array}$ & As scheduled & Day-Ahead & None \\
\hline $\begin{array}{l}\text { Economic } \\
\text { (Reserve) }\end{array}$ & $1 \mathrm{MW}$ & Yes & $\begin{array}{l}10 \text { to } 30 \\
\text { Minutes } \\
\text { (Mandatory) }\end{array}$ & As scheduled & 1 hour & Telemetry \\
\hline $\begin{array}{l}\text { Economic } \\
\text { (Regulation) }\end{array}$ & $1 \mathrm{MW}$ & No & $\begin{array}{l}\text { Continuous } \\
\text { (Mandatory) }\end{array}$ & As scheduled & None & $\begin{array}{l}\text { Telemetry } \\
\text { (2-4 seconds) }\end{array}$ \\
\hline $\begin{array}{l}\text { Emergency } \\
\text { (Energy) }\end{array}$ & $100 \mathrm{~kW}$ & Yes & $\begin{array}{l}1 \text { to } 2 \text { hours } \\
\text { (Voluntary) }\end{array}$ & As scheduled & 2 Hours & \\
\hline $\begin{array}{l}\text { Emergency } \\
\text { (Capacity) }\end{array}$ & $100 \mathrm{~kW}$ & Yes & $\begin{array}{l}1 \text { to } 2 \text { hours } \\
\text { (Mandatory) }\end{array}$ & As scheduled & 2 Hours & \\
\hline \multicolumn{7}{|l|}{ ISO-NE } \\
\hline $\begin{array}{l}\text { RTDRP } \\
\text { (Energy/Capacity) }\end{array}$ & $100 \mathrm{~kW}$ & Yes & $\begin{array}{l}\text { Within } 10 \text { to } 30 \\
\text { minutes } \\
\text { (Mandatory) }\end{array}$ & As scheduled & None & $\begin{array}{l}\text { Telemetry } \\
\text { (5-Minute) }\end{array}$ \\
\hline $\begin{array}{l}\text { DALRP } \\
\text { (Energy) }\end{array}$ & $100 \mathrm{~kW}$ & Yes & $\begin{array}{l}\text { Continuous } \\
\text { (Mandatory) }\end{array}$ & As scheduled & Day-Ahead & Not Monitored \\
\hline RTPR & $100 \mathrm{~kW}$ & Yes & Continuous & As scheduled & None & Not Monitored \\
\hline
\end{tabular}

${ }^{1}$ Small customers must be aggregated to a value of $2 \mathrm{MW}$.

${ }^{2}$ Small customers must be aggregated to a value of $500 \mathrm{~kW}$.

${ }^{3}$ Participant selects 


\begin{tabular}{|c|c|c|c|c|c|c|}
\hline (Energy) & & & (Voluntary) & & & \\
\hline $\begin{array}{l}\text { OP/SP } \\
\text { (Capacity) }\end{array}$ & $100 \mathrm{~kW}$ & Yes & $\begin{array}{l}\text { Continuous } \\
\text { (Mandatory) }\end{array}$ & $\begin{array}{l}\text { Peak Hours } \\
\text { only }\end{array}$ & None & Not Monitored \\
\hline \multicolumn{7}{|l|}{ Midwest ISO } \\
\hline $\begin{array}{l}\text { EDR } \\
\text { (Energy) }\end{array}$ & $100 \mathrm{~kW}$ & Yes & $\begin{array}{l}\text { Resource } \\
\text { specific } \\
\text { (Voluntary) }\end{array}$ & As scheduled & None & Daily Measurement \\
\hline $\begin{array}{l}\text { DRR-I } \\
\text { (Energy) }\end{array}$ & $1 \mathrm{MW}$ & Yes & $\begin{array}{l}5 \text { Minutes } \\
\text { (Voluntary) }\end{array}$ & $\begin{array}{l}\text { As scheduled } \\
\text { (1 hour min) }\end{array}$ & Day-Ahead & Telemetry \\
\hline $\begin{array}{l}\text { DRR-I } \\
\text { (Reserves) }\end{array}$ & $1 \mathrm{MW}$ & Yes & $\begin{array}{l}10 \text { Minutes } \\
\text { (Mandatory) }\end{array}$ & $\begin{array}{l}\text { As scheduled } \\
\text { (1 hour min) }\end{array}$ & Day-Ahead & Telemetry \\
\hline $\begin{array}{l}\text { DRR-II } \\
\text { (Energy) }\end{array}$ & $1 \mathrm{MW}$ & No & $\begin{array}{l}5 \text { Minutes } \\
\text { (Voluntary) }\end{array}$ & $\begin{array}{l}\text { As scheduled } \\
\text { (1 hour min) }\end{array}$ & Day-Ahead & $\begin{array}{l}\text { Telemetry } \\
\text { (4 seconds) }\end{array}$ \\
\hline $\begin{array}{l}\text { DRR-II } \\
\text { (Reserves) }\end{array}$ & $1 \mathrm{MW}$ & No & $\begin{array}{l}10 \text { Minutes } \\
\text { (Mandatory) }\end{array}$ & $\begin{array}{l}\text { As scheduled } \\
(1 \text { hour min) }\end{array}$ & Day-Ahead & $\begin{array}{l}\text { Telemetry } \\
\text { (4 seconds) }\end{array}$ \\
\hline $\begin{array}{l}\text { DRR-II } \\
\text { (Regulation) }\end{array}$ & $1 \mathrm{MW}$ & No & $\begin{array}{l}\text { Continuous } \\
\text { (Mandatory) }\end{array}$ & $\begin{array}{l}\text { As scheduled } \\
\text { (1 hour min) }\end{array}$ & Day-Ahead & $\begin{array}{l}\text { Telemetry } \\
\text { (4 seconds) }\end{array}$ \\
\hline \multicolumn{7}{|l|}{ CAISO } \\
\hline $\begin{array}{l}\text { Participating Loads } \\
\text { (Energy) }\end{array}$ & $100 \mathrm{~kW}$ & Yes & $\begin{array}{l}1 \text { Hour } \\
\text { (Mandatory) }\end{array}$ & As scheduled & Day-Ahead & None \\
\hline $\begin{array}{l}\text { Participating Loads } \\
\text { (Reserve) }\end{array}$ & $100 \mathrm{~kW}$ & Yes & $\begin{array}{l}10 \text { Minutes } \\
\text { (Mandatory) }\end{array}$ & As scheduled & Day-Ahead & $\begin{array}{l}\text { Telemetry } \\
(1 \text { minute })\end{array}$ \\
\hline \multicolumn{7}{|l|}{ ERCOT } \\
\hline $\begin{array}{l}\text { EILS } \\
\text { (Capacity) }\end{array}$ & $1 \mathrm{MW}$ & Yes & $\begin{array}{l}10 \text { Minutes } \\
\text { (Mandatory) }\end{array}$ & As scheduled & None & None \\
\hline $\begin{array}{l}\text { LaaR } \\
\text { (Reserve) }\end{array}$ & $1 \mathrm{MW}$ & Yes & $\begin{array}{l}10 \text { to } 30 \\
\text { Minutes } \\
\text { (Mandatory) }\end{array}$ & As scheduled & Day-Ahead & $\begin{array}{l}\text { Telemetry } \\
(2 \text { seconds })\end{array}$ \\
\hline $\begin{array}{l}\text { CLR } \\
\text { (Regulation) }\end{array}$ & $1 \mathrm{MW}$ & No & $\begin{array}{l}\text { Continuous } \\
\text { (Mandatory) }\end{array}$ & As scheduled & Day-Ahead & $\begin{array}{l}\text { Telemetry } \\
(2 \text { seconds) }\end{array}$ \\
\hline \multicolumn{7}{|l|}{ SPP } \\
\hline $\begin{array}{l}\text { VDDR } \\
\text { (Energy) }\end{array}$ & $1 \mathrm{MW}$ & Yes & $\begin{array}{l}\text { (5 minutes) } \\
\text { Mandatory }\end{array}$ & 5 Minutes & 5 Minutes & $\begin{array}{l}\text { Telemetry } \\
(4 \text { seconds) }\end{array}$ \\
\hline
\end{tabular}

In all cases, the minimum load reduction accepted by the ISOs exceeds $100 \mathrm{~kW}$, which would require the aggregation of a significant number of residential consumers. However, not all of the programs allow for the aggregation of loads. As an example, the demand response programs that allow the provision of regulation currently do not accept aggregated resources.

In many cases intermediary parties are necessary to deliver the services to the ISOs as shown in Figure 2.2. These intermediary parties are often called curtailment service providers (CSPs) or demand response providers (DRPs), depending on the ISO. The CSPs or DRPs could be utilities or other organizations that respond to the ISO request by communicating the request to customer.

The CSP/DRP entity is the responsible party for demand response activities for electricity consumers. The CSP/DRP implements the necessary equipment and operational processes to enable customers to participate in the appropriate wholesale market and acts on behalf of the customers. To do this, a CSP/DRP is required to have the technological understanding of the appropriate operational infrastructure and market rules and operational procedures. Ultimately, the CSP/DRP is responsible for having the appropriate portfolio of customers to meet obligations and avoid creating power system 
issues or incurring financial penalties. Customers could include residential owners, commercial entities, or industrial parties.

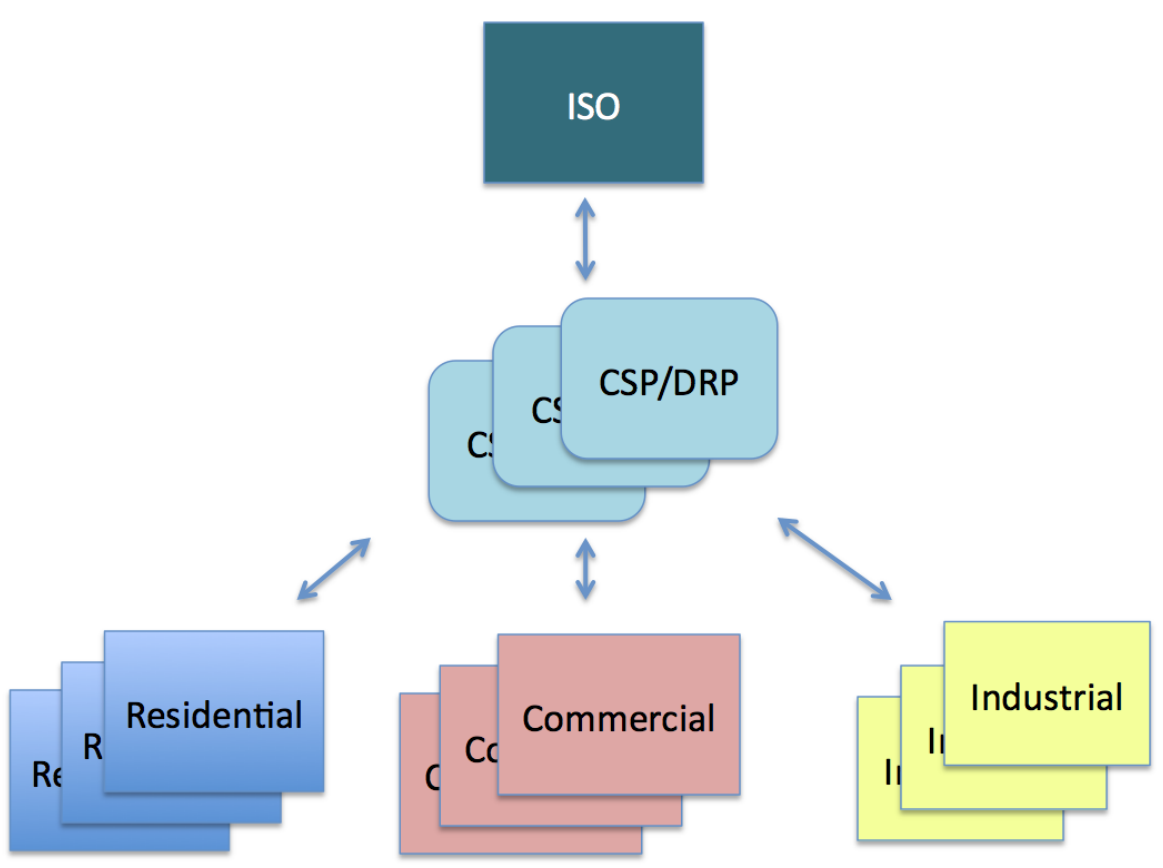

Figure 2.2 ISO Demand Response Framework.

\subsection{Benefits of Demand Response}

Demand response programs exist to improve the efficiency of generation resources in meeting loads and to reduce overall cost through creating a closer alignment of customer electricity prices and the value a customer places on the used electricity. This efficiency improvement can be attached to four main benefits: financial reward to participants, market-wide financial gains, reliability benefits, and improved market performance [3].

- Participants should see savings through reduction of load during peak periods and payments for responding during events.

- The overall markets are perceived to be able to reduce costs as the small reductions in demand during high cost period lead to large savings.

- Reliability is improved as the additional operational security of more resources reduces the potential of forced outages.

- Market performance is increased as the potential for exercising market power by suppliers is reduced.

\subsection{Grid Services and Renewables}


Prior to the restructuring of electricity markets in the United States, electric utilities were vertically integrated; a single electric utility provided the generation, transmission, and distribution infrastructure to the end customer. Restructuring of the electricity markets provided new opportunities to generator owners through the unbundling of competitive generation and regulated transmission. This gave generation facilities the ability to completely focus on delivering services (energy or reliability) that they were explicitly paid to provide (in the past, generation provided reliability response as part of their regulated obligation). The responsibility of ensuring that the appropriate amount of reliability is available shifted to the ISOs, even though the system operator does not own any generation and cannot directly provide balancing services. For the system operator to procure reliability from a competitive market, a set of grid services was defined. This market was created to ensure that reliability of the power system was adequately maintained through proper balance of generation and load and other supporting services (ancillary service markets or grid services.)

The stability of the power system relies on the ability of aggregate generation to match the existing load. Generation and load do not need to be perfectly balanced, as the North American Electric Reliability Council (NERC) has established criteria for area control error (reflecting the difference between generation and load) and standards such as control performance standards CPS-1 and CPS-2, balancing authority area control error limit (BAAL), and the disturbance control standard (DCS). These standards and criteria are in place to prevent significant departure between generation and load. Large deviations between load and generation can create significant changes in system frequency and can lead to system-wide frequency oscillations, which can contribute to load shedding, generator tripping, islanding, and in the worst case equipment destruction and system collapse [1].

The difficulty in ensuring that generation and load match is that the demand by most energy consumers is never a constant, as loads are endlessly energized and deactivated. Ideally, loads can be separated into two separate profiles, the larger portion being a distinct daily load change and a smaller portion related to minute-to-minute fluctuation. A daily load profile for the ISO PJM over the month of January as shown in Figure 2.3 demonstrates that hourly load profiles can be fairly predictable and can be handled in the real-time five-minute market [3]. The minute-to-minute oscillations, on the other hand, are not predictable and require generation to continuously adjust to follow the load. The control area error for PJM on April 12, 2010, is shown in Figure 2.4. This represents the generation and load mismatch in real time [15]. 


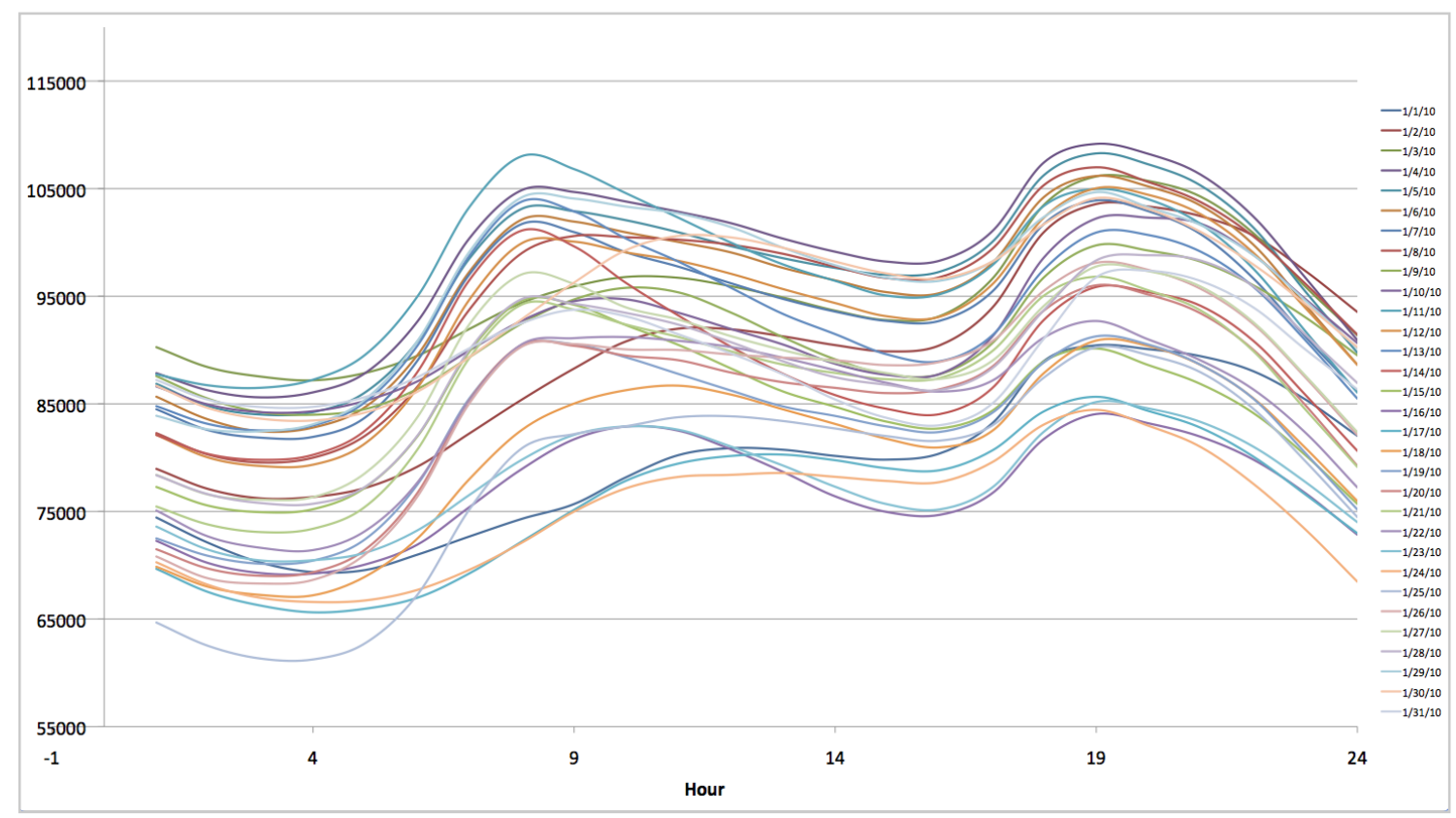

Figure 2.3 January 2010 PJM Load Profile

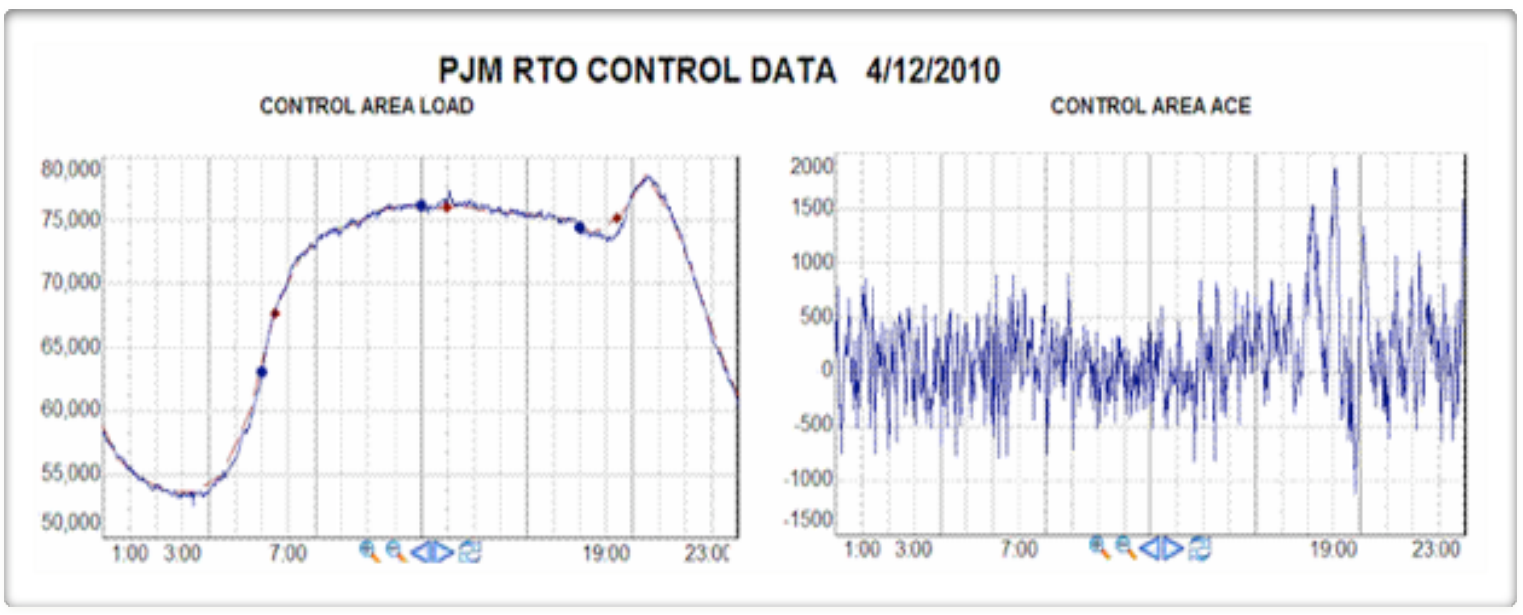

Figure 2.4 Example of system error [15].

Renewable energy resources can complicate the issue of power system reliability and the need for grid services. Many types of renewable energy resources (such as solar and wind) tend to be labeled as variable and are not always dependable on a day-to-day basis. Figure 2.5 shows the generation of wind energy in PJM in January of 2010 [15]. Day-today operation does not represent an easily distinguishable pattern and does not correlate well with the load. As the deployment of resources such as wind increase impact on the grid, there may be an increased need for grid services. 


\subsection{Grid Service Definitions}

Though definitions of grid services vary between organizations, they are all generally designed to capture the imbalance-associated imperfections in the market and ensure that the transmission system is available for the transfer of energy from seller to buyer. Failure to manage the imbalance of load and generation can lead to power system blackouts, resulting in loss of revenue for manufacturing and industry and/or the destruction of machinery and equipment. The definitions commonly employed by the power industry, ISOs, and the Federal Energy Regulatory Commission (FERC), which are referred to as "ancillary servicers," are discussed.

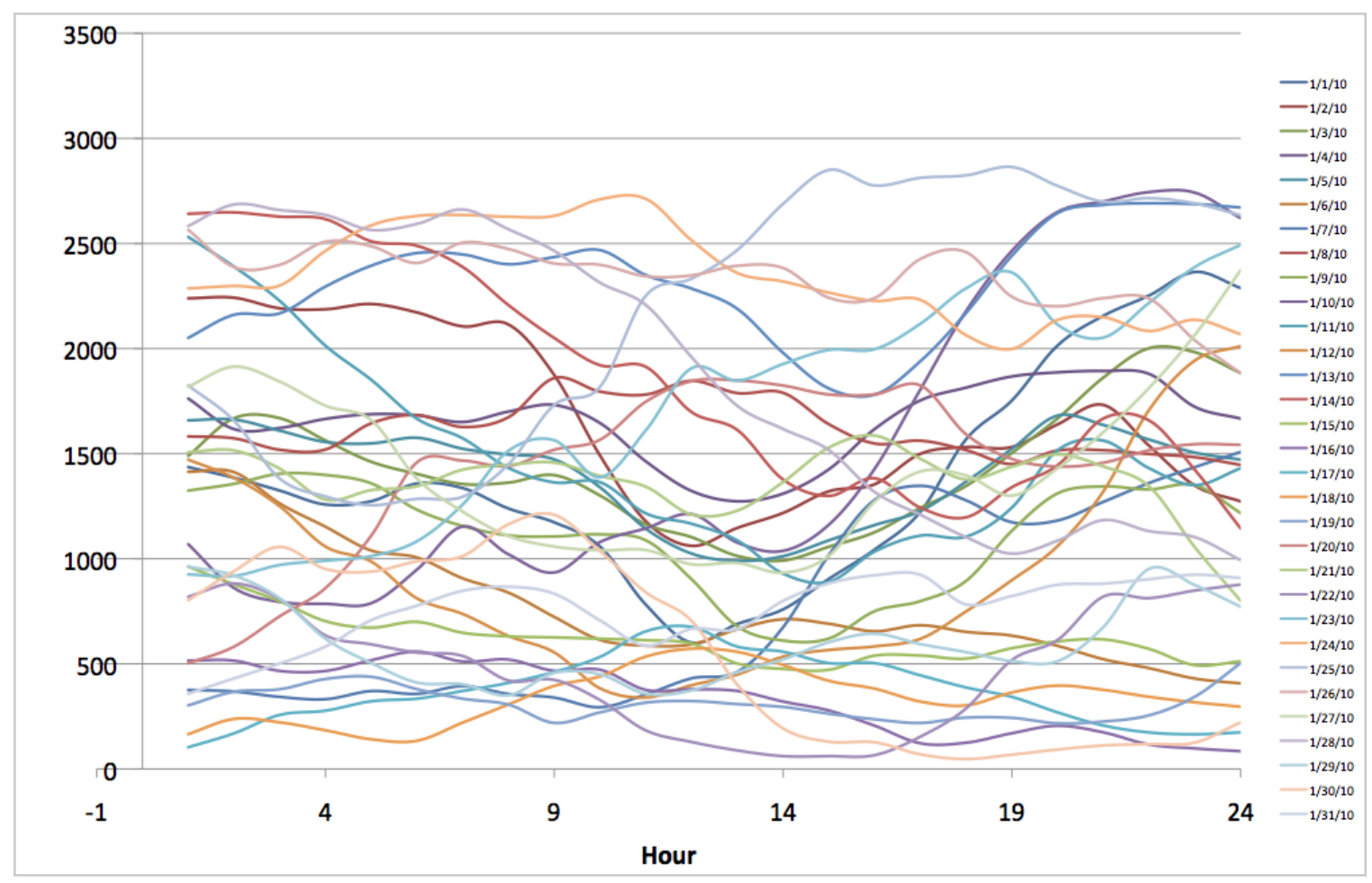

Figure 2.5 January 2010 Wind Generation Profile in PJM [15]

In 1996, FERC issued Order 888 defining a list of six essential services: (1) Scheduling, System Control and Dispatch Service, (2) Reactive Supply and Voltage Control from Generation Sources Service, (3) Regulation and Frequency Response Service, (4) Energy Imbalance Service, (5) Operating Reserve - Spinning Reserve Service, and (6) Operating Reserve - Supplemental Reserve Service. These services, as defined by Order 888, are necessary to provide basic transmission service to a customer and maintain a balance between generation and load in near real time in order to secure the integrity of the transmission system [16]. 
Each grid service provides an important function in increasing stability (normal or contingency operations) and addresses a distinct time span as shown in Figure 2.6. The services that generation facilities can potentially contribute are defined in the following subsections.

Voltage control and reactive supply are related to the control and supply of reactive power. Reactive power is necessary to maintain system voltage throughout the power system and the requirements are often location-specific. This is a generation-specific service, and at this point loads do not provide this service.

The ancillary service known as regulation or balancing services is an AGC (automatic generator controlled) signal (provided by an ISO) to ramp generation up and down and capture the minute-to-minute imbalances between generation and load under normal operating conditions. The overall objective is to ensure that the power system frequency is maintained at $60 \mathrm{~Hz}$ within a margin of $\pm .05 \mathrm{~Hz}$. Many authorities dictate 1 to $1.5 \%$ of their generation to supply regulation. Regulation tends to be the most difficult ancillary service to provide from a communication and control perspective and is a service that is utilized in normal system operation. Loads may be able to provide this service with the proper control and communication, depending on the nature of the load and the controllable interface.

Energy Imbalance Service is not an actual service, but a practice for accounting for differences between scheduled and actual transactions. Load following is a service that compensates for the inter- and intra-hour changes in demand and is the much slower counterpart to regulation. Load following is often provided by sub-hourly energy markets, and its effective price is typically very low. This service is utilized in normal system operations.

Contingency reserves are the back-up generation systems that are available for abnormal events and contingencies and encompass spinning, non-spinning, and supplemental reserves. Each has a distinct operating criterion and is compensated separately. Loads that are willing to be shut off or reduce demand based on a single communication can provide operating reserves.

Spinning Reserve Service is generation that is ready to respond immediately in case a generator or transmission line fails unexpectedly. Spinning reserve begins to respond immediately and must fully respond within ten minutes. Enough contingency reserve (spinning and non-spinning) must be available to deal with the largest failure that is anticipated. Non-Spinning Reserve Service is similar to spinning reserve except that response does not need to begin immediately. Full response is still required within 10 minutes. Replacement or Supplemental Reserve is an additional reserve required in some regions. It begins responding in 30 to 60 minutes. It is distinguished from nonspinning reserve by the response time frame. 


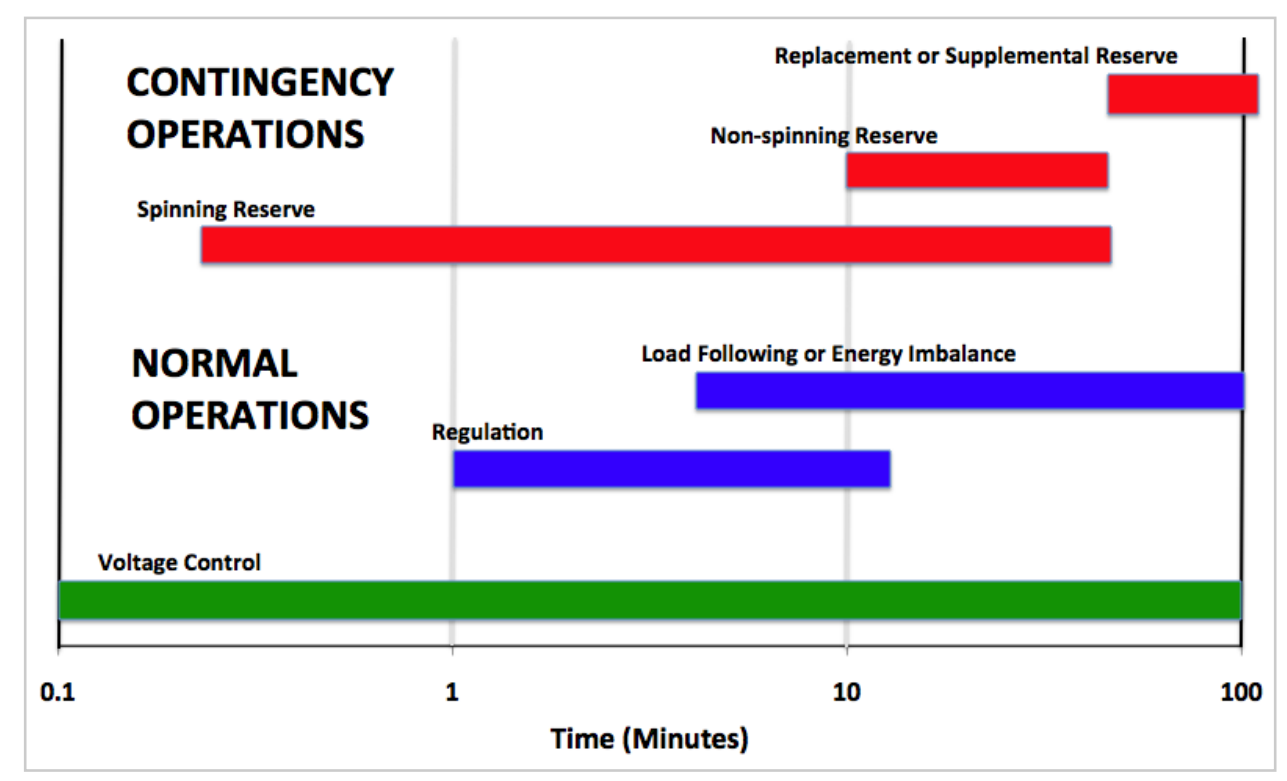

Figure 2.6. Grid services operations [1]

Black Start is a service in which generation must be able to start without grid support. This service is necessary in the unlikely case the power system undergoes a significant event that causes a blackout. Although this is not called out directly in FERC Order 888, many ISO entities have this service as part of their ancillary service package. Black start is a generation service and requires power be delivered to the power system.

\subsection{Load Factor}

Demand response can also provide avenues for increasing the load factor of the residential sector by reducing peak periods. The load factor provides an indication of the degree to which the peak demand levels exceeds the average consumption. Load factors can range between zero and one, and a low load factor indicates that a consumer has a large variation in consumption, which is more difficult and costly for a utility to provide.

Load factors can be calculated based on daily, monthly, seasonal, or annual data. The direct calculation approach involves examining the ratio of the average demand to the peak demand during a particular period. By dividing the total energy in kilowatt hours accumulated during the period by the peak demand and the number of demand intervals in this period, the load factor can be calculated as follows [17]:

$$
L F=\frac{\text { Total usage during period }}{(\text { Peak demand }) \times m}
$$


where $m$ is the number of demand intervals in period. This equation can be also represented as:

$$
L F=\frac{\text { Average demand }}{\text { Peak demand }}
$$

As an example, a characteristic profile of a home is shown in Figure 2.7 (Normal Home.) With the increase of PHEV in homes, new larger peaks are possible that could exceed equipment rating. This can be avoided by shifting load utilization to off periods, ensuring an improved load factor, while still consuming similar total energy levels.

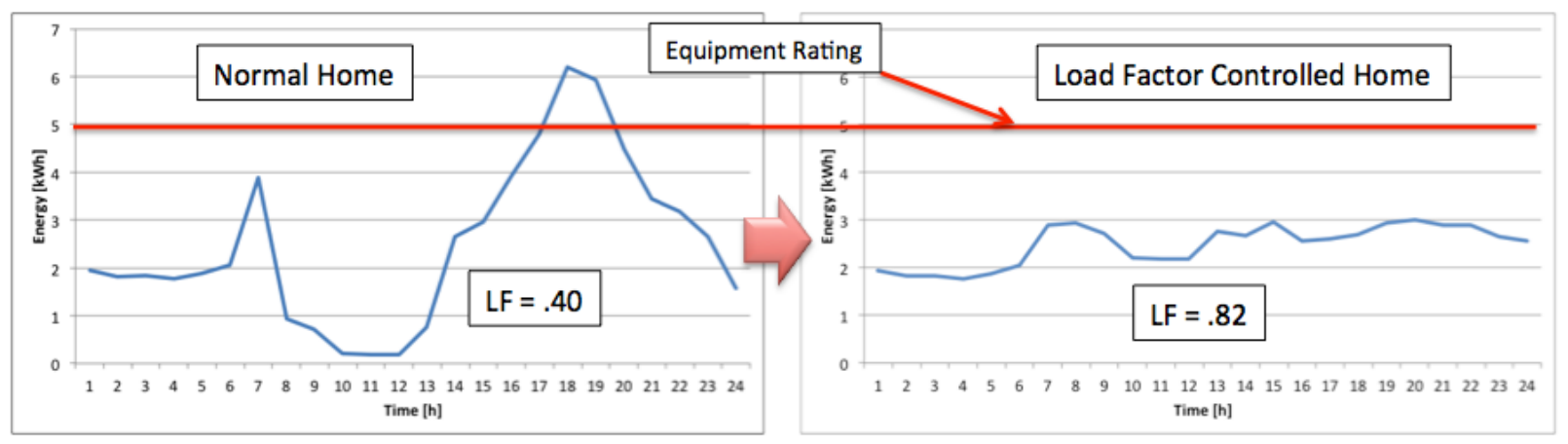

Figure 2.7 Adjustment of Load Factor

Furthermore, controlling the loads to increase the load factor through demand response provides the power system with many benefits including:

- Eliminating the need for peaking units; peaking units tend to be the most expensive sources of generation.

- Deferral of transmission and distribution equipment upgrades; by reducing the overall peak power, the upgrades of transformers, breakers, relays, lines, and etc. can potentially be delayed or eliminated as these equipment are sized on peak power rating.

- Relief of transmission and distribution congestions; if the peak demands can be reduced or shifted to off-peak demand periods, the stress on transmission system can be reduced. 


\section{RESIDENTIAL LOAD CONTROL AND ONSITE-GENERATION}

In residential buildings, electrical loads come in a variety of types, sizes, and classifications. Electrical loads can be purely resistive and/or inductive in nature and can have power electronic conversion stages that deliver power through control of the voltage and current. These voltage levels can be anywhere from a few volts DC to $240 \mathrm{~V} \mathrm{AC}$ and have the potential to utilize several watts to multiple $\mathrm{kW}$ in power. These loads can be activated on a short-term basis (minutes to an hour) or over an entire 24-hour period. These characteristics can provide a significant indication of the value of the load for demand response. Loads that are only activated during short periods and do not consume significant power may not be good candidates for participation in demand response programs.

The primary sectors responsible for consuming electrical energy across the United States for the last decade (1999-2009) have been residential, commercial, and industrial [18]. Figure 3.1 depicts the electrical energy consumption for each sector in 2010, retrieved from the Buildings Energy Data Book 2010 of the U.S. Energy Information Administration (EIA). The residential sector has been the leader in electrical energy consumption and has seen significant growth over the past 10 years of approximately $19 \%$, as shown in Figure 3.2. Utilizing this resource for demand response could have tremendous impact on power system reliability and energy costs.

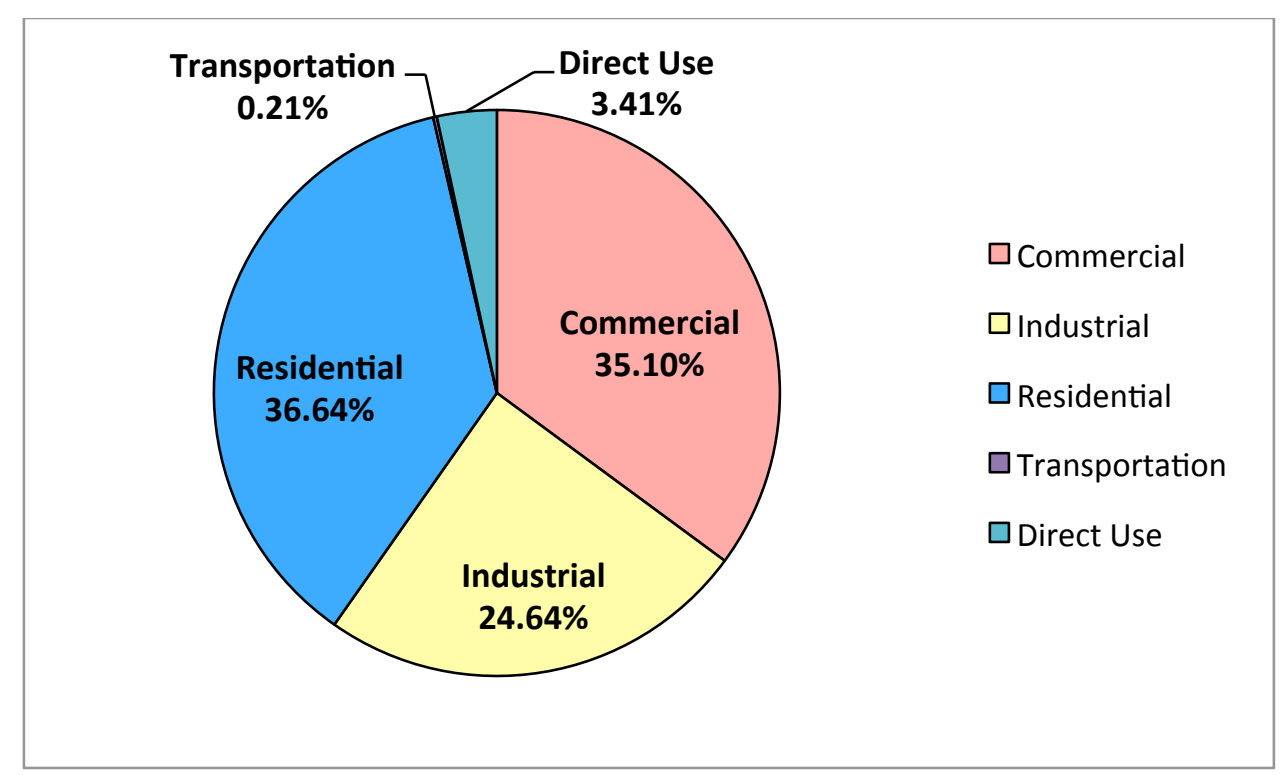

Figure 3.1. Electrical energy consumption by sector [18] 


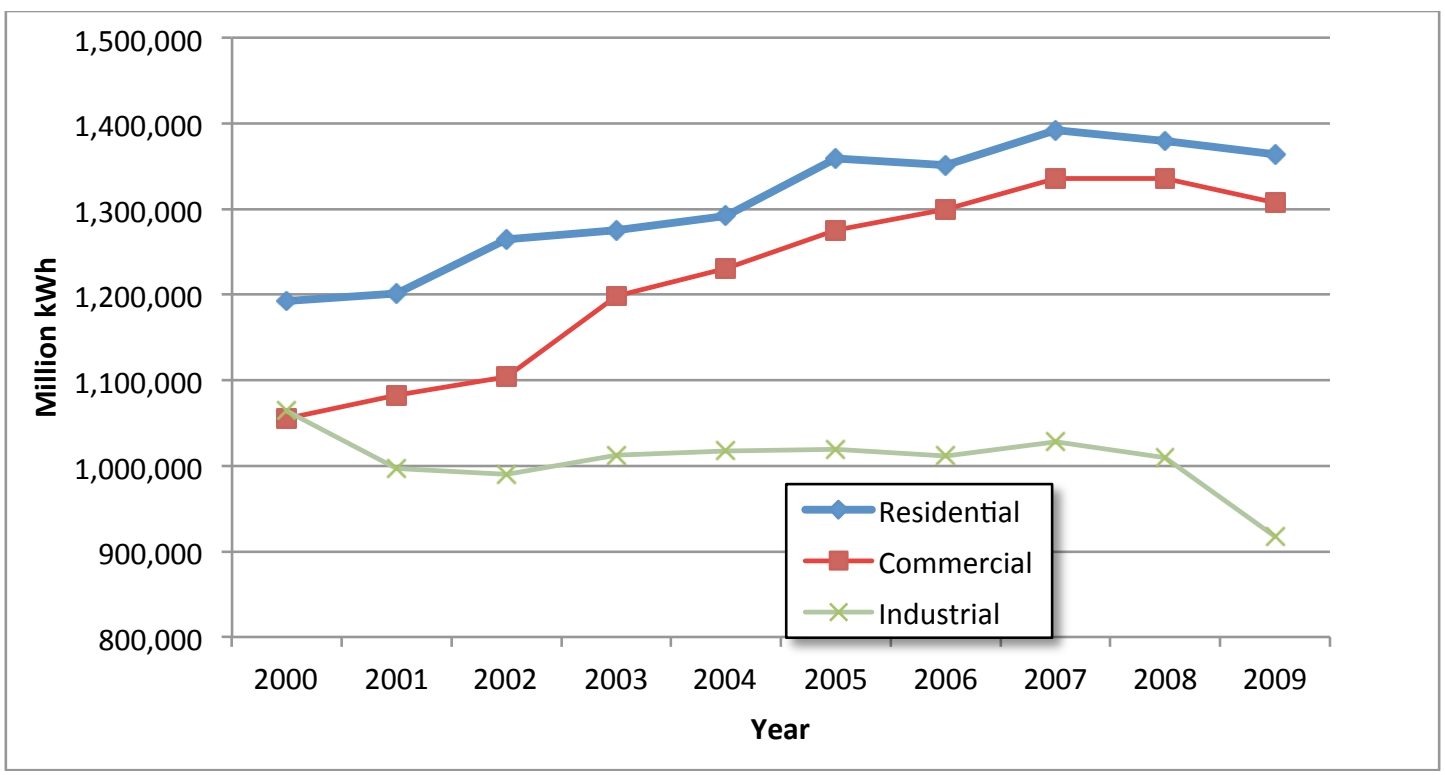

Figure 3.2. Annual energy consumption by sector between 1999-2009 [18].

EIA has broken down the consumption levels and types of residential electrical loads. The primary loads and their associated percentages of electrical energy consumption identified by EIA include space cooling $22.33 \%$, lighting $14.29 \%$, water heating $8.85 \%$, refrigeration $8.83 \%$, space heating $8.65 \%$, electronics $6.84 \%$, wet clean (dish washer, dryer, and clothes washer) $6.24 \%$, computers $3.62 \%$, and cooking $2.21 \%$, as shown in Figure 3.3. These loads should provide the largest benefit to demand response. Attempting to perform demand response of small loads (often termed "vampire" loads) could be extremely costly and provide little contribution to the power system. However, understanding the power levels and availability of the larger electrical energy consumers is important in capturing demand response opportunities. For example, dishwashers, clothes washers, and dryers can consume significant electrical power, but only do so for a short time, and are not often in operation coincident with peak electric demand.

In understanding the control necessary for participation of residential loads in demand response programs, the maneuverability of the load must be determined. Establishing whether a load can be ramped to different power consumption levels, be controlled in a step-change fashion, has thermal storage capabilities, or would need supplementary addon devices or retrofitting is crucial in capturing a load's demand response value. Still, the balance of occupancy health and comfort and electrical energy consumption must be not be neglected. Interrupting the lives of consumers by adjusting loads in a haphazard manner may lead to discontinued participation and deactivation of load controllers.

Profiles of the electrical energy consumption for various loads across the residential sector can provide a significant indication of the value of the load for demand response. As mentioned previously, loads that are only activated during short periods and do not consume significant power may not be good candidates for participation in demand response programs. However, loads that consistently consume high levels of power at or 
near peak electric demand times and that have a significant role in the total electrical energy consumption could be great assets.

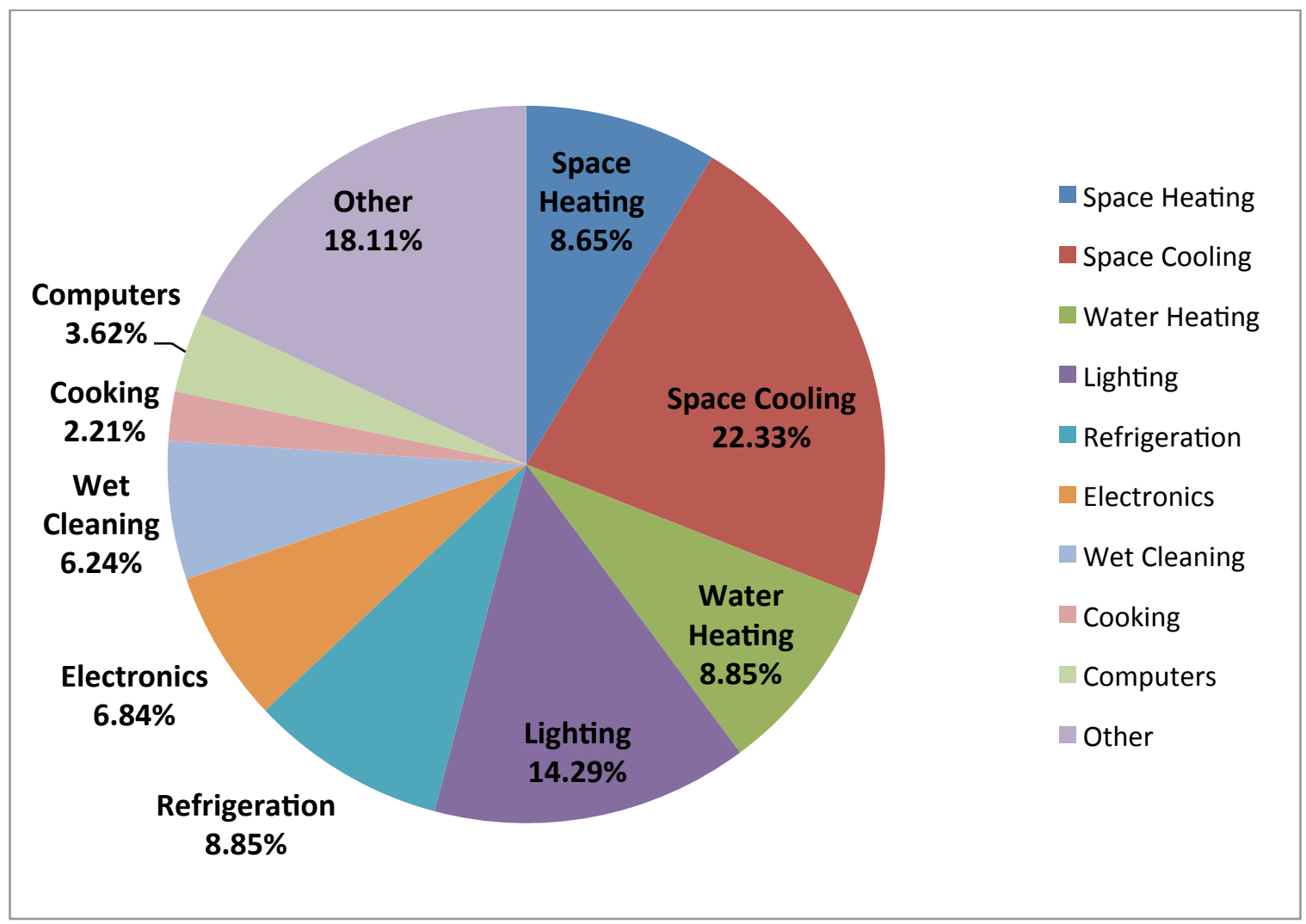

Figure 3.3. Residential load breakdown by electrical energy consumption [18].

In capturing load characteristics, the residential daily energy consumption profiles of typical home appliances were gathered from real houses that were built for the Tennessee Valley Authority's (TVA) Campbell Creek energy efficient homes project and another project involving occupied homes in Atlanta, GA[19]. This data set is applied as a case study to represent load behavior.

Three houses of similar floor plans were built to compare energy consumption of various degrees in the state-of-art home design and retrofit. The trio of three bedroom houses is located in the mixed-humid climate of east Tennessee. The CC1 control home, is a 2400 $\mathrm{ft}^{2}$ house with $100 \%$ incandescent lighting. A 1.5 ton $(5.3 \mathrm{~kW})$ capacity heat pump with a seasonal energy efficiency ratio (SEER) of 13 supplies the first level, and a 2.5 ton (8.8 $\mathrm{kW}$ ) SEER 13 heat pump supplies the second level. The CC2 retrofit house has the same floor plan as the builder house, but has significant retrofits. These retrofits include high performance windows, a sealed and insulated attic, 3 ton $(10.5 \mathrm{~kW})$ SEER 16 single stage heat pump with zone control, ducts in conditioned space, $100 \%$ compact fluorescent (CFL) lighting, energy star appliances, and a 50 gal (189.2 L) heat pump water heater. The CC3 high performance house has a similar floor plan as the first two houses and was built using optimum-value framing techniques for minimizing wood (which is a thermal short in the envelope) and maximizing cavity insulation. Technologies used in the third 
house include triple layer windows, 2 ton $(7 \mathrm{~kW})$ SEER 16 two stage heat pump, ducts inside conditioned space, $100 \%$ CFL lighting, energy star appliances, $2.5 \mathrm{~kW}$ peak photovoltaic (PV) system, and a drain back solar water heating system with electric backup [19].

Leveraging existing community, utility, and industry partnerships in the Metro Atlanta, GA region, ORNL is also providing technical assistance for 10 deep energy retrofits. A subset of these homes is instrumented for detailed monitoring and previous utility bills (dating back at least one year) are being collected for each home and compared to utility bills after the retrofit work is completed. By working with homeowners and retrofit contractors, this project has enhanced the science base and advanced the state of the art in deep energy efficient residential retrofits in mixed-humid climates. In addition to verifying the energy improvements achieved through residential retrofits, this project is also seeking to identify and better understand other non-energy benefits such as health, safety, comfort, and durability as well as utility and industry partner needs. Southern Company, Georgia Power, Johns Manville, and A.O. Smith have been identified as utility and industry partners.

The overall hourly energy consumption for the baseline CC1 typical builder house is plotted in Figure 3.4. The load profile has distinct characteristics that are based on season and is dependent on the behavior of the occupants and utilization of the loads.

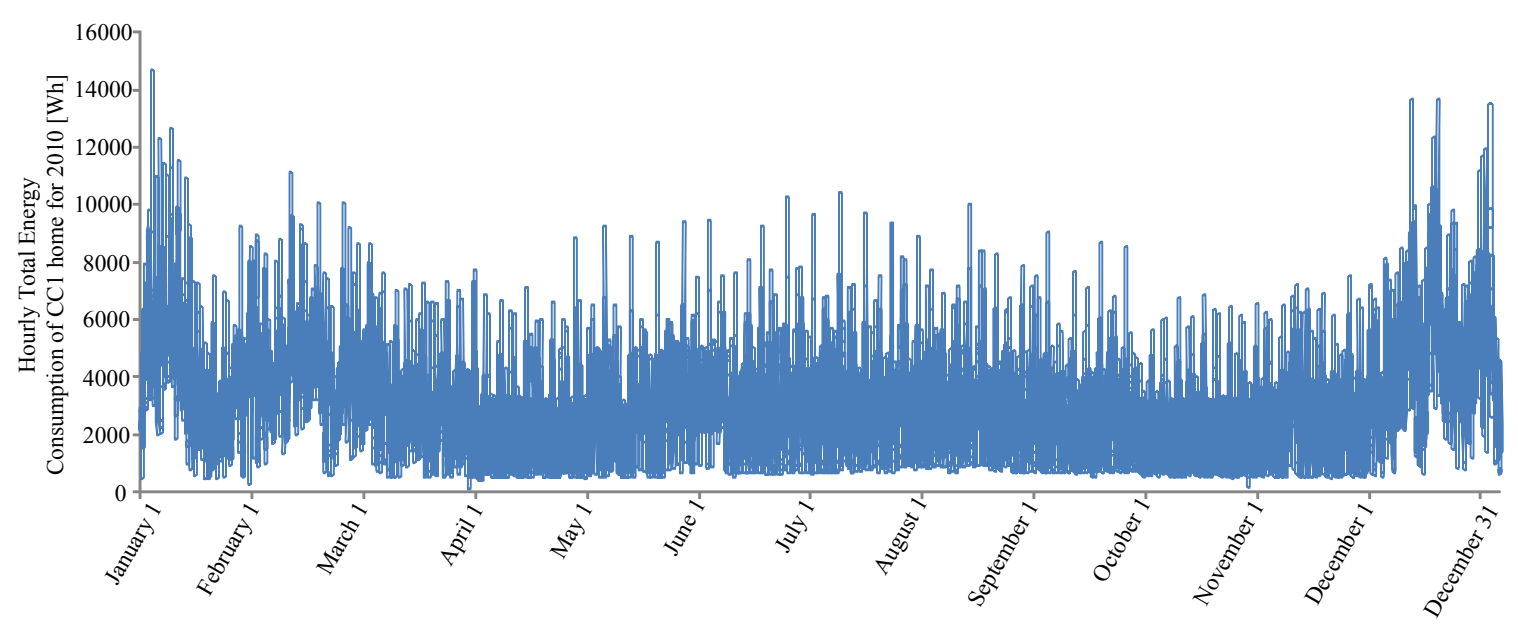

Figure 3.4 Hourly usage for CC1 type home for 2010 (including all loads).

\section{Peak Demand}

Electric utilities experience the highest electric demand (peak load) on the hottest (summer peak) and coldest (winter peak) days of the year. The annual peak loads of conventional all-electric homes with heat pumps normally occur on very cold winter 
mornings. The average $1 \mathrm{~h}$ peak winter demand for the CC1 was $14 \mathrm{~kW}$. Homes that are air-conditioned, but do not use electricity as the primary means of heating are typically summer peaking. Although they are all electric homes, the summer load profiles for the three Campbell Creek homes should be representative of comparable homes with airconditioners, since the heat pump's performance (and electric load) in summer closely matches that of an air-conditioner.

The electrical design of the primary energy-consuming equipment is examined to determine load consumption and the physical capability to control the loads. Load profiles for $\mathrm{CCl}$ are examined for behavior. The data was processed to understand the number of occurrences in which a particular load consumed specific levels of power and the availability of the load. In this way, the amount of potential energy that could be used either for grid reliability enhancement through demand response or peak management could be quantified. Anticipated future loads such as plug-in vehicles are also evaluated.

\subsection{Heating and Cooling}

In order to provide cooling, air conditioners use the evaporation of a refrigerant such as Freon. Starting at the compressor, the HVAC (heating, ventilation, and cooling) unit compresses the refrigerant, increasing its pressure and temperature. This hot gas, under pressure, travels through the heat dissipation coils while interspersing the generated heat to the outside and finally condensing into a liquid. The liquid refrigerant passes through an expansion valve, dropping the pressure due to the suction from the compressor, and lowering the temperature of the refrigerant, which is passed through the heat-absorbing coils and evaporated to deliver cool air to the conditioned space [21]. In dissipating cooling or heating, typically two fans are used within an air conditioning system to blow air over the coils (an outdoor fan and an indoor fan). The operating principle of the HVAC unit is illustrated in Figure 3.5.

The energy consumption for the heating and cooling in $\mathrm{CC} 1$ is shown in Figure 3.6. The largest consumer of energy for heating and cooling in $\mathrm{CC} 1$ comes from the compressor. The refrigeration cycle of an air conditioner with heat pump functionality can be reversed to produce heat instead of cold in the indoor environment. The indoor evaporator coil becomes the condenser coil and produces heat, whereas the outdoor condenser unit becomes the evaporator and produces cold air [22], [23]. Many units also utilize strip heaters when the air temperature outside is too cold for the heat pump to be efficient. Hourly profiles for the home in summer and winter peaks are shown in Figure 3.7 and Figure 3.8. This demonstrates the difference in overall power consumption during these periods. 


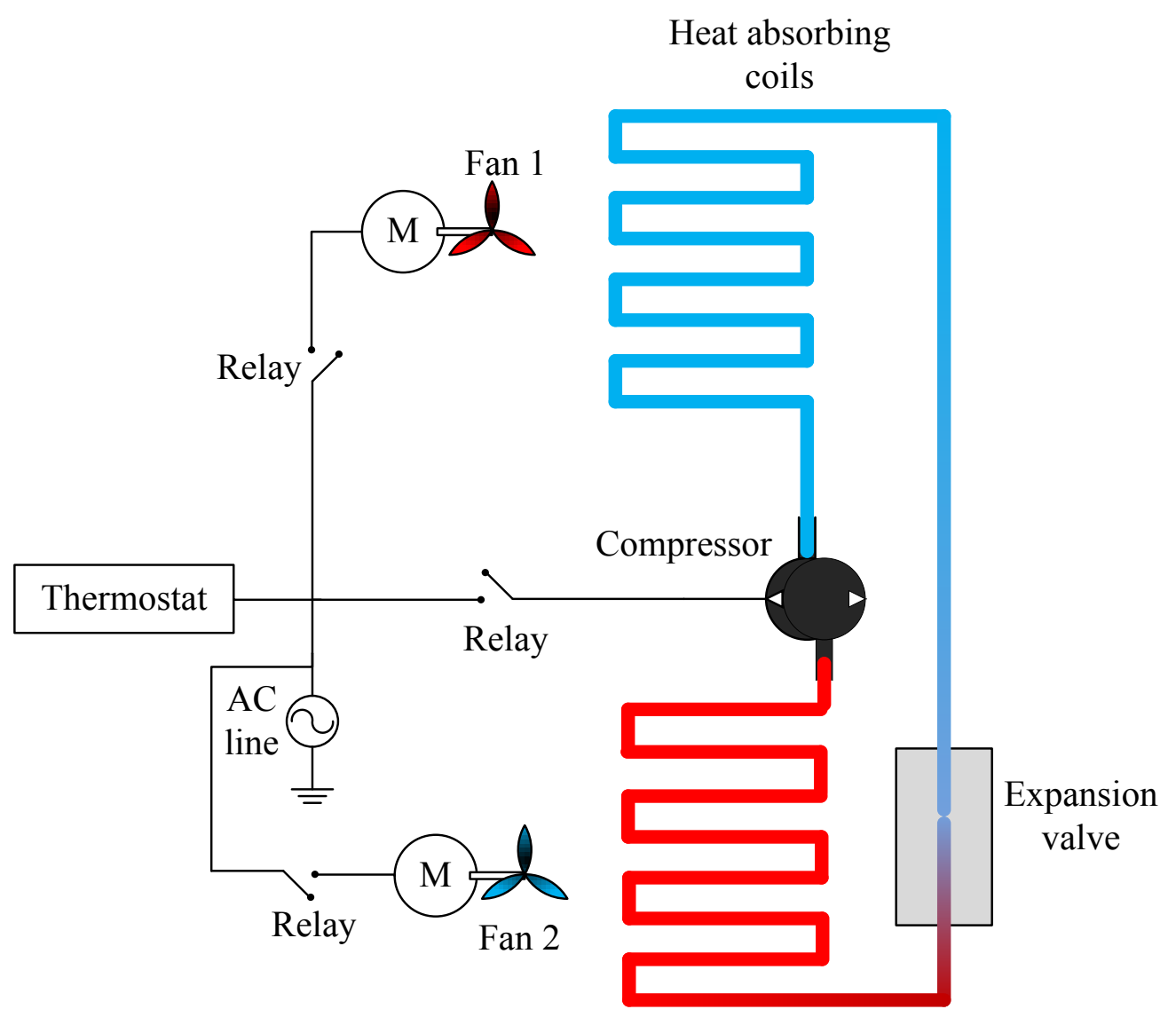

Heat dissipation

coils

Figure 3.5 Simplified diagram of a vapor compression air-conditioning cycle operating principle.

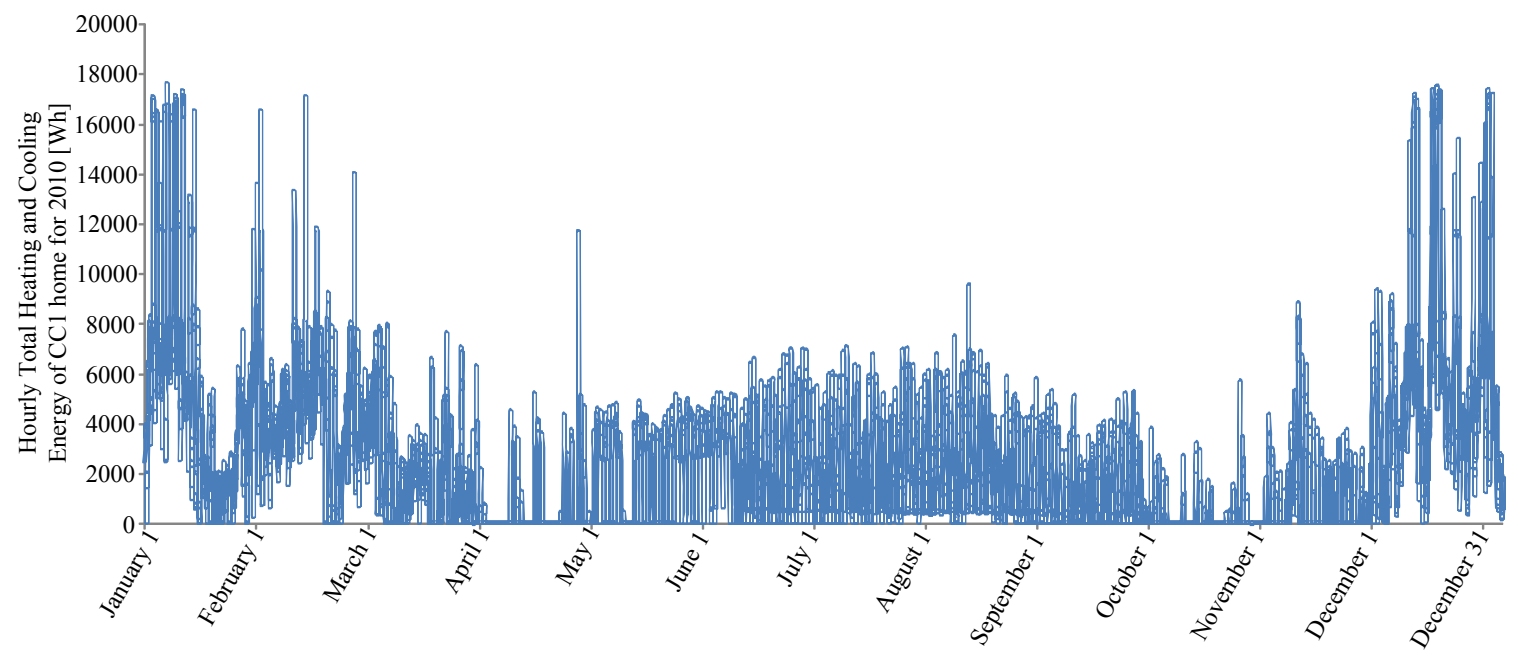

Figure 3.6 Hourly heating and cooling consumption for CC1 type home for 2010. 


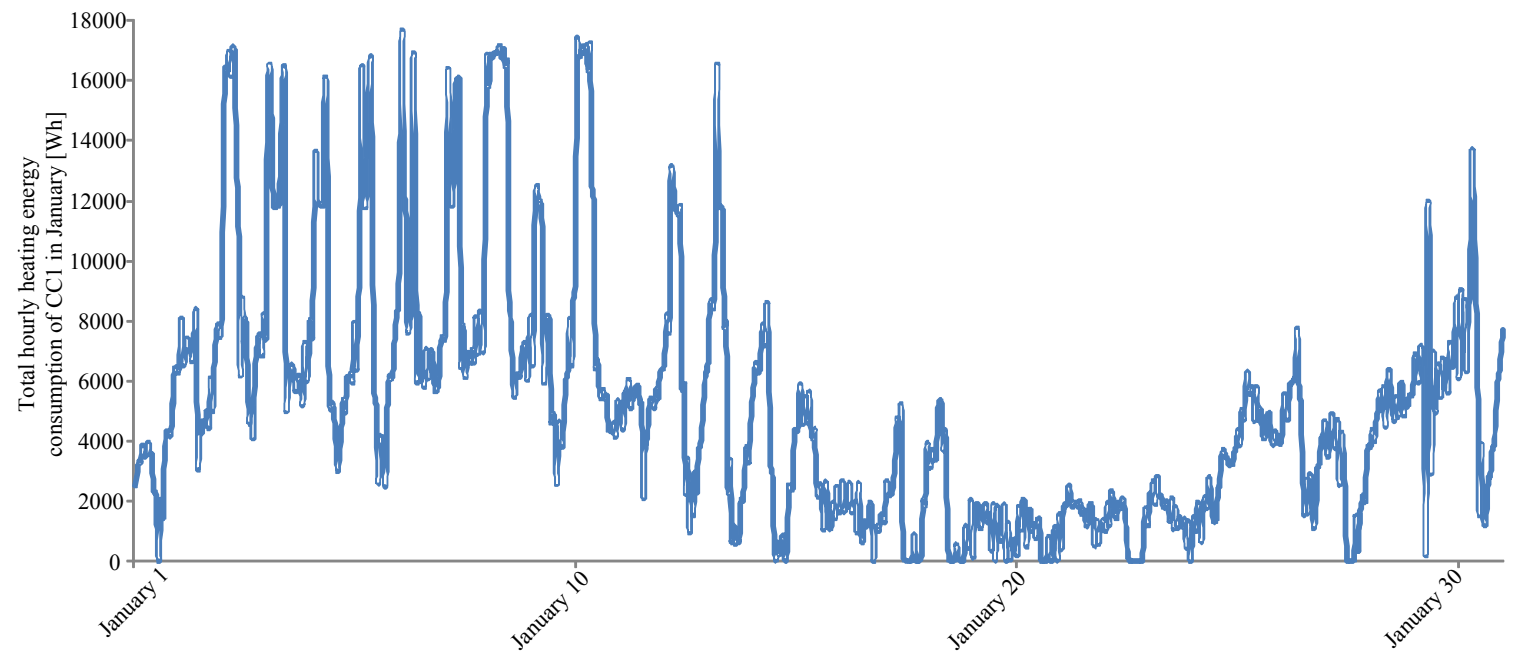

Figure 3.7 Winter consumption example for HVAC in 2010.

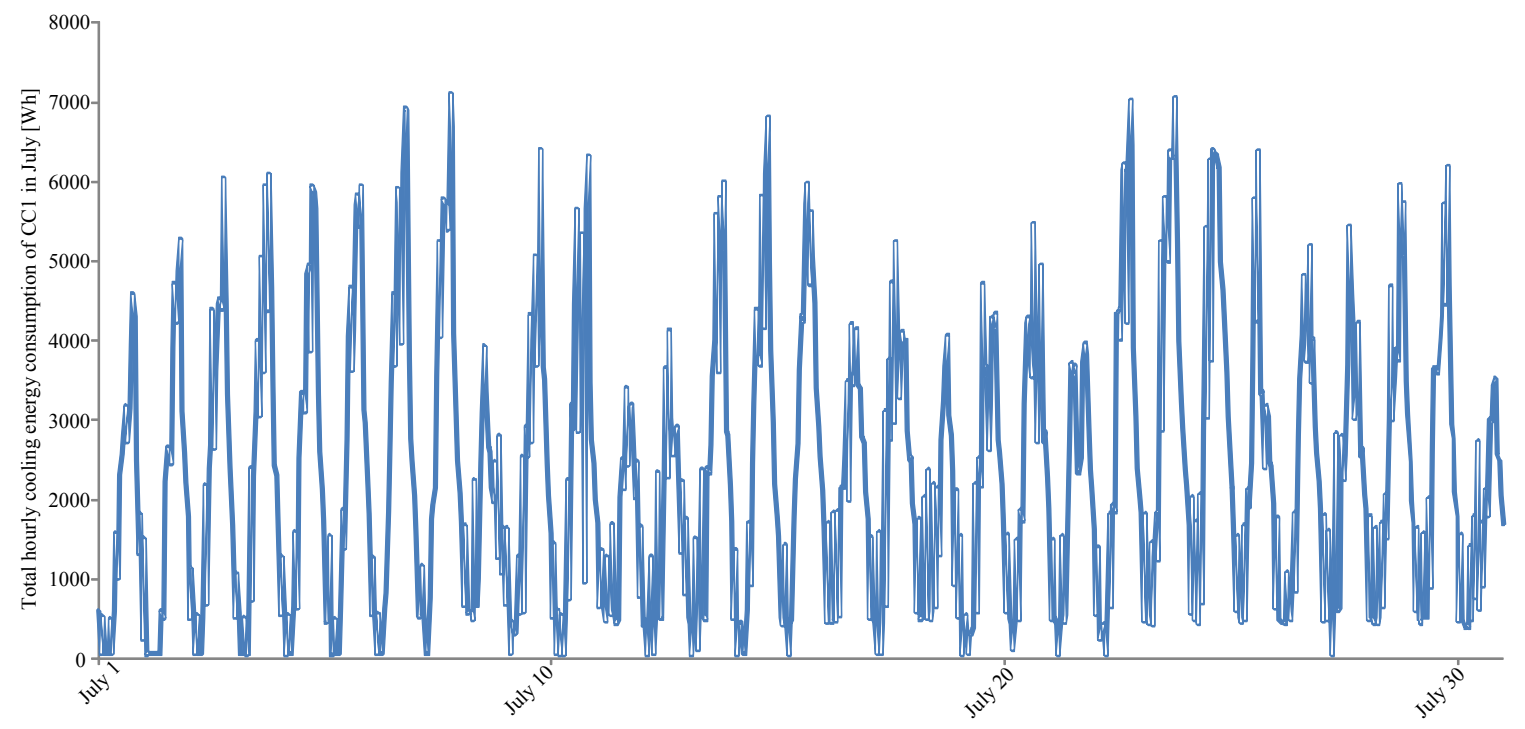

Figure 3.8 Summer consumption example of HVAC for 2010. 
The detailed HVAC data for all HVAC components was available only for hourly time steps. 1-minute interval data needed for real-time power consumptions profiles was not available for some components, so real-time power consumptions profiles could not be prepared for the entire HVAC system for this Phase 1 report. Future work will include obtaining additional 1-minute interval data needed to prepare real-time power consumptions profiles for all HVAC components.

In terms of electrical load, an HVAC unit employs three major components: a compressor, a number of indoor fans, and one or more outdoor fans. For the compressor, generally an on/off control keeps the compressor working until the indoor temperature reaches the preset user input. In most modern HVAC systems, the user can also set the fan speed at low, medium, high, or auto, so the fan motors are driven based on user input as well. Comfort levels of occupants associated with temperature are related to air-flow, humidity, and the relationship between indoor and outdoor temperature.

The temperature in the home can be raised or lowered based on knowledge of future and current outdoor temperatures. ASHRAE has developed occupancy-related metrics on acceptable limits, as shown in Figure 3.9. These metrics should create a range of appropriate control for the heating and cooling units to allow occupants to participate in demand response programs. For well-insulated homes or apartments, increasing levels of humidity often require lowering the temperature to sustain comfort. ASHRAE has developed standards that associate occupant comfort with humidity, as shown in Figure $3.10[24]$.

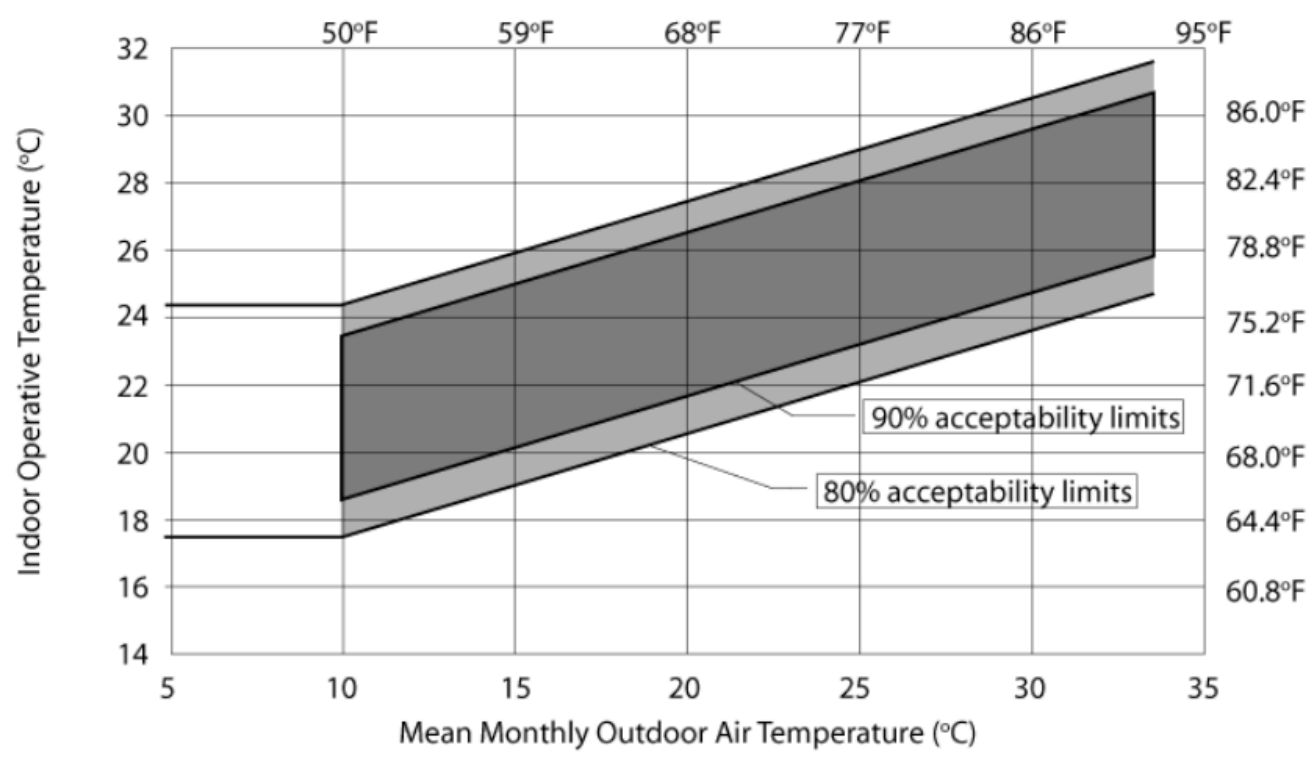

Figure 3.9. Indoor/Outdoor temperature and comfort relationship [24]. 


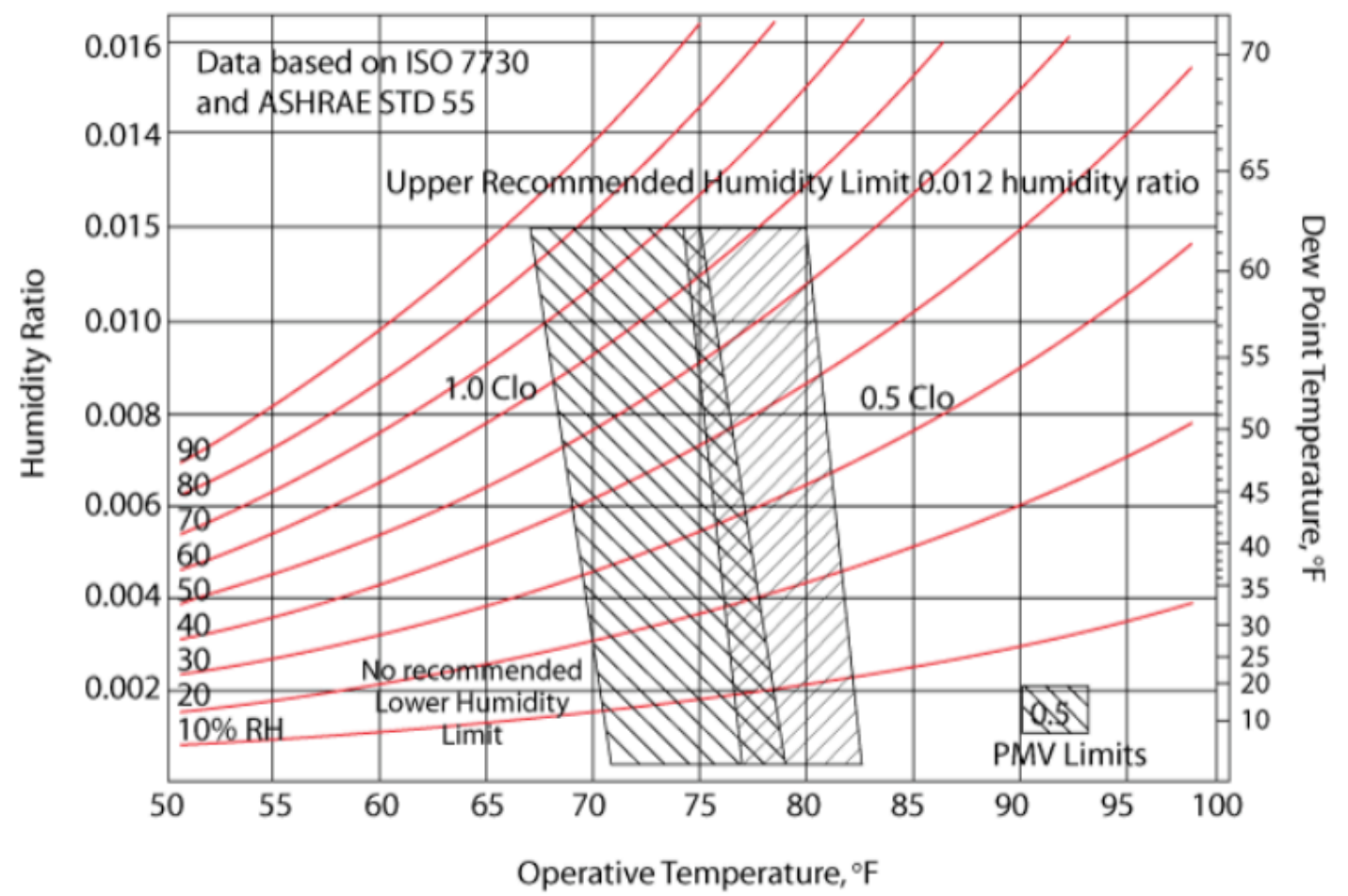

Figure 3.10 Humidity versus operating temperature acceptable operating range. [24]

\subsection{Refrigerator}

Refrigerators and HVAC units operate on similar principles. A refrigerator comprises a compressor, condenser, expansion valve and evaporator using ammonia, R134, or a similar material as the refrigerant along with the thermally insulated compartment. The heat from the thermally insulated compartment is transferred to the external environment in order to cool the temperature of the contents to a temperature below the ambient [25].

In most refrigerator systems, a vapor compression cycle is used where a circulating refrigerant undergoes a number of phase changes, delivering cool air inside the refrigerator and dissipating warm air outside the refrigerator. The refrigerant enters the compression cycle as low-pressure vapor at slightly above the temperature of the refrigerator compartment. Once the vapor is compressed, the pressure is increased and the refrigerant becomes a superheated vapor, which, under high pressure, flows through the tubes that form the condenser. These tubes or coils at the back of the refrigerator are passively cooled by exposure to the air in the room. Once the vapor cools during the condensing stage, the refrigerant returns to the liquid phase. At this point, the temperature of the vapor is slightly above room temperature and flows through the expansion valve to an area of much lower pressure. During evaporation, the refrigerant absorbs the heat from the refrigerator's contents, thereby cooling the inside of the refrigerator. The refrigerant absorbs the heat from the coils inside the refrigerator and the heat is dissipated through 
the coils at the back of the many refrigerator designs. After the expansion stage, the lower temperature gas is pulled by the compressor and a low pressure area is created. The cycle, as shown in Figure 3.11, then repeats [26].

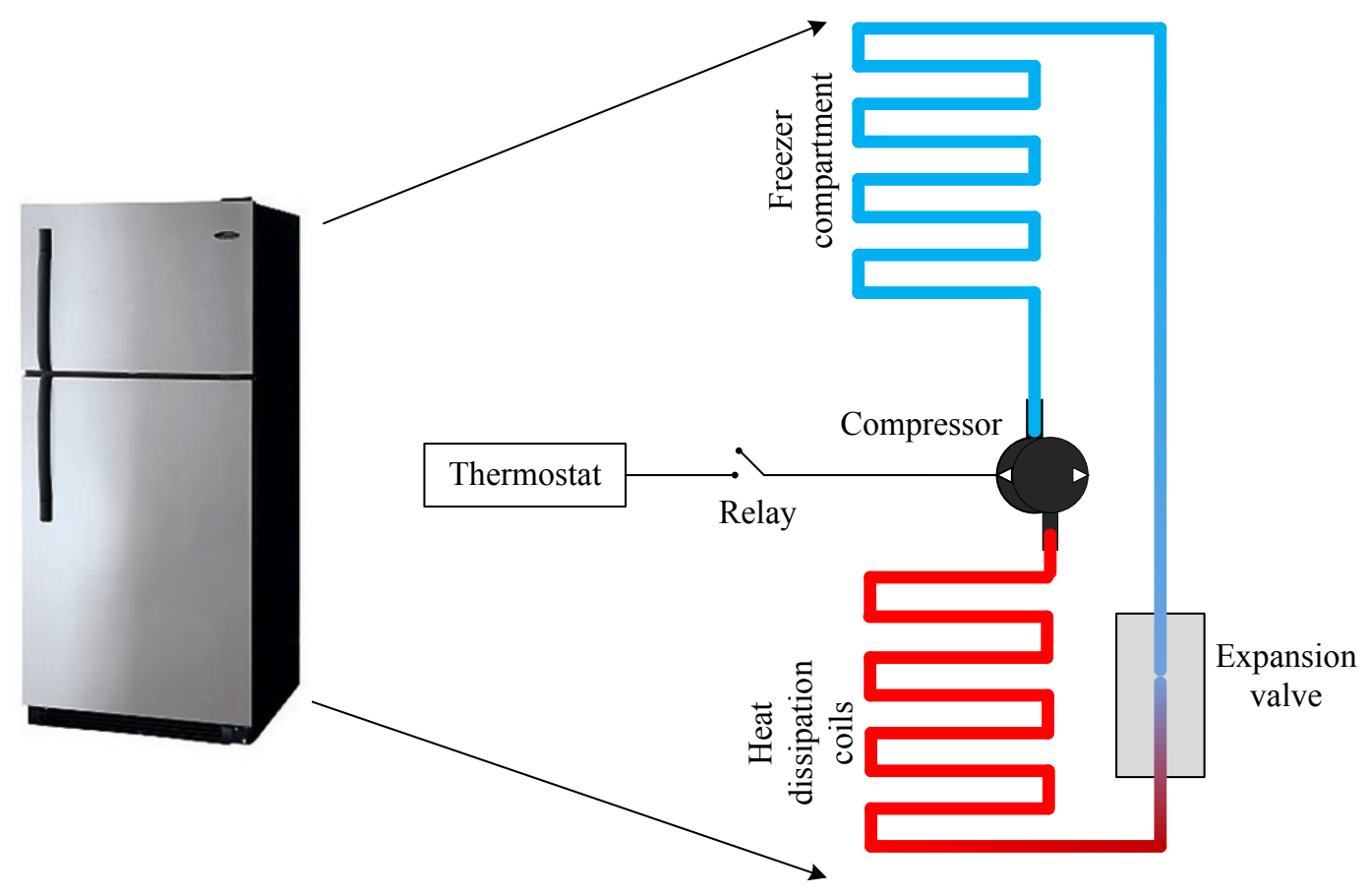

Figure 3.11 Refrigerator cooling and heating loop schematic

The compressor is the most significant load of overall refrigerator power consumption and is activated when the refrigerator thermostat requests cooling based on the cooling setting [27]. Levels of power consumption depend on the user setting, as the larger the deviation in temperature, the higher the energy consumed by the compressor. Other factors that control the level of power needed include relative humidity, refrigerator loading by means of placing more food inside, opening the refrigerator door, and the ambient temperature [27].

In addition to the compressor load, modern refrigerators have two fans driven by motors. The first fan is located under the refrigerator and is used to cool the compressor and to also partially help dissipate the heat from the external coils. The second fan is inside the refrigerator and moves the air from the interior coils to provide further cooling while supporting the defrosting process.

Lighting also accounts for a small portion of the refrigerator load. The internal light of the refrigerator is activated when the refrigerator door is opened. A push-button mounted near the door automatically pops out to turn the light on through a switch. Once the door closes, the door pushes the button back to turn off the light. The light and fan loads tend to be relatively small compared to the compressor. 
The general electrical energy consumption of the refrigerator for the entire year of 2010 in $\mathrm{CC} 1$ is shown in Figure 3.12. Based on hourly energy consumption, the refrigerator appears to consume approximately $50 \mathrm{Wh}$ for most of the year. Examining a single day shows that the refrigerator cycles most of the day, as shown in Figure 3.13. Instantaneous consumption levels ranged from $120 \mathrm{~W}$ to $140 \mathrm{~W}$. The specific characteristic behavior of the refrigerator is shown in Figure 3.14. Variations in consumption can be attributed to additional loading on the compressor due to events such as refrigerator door openings.

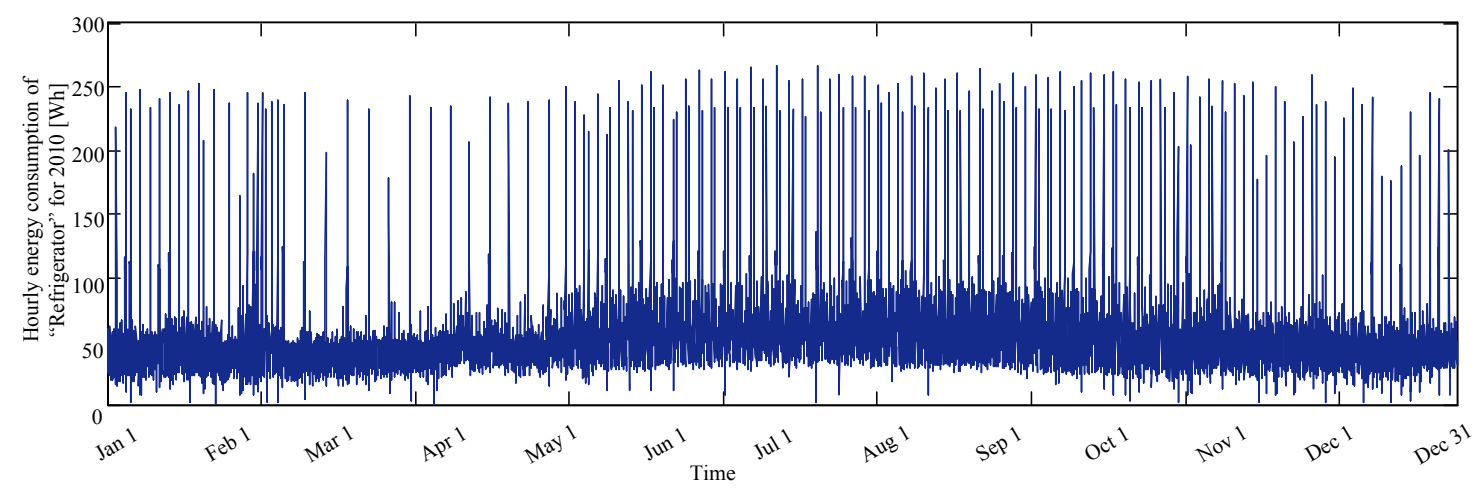

Figure 3.12 Hourly refrigerator usage for CC1 type home for 2010.

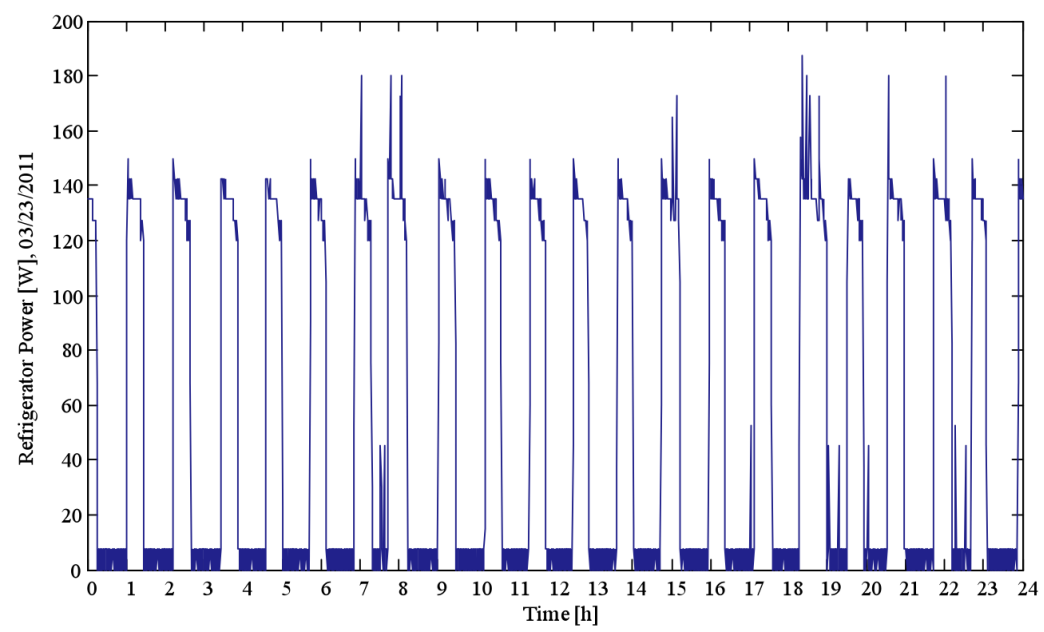

Figure 3.13 Refrigerator characteristic profile 


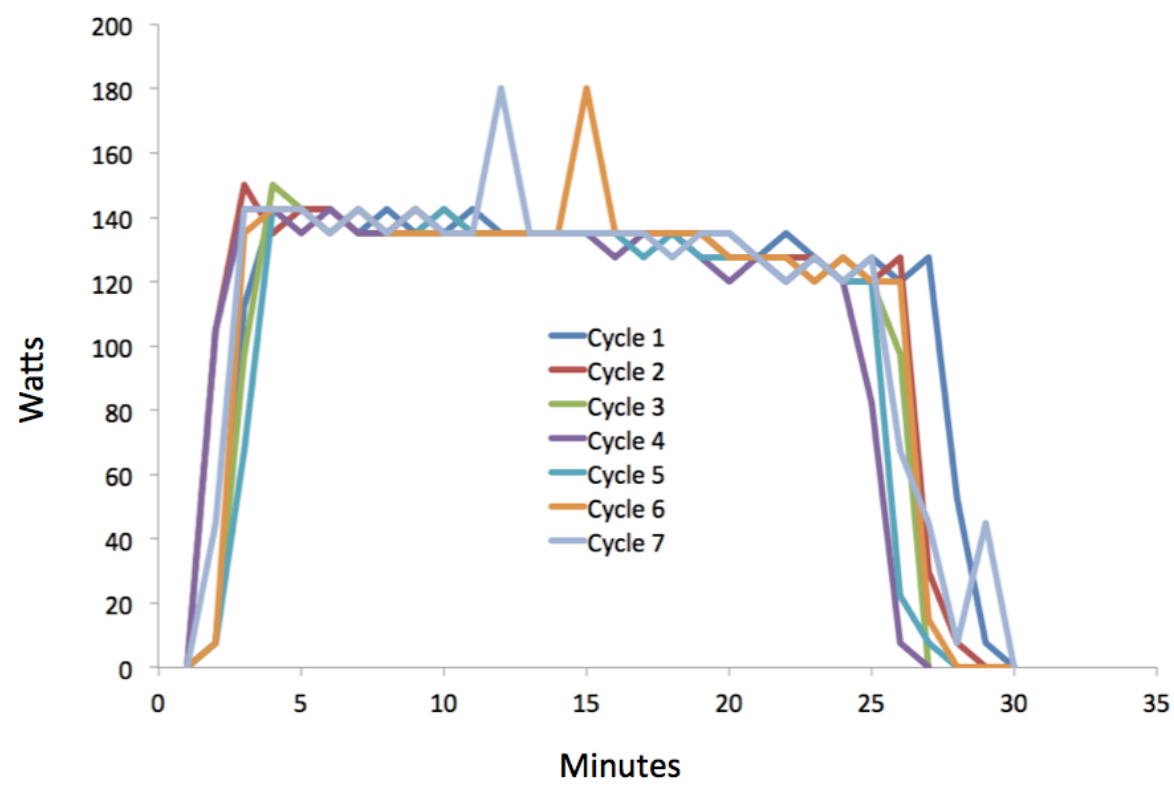

Figure 3.14. Refrigerator load behavior.

Typically, in controlling the refrigerator temperature, a hysteresis band is used to capture the operating range in order to avoid frequent turn on/off events of the compressor. When the refrigerator reaches the lowest set temperature, the thermostat turns off and a relay cuts the power of the compressor to stop the cooling. As the temperature of the refrigerator increases beyond the set point, the thermostat reactivates the relay and starts the compressor. The temperature control equipped with on-off compressor control is given in Figure 3.15 [28]. In Figure 3.15, $T_{\text {ref }}$ and $T_{m s r d}$ indicate the reference and measured temperatures, respectively, whereas $\varepsilon$ is the temperature error (difference between actual and reference values). The error signal is fed to a hysteresis band controller and based on the magnitude of the error the compressor is either turned on or off.

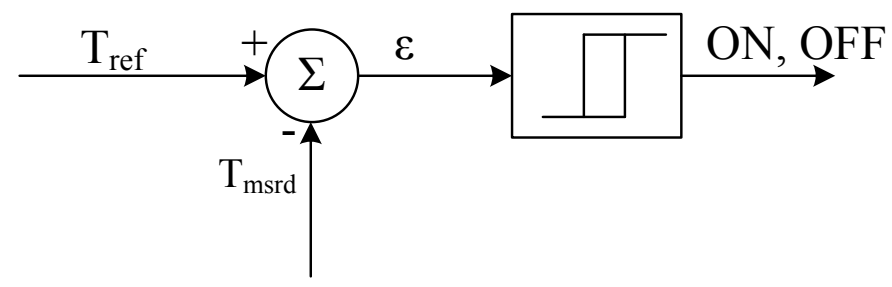

Figure 3.15 Relay control system for compressor control

The temperature range for refrigeration is based on two factors: (1) ensuring that food is adequately preserved and (2) not freezing the food. A low temperature of $40^{\circ} \mathrm{F}$ is often recommended for the refrigerator, and the Food and Drug Administration recommends not consuming the food that has been above $40^{\circ} \mathrm{F}$ for longer than 2 hours, [29]. To 
prevent freezing, temperatures above $32^{\circ} \mathrm{F}$ should be maintained. GE is currently looking at four approaches to demand response for refrigerators: (1) delay defrost, (2) modify run time during peak, (3) reduced features, and (4) adjust temperature set point [30].

\subsection{Water Heater}

Water heating utilizes electrical energy to increase the water temperature above initial temperatures. The conventional electric water heaters used in the United States consist of two heating elements and two thermostats [31]. With most water heaters, only one heating element can be turned on at a time. Since hot water is less dense than cold water, the hot water's outlet is at the upper level of the water heater. As the hot water is being used, cold water is taken into the bottom level of the water heater and remains there due to its higher density. As the cold water temperature increases, the water rises to the upper levels and replaces the used hot water. During hot water usage, the lower thermostat turns the lower heating element on in order to warm up the cold water that enters the tank. When no hot water is being used, only the upper thermostat turns on the upper heating element for short periods of time just to keep the water temperature between the preset temperature limits so that hot water can be provided on demand. Typically, the temperature is set between 120 and $140^{\circ} \mathrm{F}\left(49\right.$ to $\left.60^{\circ} \mathrm{C}\right)$. Since there are two thermostats and heating elements, the water in the heater tank can be considered to be in three levels; higher density cold water, a mixing layer, and lower density hot water, as shown in Figure 3.16 .

As seen in Figure 3.16, in order to turn on the upper heating element, the upper thermostat switches to position 1, whereas it switches to position 2 to turn on the lower heating while the lower thermostat also closes the switch. As the hot water is used, water at the mixing layer moves to the upper level of the tank and some amount of cold water is taken into the tank to replace the used hot water. If the lower thermostat is triggered due to the low temperature of the cold water, the lower heating element is turned on to heat the cold water. The cold water layer may rise to a level that triggers the upper thermostat if the hot water is continuously being consumed. In this case, the lower heating element is turned off whereas the upper heating element is turned on in order to give the priority to heating only the top layer of water. Once the upper layer water has been heated, the thermostat turns off the upper heating element and the lower heating element is turned on to heat the water from the bottom [32], [33]. 


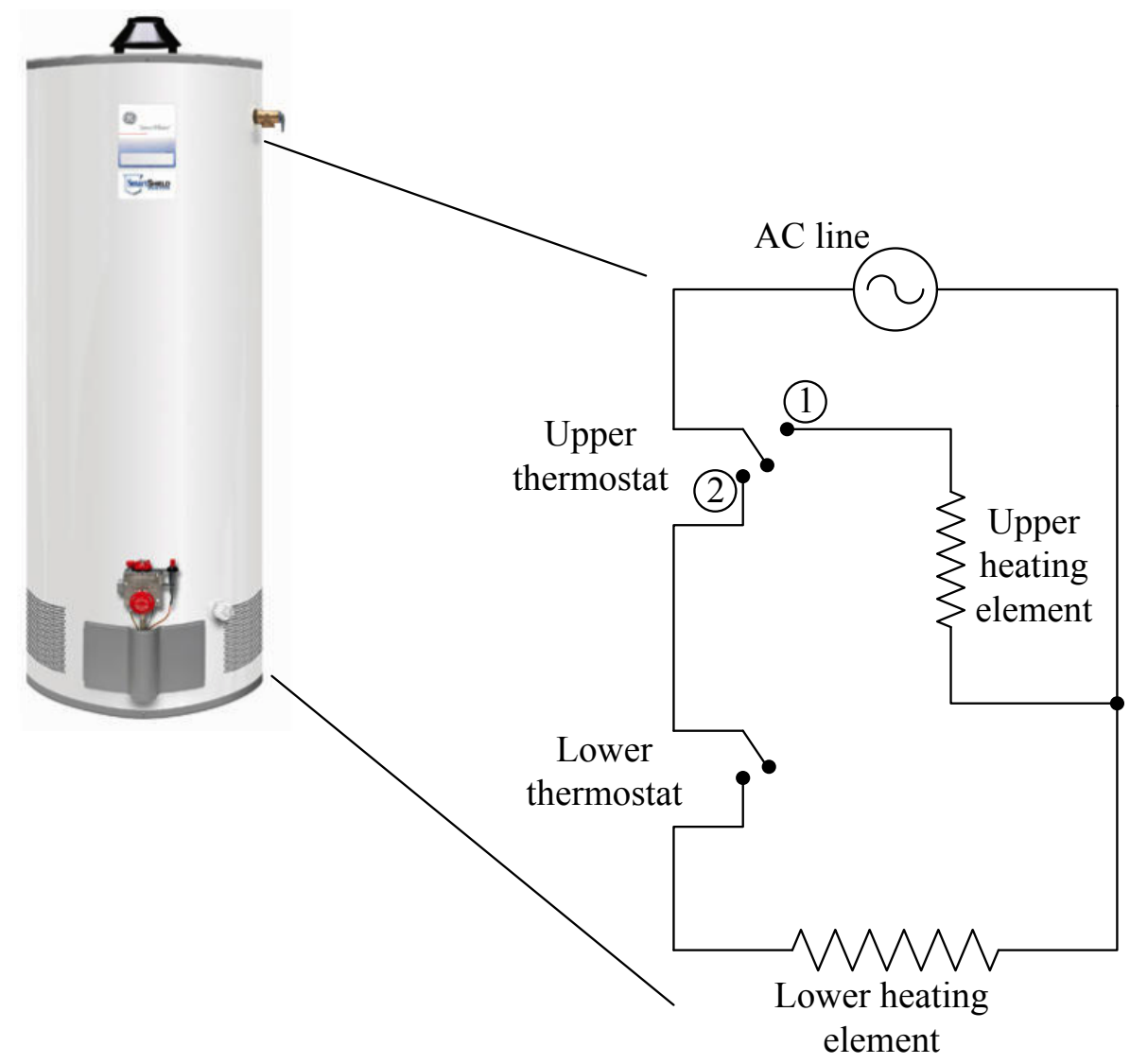

Figure 3.16 Electrical schematic of a conventional water heater.

In the new GE high efficiency hybrid electric water heater, a conventional heating element is utilized as well as a heat pump system. Using two variable speed fans and an evaporator, the heat of the ambient air is collected and delivered through tubes that wrap the water heater tank from top to bottom. Refrigerant, heated by the compressor, constantly flows through the tubing to heat the water in the tank. The conventional heating elements are only turned on during high hot water demand periods and during standard operation when needed [34].

The water heater from $\mathrm{CC} 1$ has a characteristic daily profile that is independent of season, but is directly related to water use, as shown in Figure 3.17. Over a number of hours during the day, the water heater will cycle on and off to provide adequate heating to maintain an appropriate water temperature. Typically, a water heater consumes more power during morning shower periods and during evening hours for cooking, dishwashing, and possibly for showers. A characteristic profile for the water heater on June 1st for CC1 is shown in Figure 3.18. 


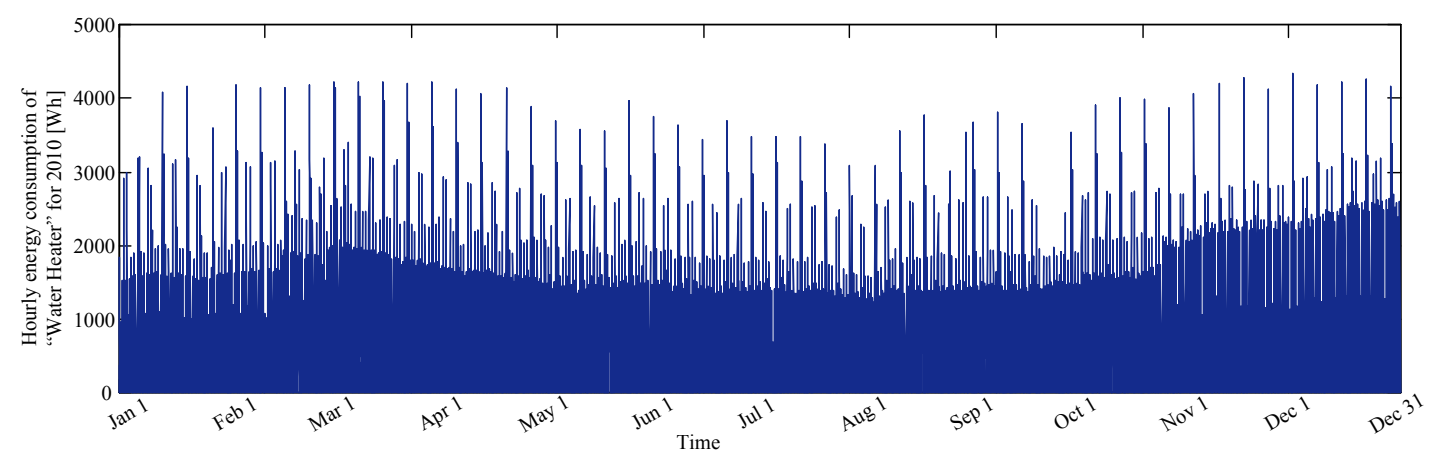

Figure 3.17. Hourly water heater usage for CC1 type home for 2010.

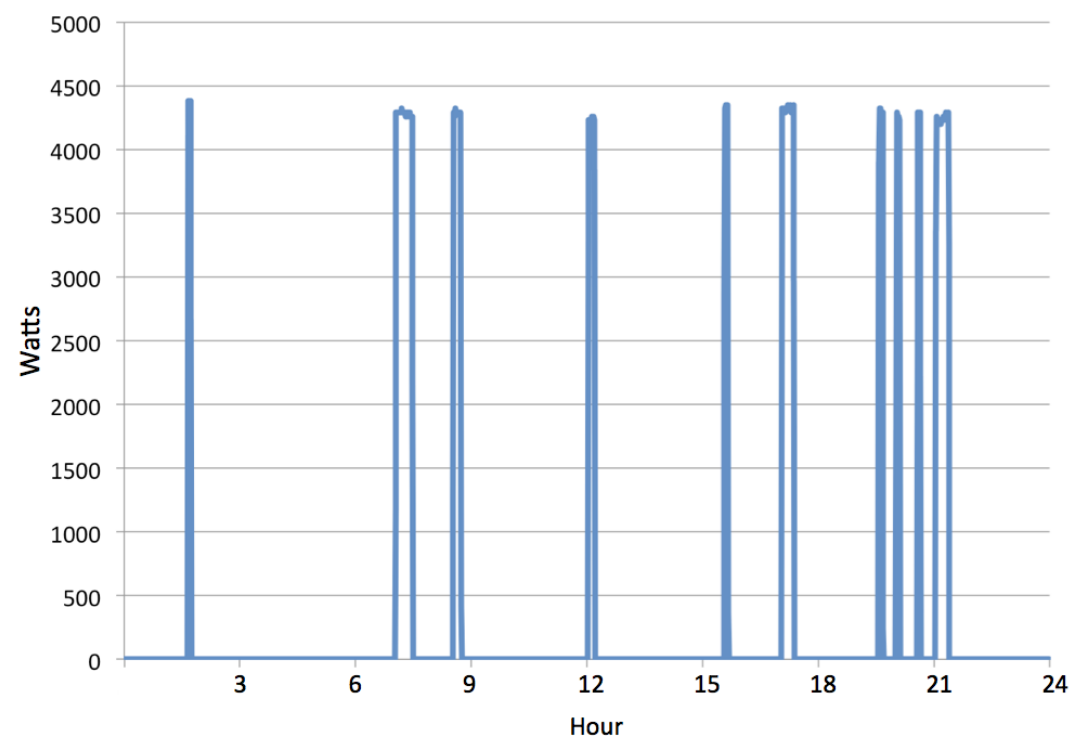

Figure 3.18. Water heater profile $(6 / 01 / 2010)$

Characteristic power profiles of the water heater in operation are shown in Figure 3.19. This load consumes roughly $4200 \mathrm{~W}$ when activated and is utilized for varying degrees in time. These operational periods are dependent on the initial temperature of the stored water before heating and ongoing usage of hot water.

Some methods extending beyond the conventional electrical layout given in Figure 3.16 have been proposed for load reduction of electric water heaters [35]. One of these approaches uses $240 \mathrm{~V}$ and $120 \mathrm{~V}$ AC voltage levels that are readily available to North American residential buildings. In this case, either $120 \mathrm{~V}$ or $240 \mathrm{~V}$ can be applied across the heating element of the water heater, as shown in Figure 3.20 (depending on the hot water demand and the load reduction purpose). Since the heating element is a resistive load, the power demand of the water heater can be reduced four times if switched from $240 \mathrm{~V}$ to $120 \mathrm{~V}$ AC line voltage ( $P=V^{2} / R$ ). As shown in Figure 3.20, the thermostat can switch between $120 \mathrm{~V}$ and $240 \mathrm{~V}$ input voltages on positions 1 and 2, respectively. 


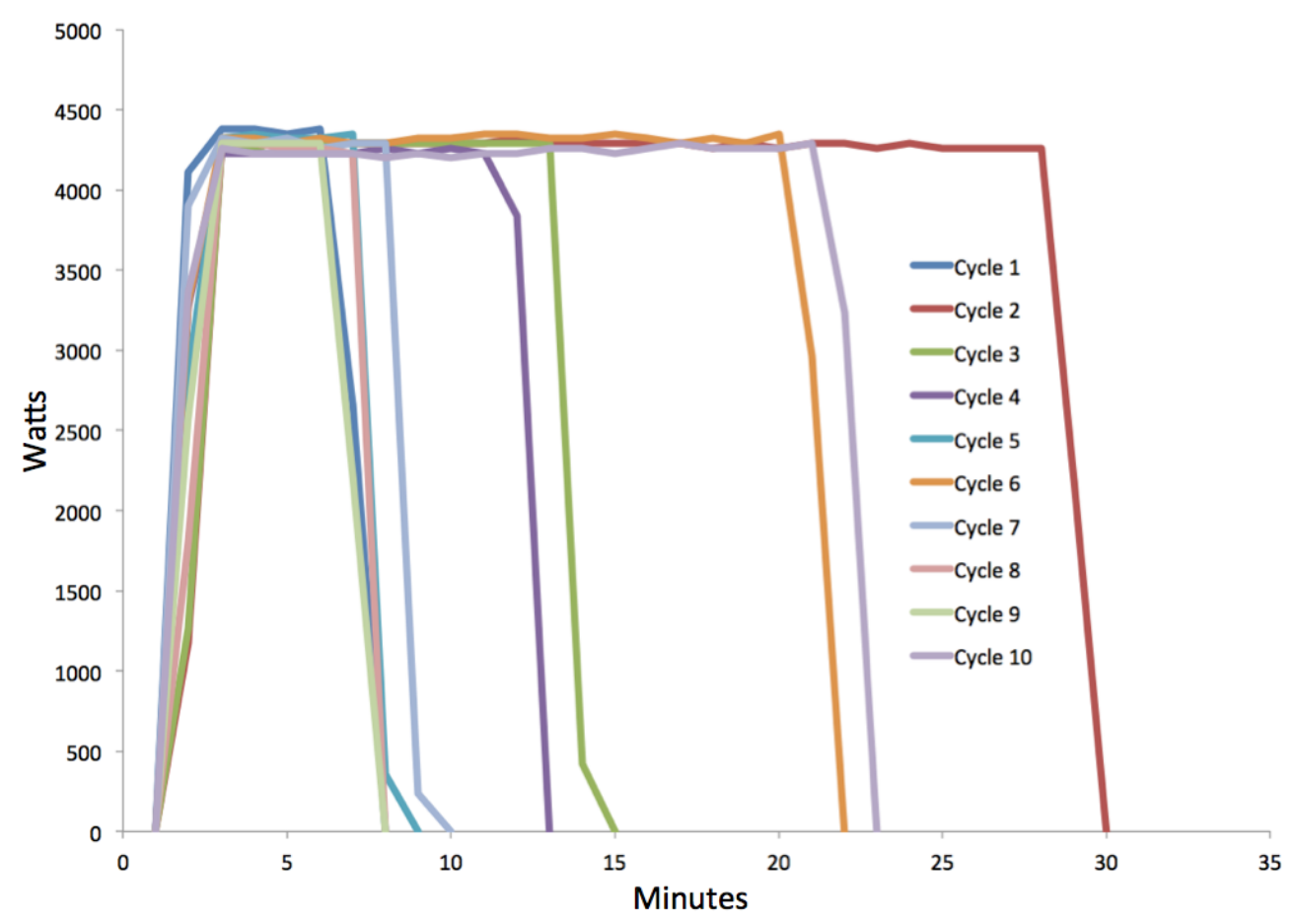

Figure 3.19. Water heater performance behavior.

Another option for load reduction of the water heaters is to use a number of heating elements with their parallel by-pass switches or simply paralleling the heating elements with series resistors as illustrated in Figure 3.21. In this case, the highest equivalent resistance would result in the lowest power demand whereas the lowest equivalent resistance would result in the highest power demand.

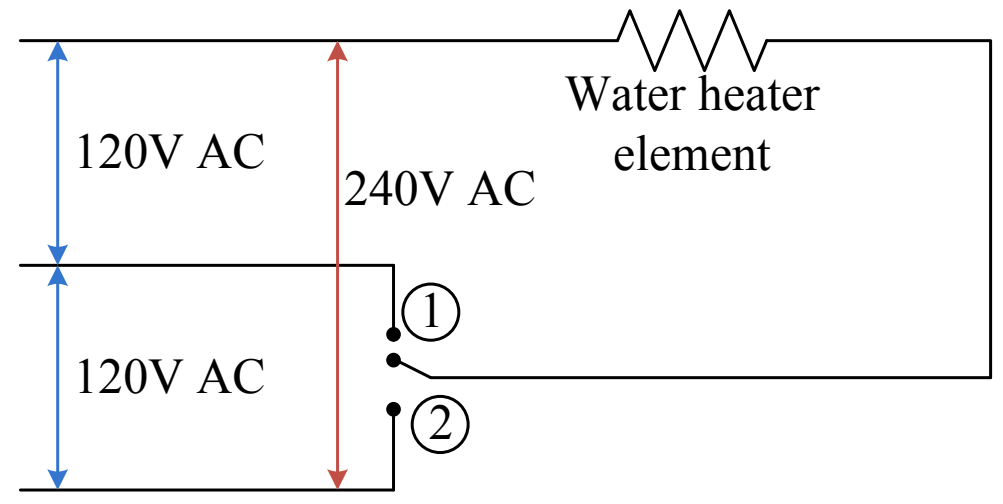

Figure 3.20 Water heater with 120-240V position switch for load reduction 
As proposed in Ref. [35], the switchable elements can be switched during peak-demand periods by the utility or by the customer. Both methods presented can be used in new water heater designs or other thermostatically controlled appliances. The approach shown in Figure 3.20 is applicable to the existing commercial water heaters. With some embedded or externally controlled smart equipment, the switching can be triggered automatically. System frequency, voltage, and electricity tariff can be used as controller inputs either individually or cooperatively for regulation purposes [36], [37].

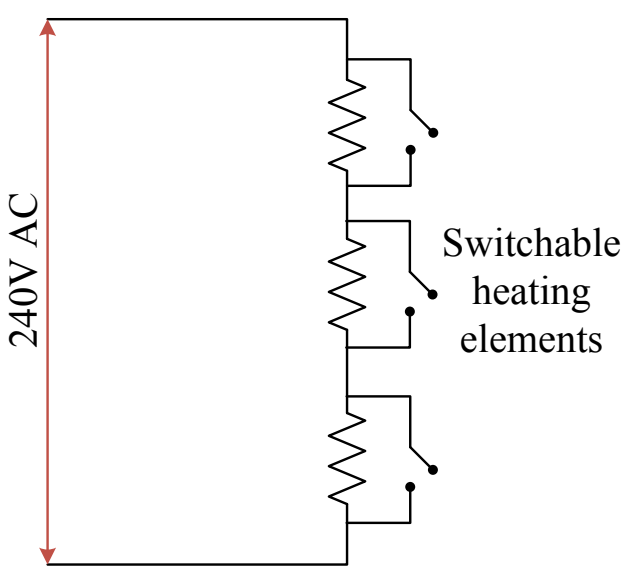

(a)

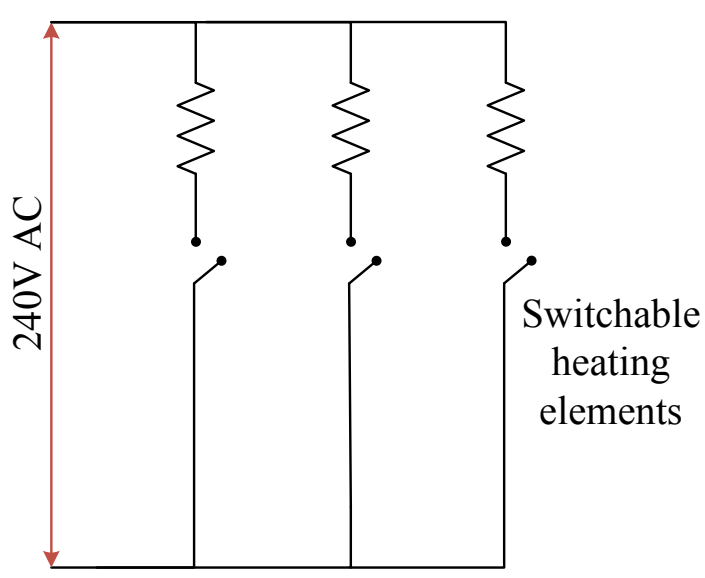

(b)

Figure 3.21 Water heater with switchable heating elements; (a) series elements with parallel by-pass switches, (b) parallel elements with series switches.

Two guiding limits are often imposed on the temperature range of water heaters [38]. At the high level, there is a risk of scalding when temperatures reach $140^{\circ} \mathrm{F}$ in the water tank. In many cases a tempering value (a tempering valve mixes enough cold water with the hot from the heater to keep the outgoing water temperature fixed) can be used to limit the potential for scalding. At the low end, exposure to Legionella, the bacteria responsible for Legionnaires' disease, is possible when temperatures are below $120^{\circ} \mathrm{F}$ for extended periods [39]. Table 3.1 shows the temperature conditions for various growth and disinfection of Legionella. Legionnaire's disease has similar symptoms to pneumonia and is often difficult to diagnose. The Occupational Safety and Health Administration suggests that 10,000 to 50,000 cases occur each year in the United States. 
Table 3.1. Legionella growth range with water temperature [39]

\begin{tabular}{|l|l|}
\hline 70 to $80^{\circ} \mathrm{C}\left(158\right.$ to $\left.176^{\circ} \mathrm{F}\right):$ & Disinfection range \\
\hline At $66^{\circ} \mathrm{C}\left(151^{\circ} \mathrm{F}\right):$ & Legionella die within 2 minutes \\
\hline At $60^{\circ} \mathrm{C}\left(140^{\circ} \mathrm{F}\right):$ & Legionella die within 32 minutes \\
\hline At $55^{\circ} \mathrm{C}\left(131^{\circ} \mathrm{F}\right):$ & Legionella die within 5 to 6 hours \\
\hline Above $50^{\circ} \mathrm{C}\left(122^{\circ} \mathrm{F}\right):$ & They can survive but do not multiply \\
\hline 35 to $46^{\circ} \mathrm{C}\left(95\right.$ to $\left.115^{\circ} \mathrm{F}\right):$ & Ideal growth range \\
\hline 20 to $50^{\circ} \mathrm{C}\left(68\right.$ to $\left.122^{\circ} \mathrm{F}\right):$ & Legionella growth range \\
\hline Below $20^{\circ} \mathrm{C}\left(68^{\circ} \mathrm{F}\right):$ & Legionella can survive but are dormant \\
\hline
\end{tabular}

\subsection{Clothes Washer}

In general, a clothes washer has three basic sets of components that are utilized during operation: solenoid valves for water control, a motor/pump for wash and spin cycles, and a timer motor, as shown in Figure 3.22. The clothes washer essentially has three cycles that are repeated to complete the laundry washing process: wash cycle, rinse cycle, spin cycle. During the wash cycle, the clothes washer water level sensor checks the condition of the water in the machine, closes switch S1 to empty, and activates the values for hot and cold water based on the control settings applied by the user. Once the clothes washer has filled to the appropriate level, switch S1 is moved to full, the timer is engaged, and the high, low, and/or starter coils are activated to spin the drum. Once the clothes washer has reached the correct speed, the starter coil is deactivated or switch S6 is opened. The pump circulates the water during the wash cycle and removes the water once the cycle is completed. During the clothes washer rinse cycle, the clothes washer water level sensor checks the condition of the water in the clothes washer, closes switch S1 to empty, and activates the cold water valve. Once the clothes washer has filled to the appropriate level, switch S1 is moved to full, the timer is engaged, and the high, low and starter coils are activated. Once the clothes washer has reached the correct speed, the starter coil is deactivated or switch S6 is opened. Again the pump is utilized to circulate water and remove the water upon completion of the rinse cycle. During the spin cycle only the high coils are activated. This gives the clothes washer a faster speed to spin dry.

The expected operational time of the clothes washer depends on the resident's schedule and can vary from early morning hours to evening hours or weekends. Table 3.2 lists statistics from 2005 on washer usage developed by EIA. In general, homes that utilize clothes washer mostly employ the devices from 2 to 9 times a week [40]. 


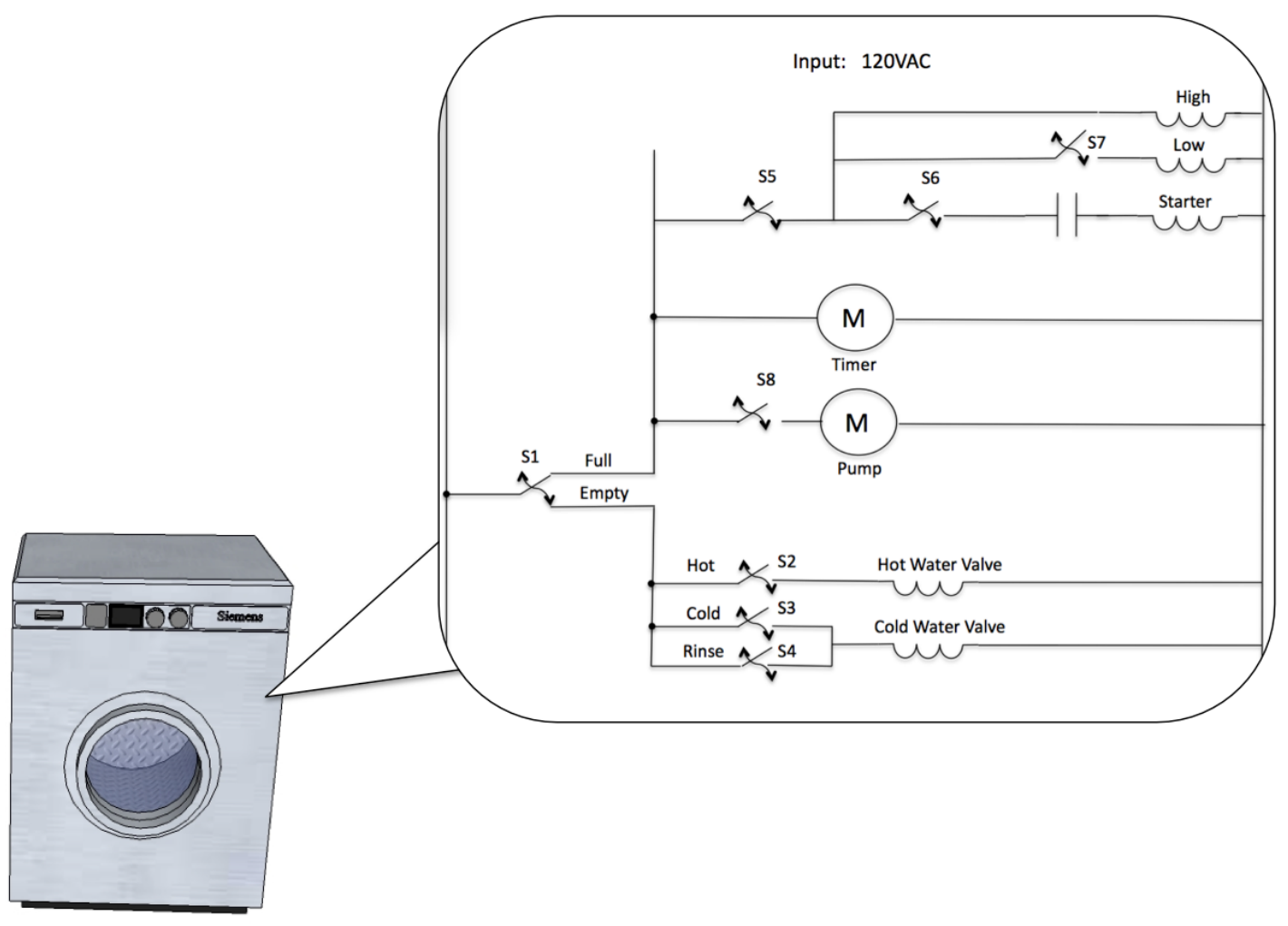

Figure 3.22 Clothes washer electrical schematic

Table 3.2. Clothes washer usage in millions of U.S. homes, EIA 2005 [40]

\begin{tabular}{|c|c|}
\hline 1 load each week & 7.3 \\
\hline 2 to 5 loads each week & 39.0 \\
\hline 6 to 9 loads each week & 33.8 \\
\hline 10 to 15 loads each week & 9.3 \\
\hline More than 15 loads each week & 2.4 \\
\hline
\end{tabular}


In $\mathrm{CC} 1$, the clothes washer was only operated for short periods within a day and was not operated every day as shown in Figure 3.23. The daily power profile of the clothes washer is shown in Figure 3.24.

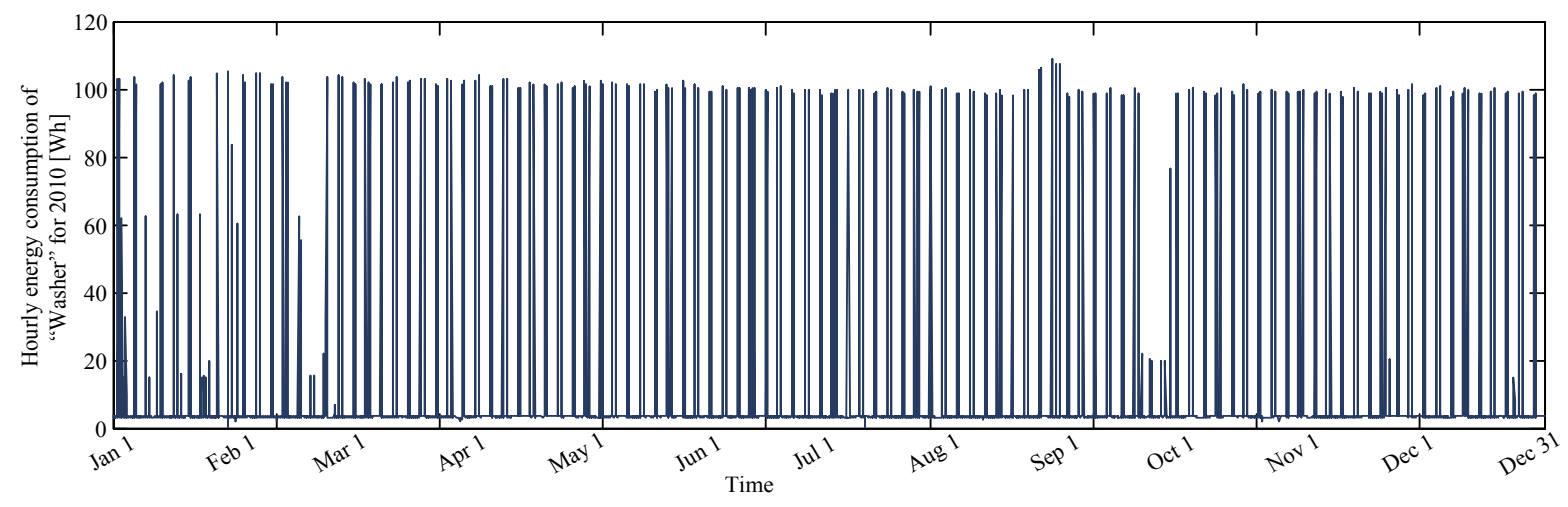

Figure 3.23. Clothes washer usage for CC1 type home for 2010.

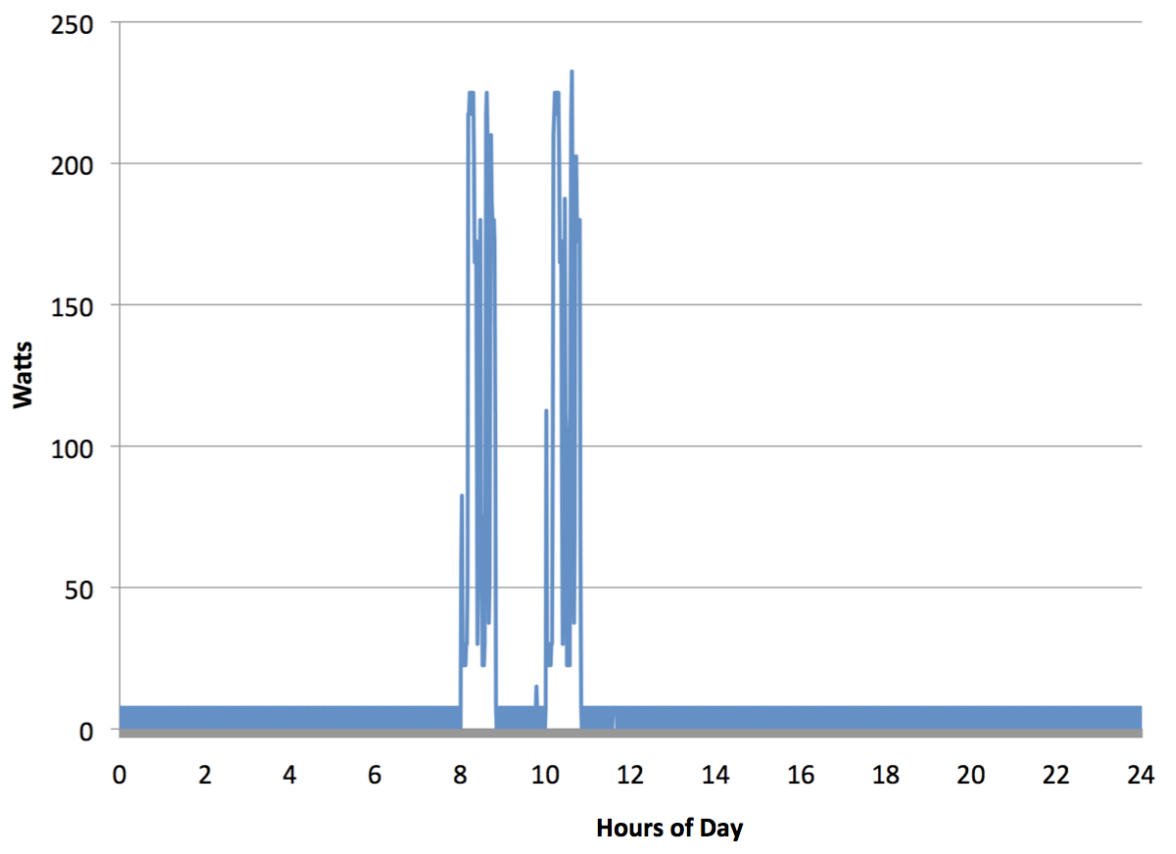

Figure 3.24. Clothes washer characteristics CC1 
The clothes washer has periods of operation that depend on the input settings by the user but are often in the range of $45-50$ minutes. The power utilized for two different clothes washers during a number of cycles are shown in Figure 3.25 and Figure 3.26. This demonstrates that the clothes washer power levels not only vary between manufacturers, but also depend on the loading and user input.

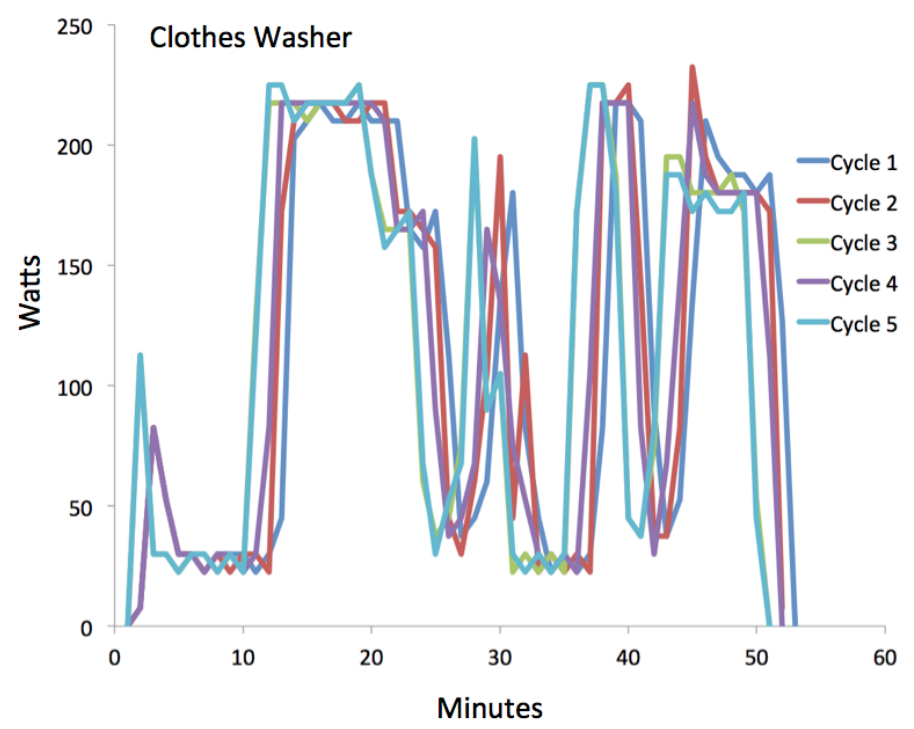

Figure 3.25 CC1 clothes washer behavior

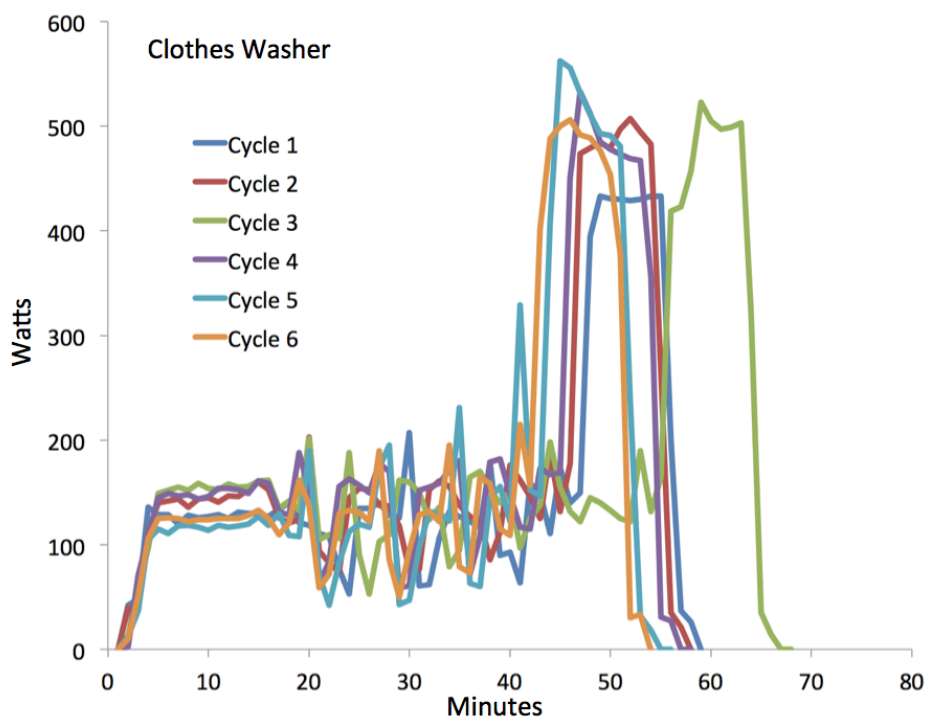

Figure 3.26 Clothes washer behavior behavior for Atlanta homes. 
Many of the functions in the washer are not available for making an impact on the power system through demand side reduction. Adjusting the valves for cold/hot water does not affect the power system, but can have an impact on the water heater when only cold water is used. Turning the motor from on to off or delaying the motor operation are the only available demand response mechanisms that could be utilized with the washing machine. GE is currently implementing technologies that delay activation of the washing machine under "critical and high levels" through an add-on demand response module [41]. The "critical and high levels" are directly related to the current status of the power system.

\subsection{Dryer}

The dryer is similar in design to the washing machine in that a machine is used to spin laundry. However, the dryer does not employ any water and uses resistive heating coils, as shown in Figure 3.27. The dryer utilizes the spin and heat to dry laundry.

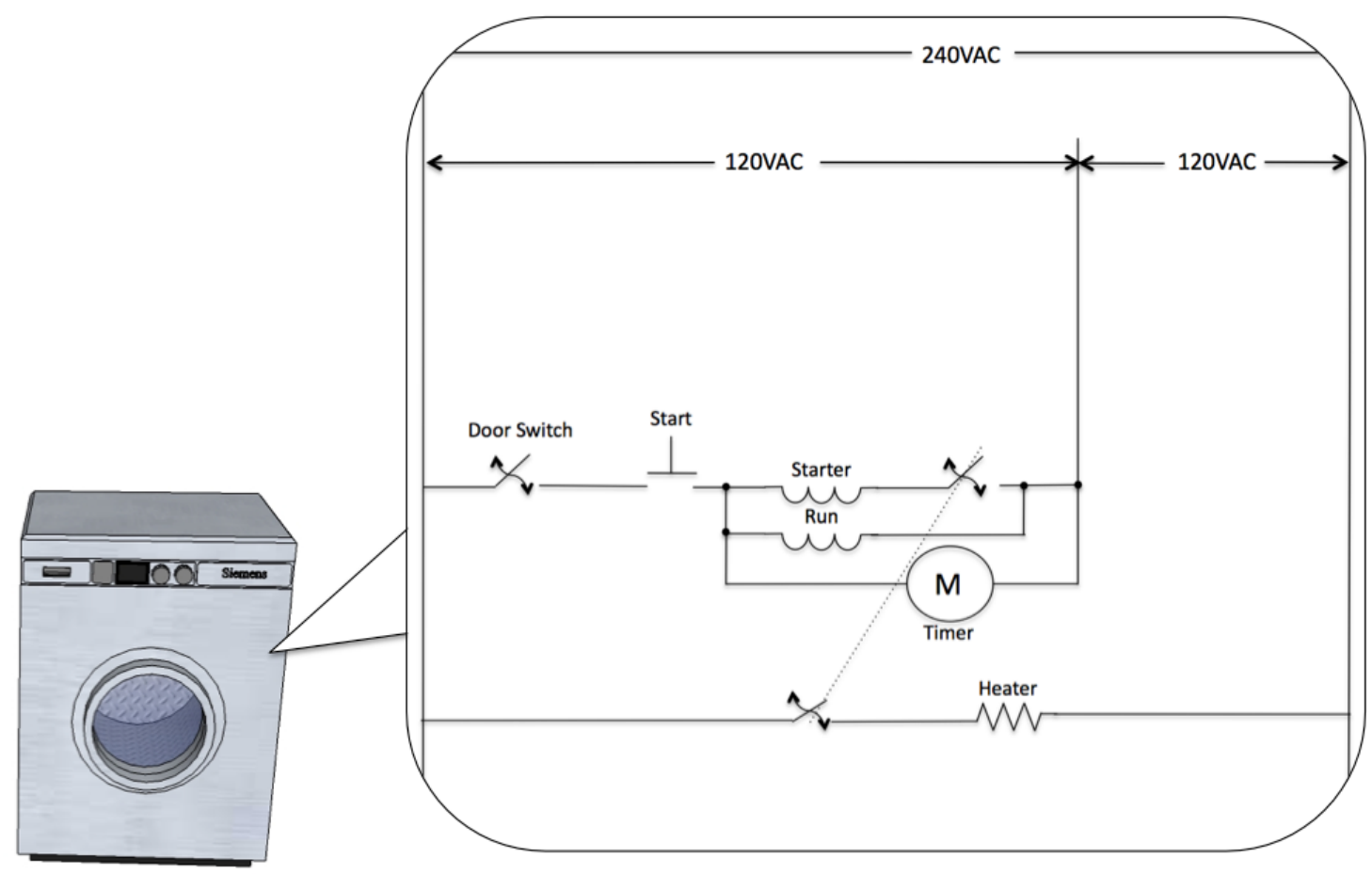

Figure 3.27 Dryer electrical schematic 
The dryer often operates in tandem to the washing machine. Figure 3.28 shows the hourly consumption for 2010 of the dryer in CC1. As with the washing machine, the expected operating time of these loads depends on the resident's schedule and can vary between early morning, evening, and weekends. An example profile consumption for the dryer is provided in Figure 3.29.

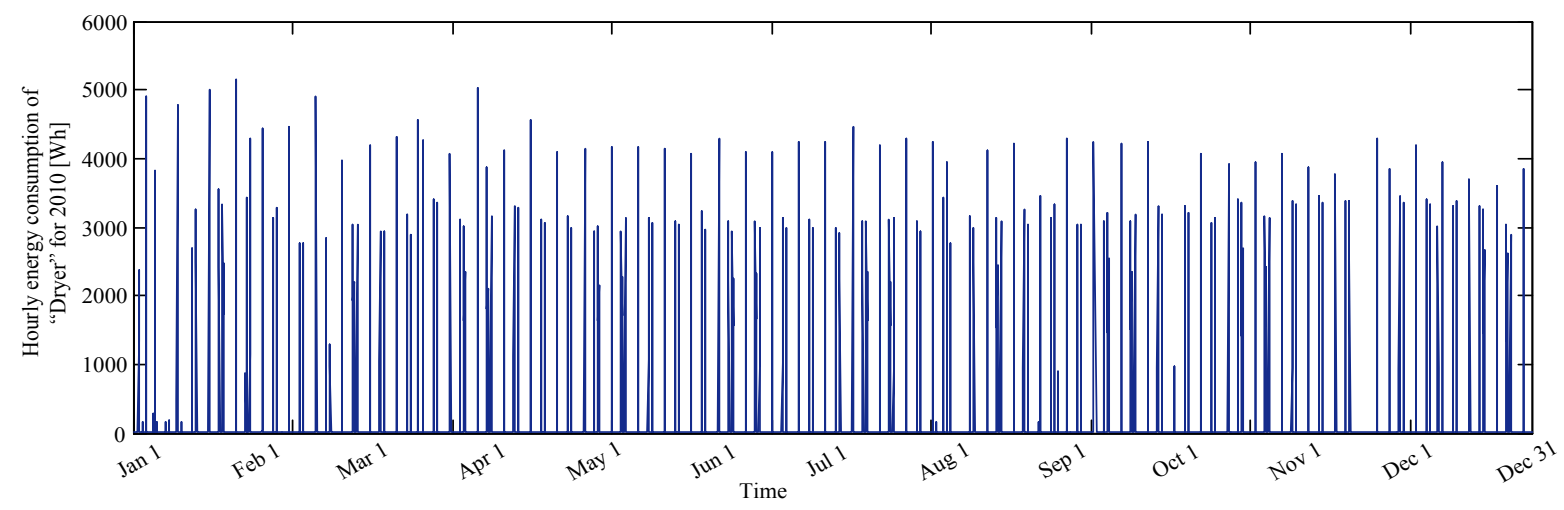

Figure 3.28. Dryer usage for CC1 type home for 2010

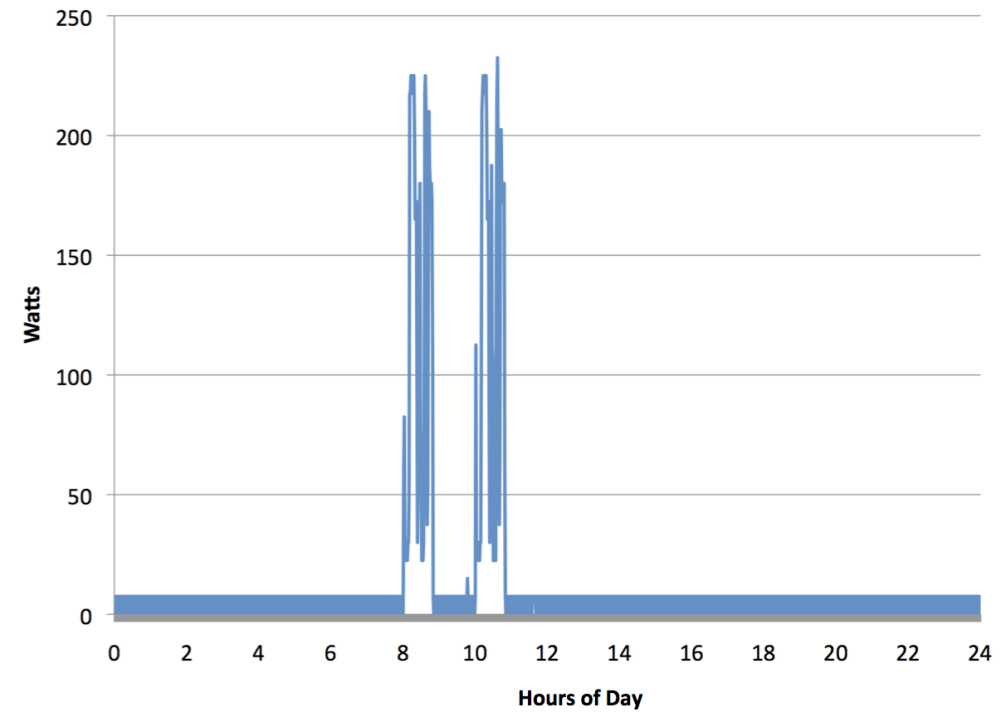

Figure 3.29 Dryer characteristics

A closer examination of the dryer power behavior shows the cycling of the heating coils and the constant power use of the motor as shown Figure 3.30 and Figure 3.31. The heating coil of the dryer consumes the most power and cycles depending on the 
manufacturer controls, laundry loading, and user settings. Most often the power was in the range of 4000 to $5600 \mathrm{~W}$.

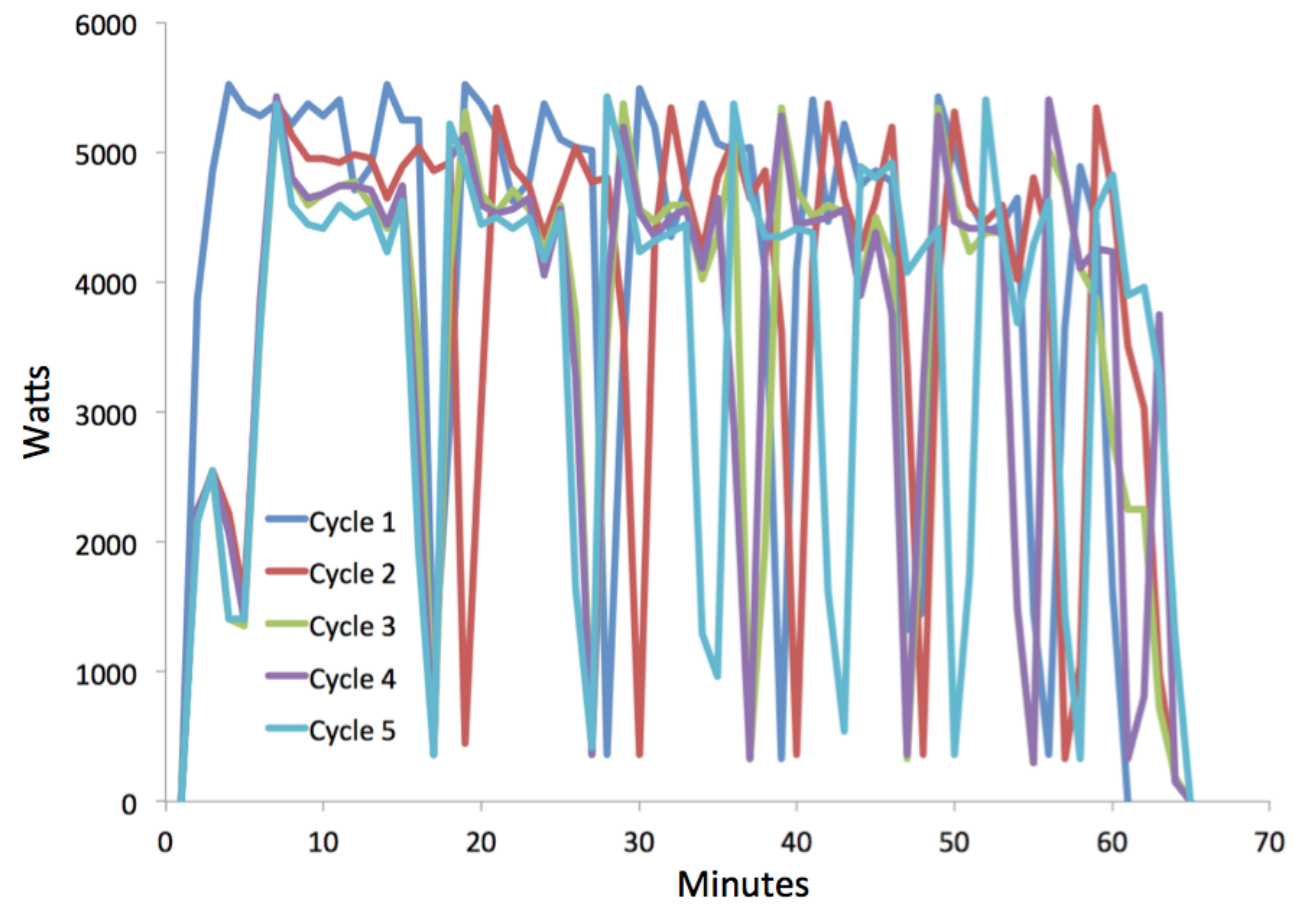

Figure 3.30 Dryer behavior for CC1 homes

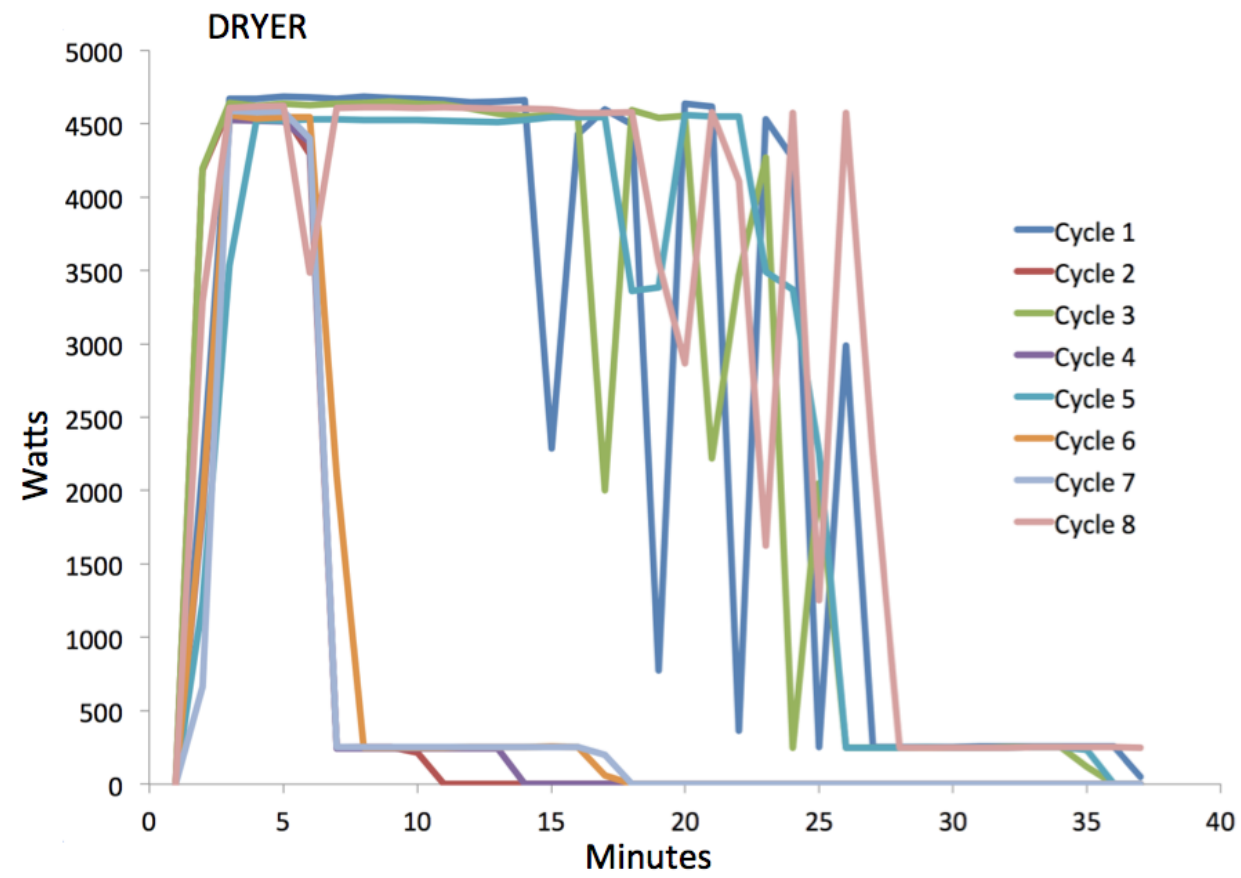

Figure 3.31 Dryer behavior for Atlanta homes. 
The dryer's heating element has the potential to reduce demand and delay the operation of the motor. Already companies such as GE and Whirlpool have developed demand response modules that adjust the run levels based on user settings, either delaying startup under "critical and high levels" or reducing the heat load and extending run time [42]. An opportunity still exists to potentially modulate the heat load to provide the service of regulation, although further research into the heating/cooling degradation in the heating element would need to be investigated.

\subsection{Dishwasher}

The dishwasher in $\mathrm{CC} 1$ is a load that did not vary from season to season as shown in Figure 3.32. Based on EIA statistics, dishwasher operation only occurs during a single event each day or less as depicted in Table 3.3.

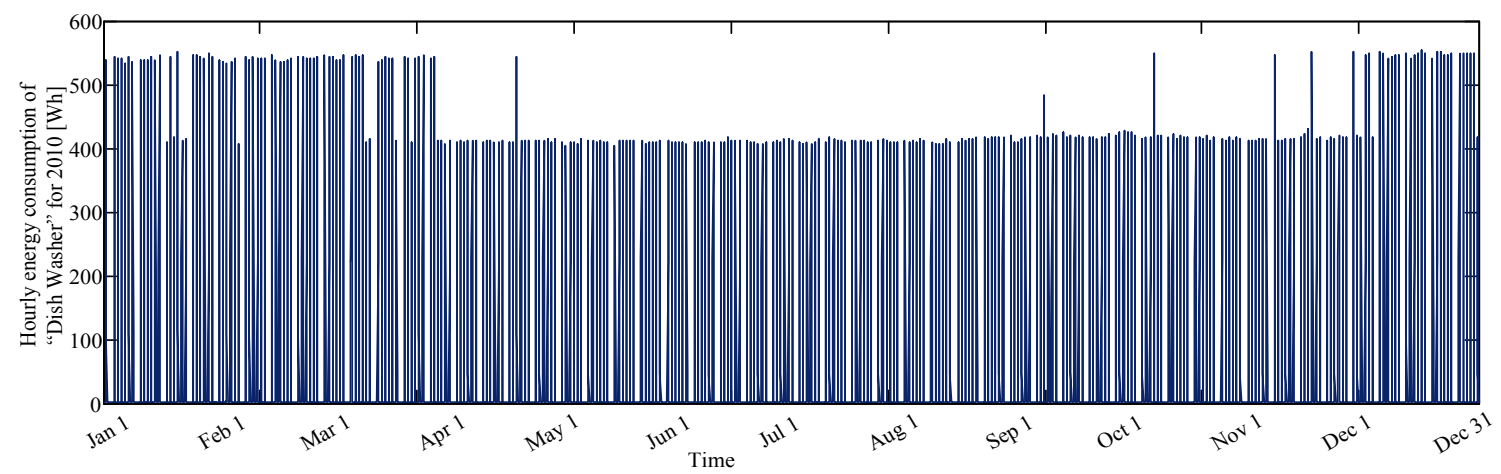

Figure 3.32. Dishwasher usage for CC1 type home for 2010 .

Table 3.3. Dishwasher usage in millions of U.S. homes, EIA 2005 [40]

\begin{tabular}{|c|c|}
\hline At least once a day & 11.3 \\
\hline 4 to 6 Times a Week & 11.7 \\
\hline 2 to 3 Times a Week & 21.8 \\
\hline Once a week & 9.0 \\
\hline Less than once a week & 10.9 \\
\hline
\end{tabular}




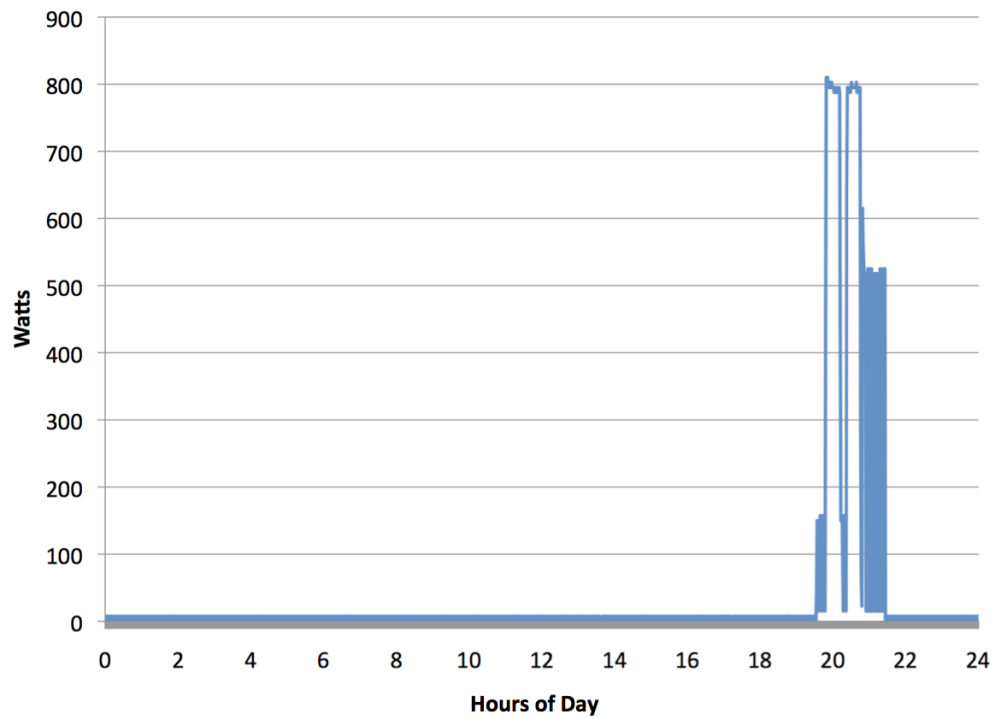

Figure 3.33 Dishwasher characteristics

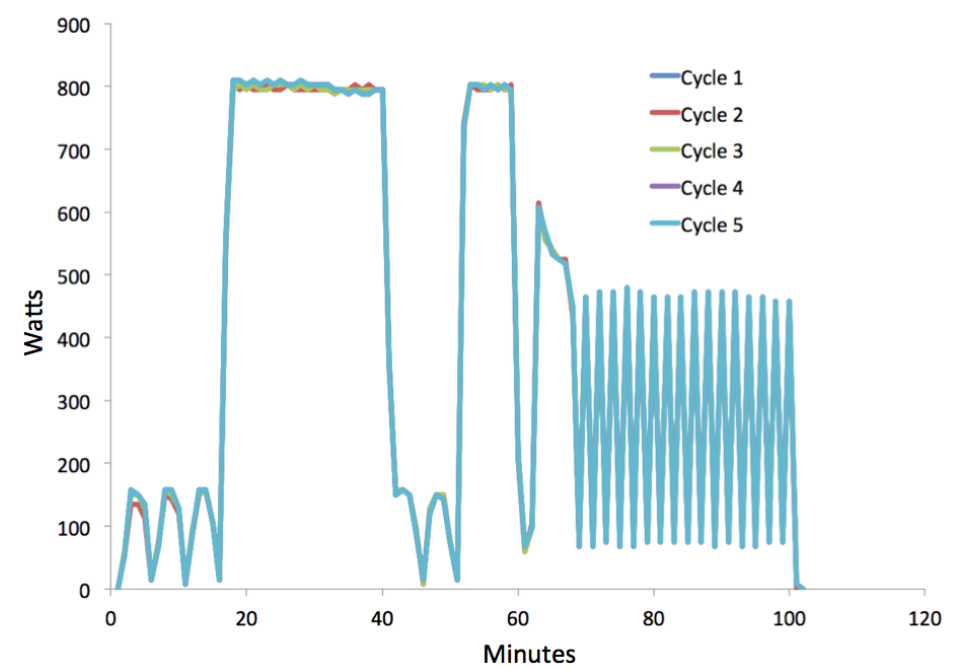

Figure 3.34 Dishwasher performance for CC1 homes. 


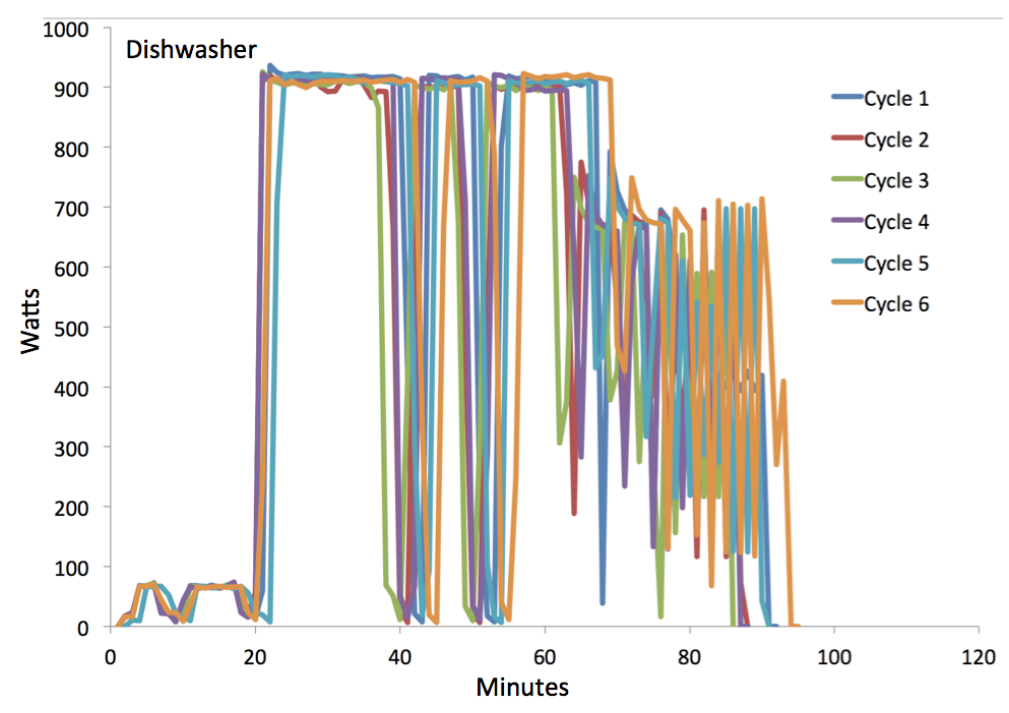

Figure 3.35 Dishwasher performance for Atlanta homes.

\subsection{Range}

Electric stoves use resistive heating coils that heat hotplates [43]. Since the 1970s, glassceramic cooktops have been applied in many electric cooking appliances. Although glassceramic has very low thermal conductivity, it readily conducts infrared radiation. Therefore, heating elements can be infrared halogen, tungsten, or heating coils (all are resistive loads, too). The simplified electrical design layout of a cooktop range is shown in Figure 3.36.

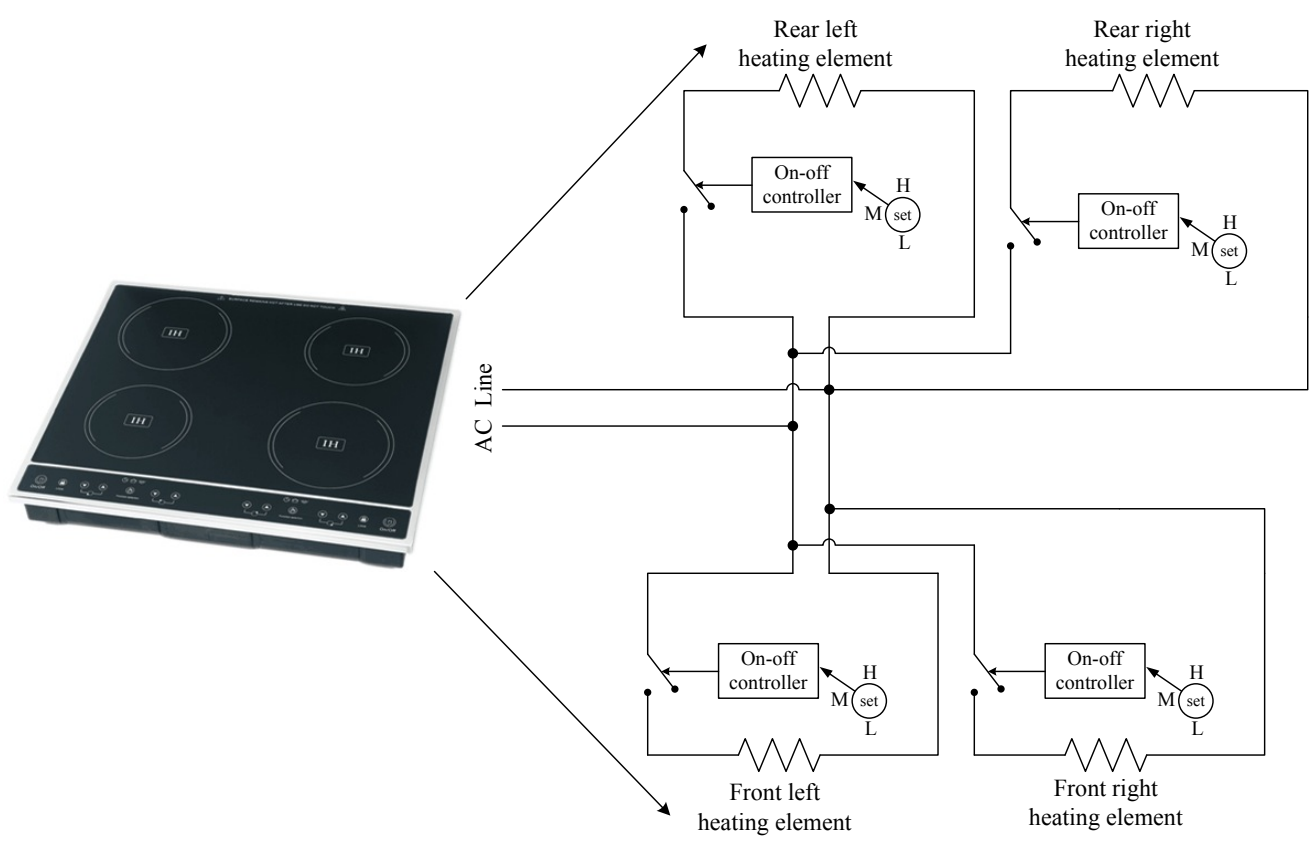

Figure 3.36. Electrical schematic of a range. 
Most ovens have two heating elements: one on the bottom for baking and one on the top for broiling. Depending on the user's baking or broiling selection, one of the heating elements is operated. Again, depending on the user's temperature input, a thermostat turns the respective heating element on and off to maintain the desired temperature within the oven [44]. Generally, ovens are equipped with timers that allow the oven to be turned on for a pre-set period of time and then automatically turn off at the end of the period. A general electrical layout for an oven is illustrated in Figure 3.37.

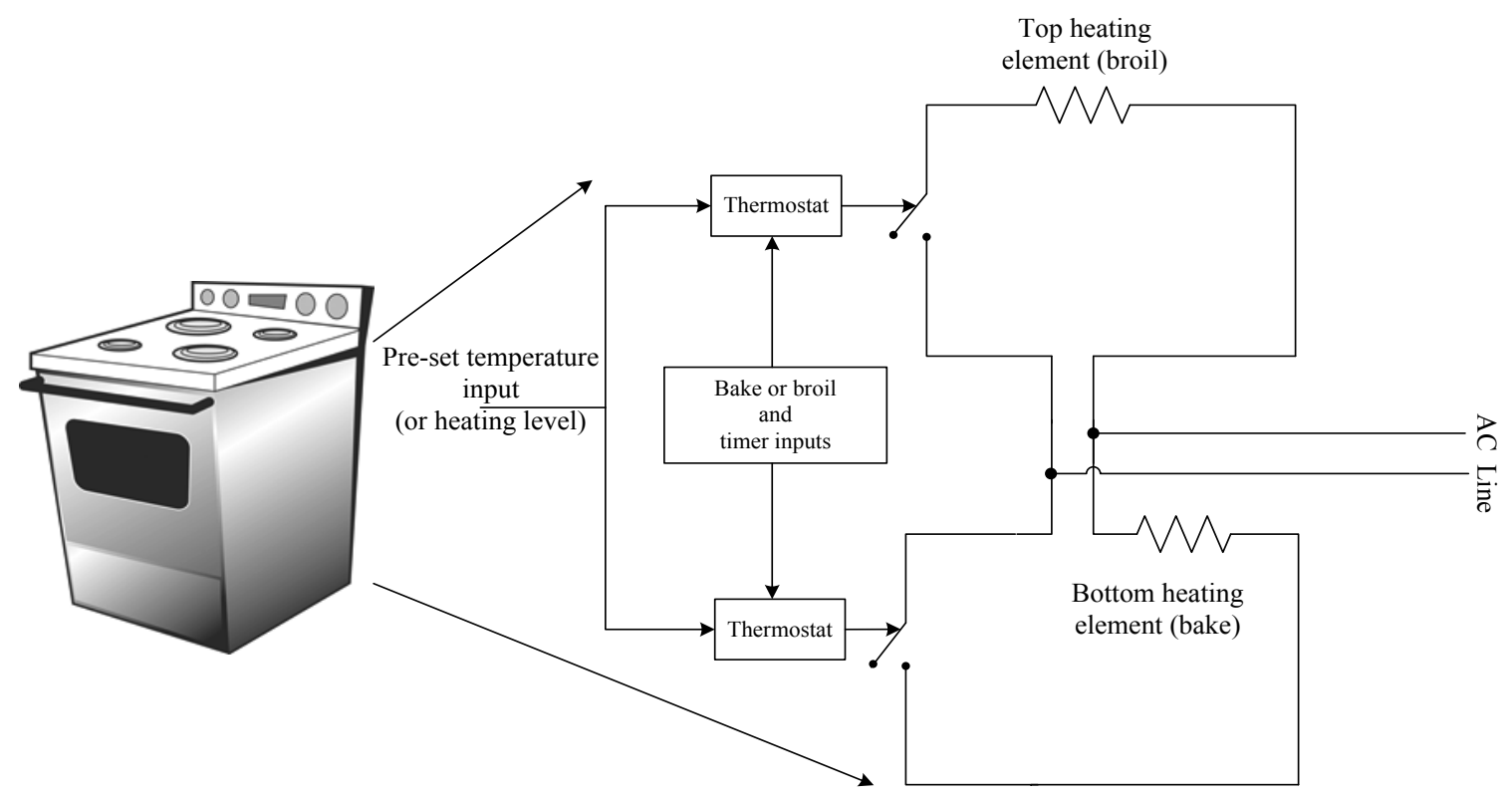

Figure 3.37. Electrical layout of an oven with bake and broil heating elements.

The electric range and dishwasher power consumption for 2010 in $\mathrm{CC} 1$ is shown in Figure 3.38. The range may be operated during several periods of the day (typically associated with cooking periods). Statistics from EIA on the usage of the range are presented in Table 3.4. Most often, the U.S. ranges are used anywhere between once a day and once a week.

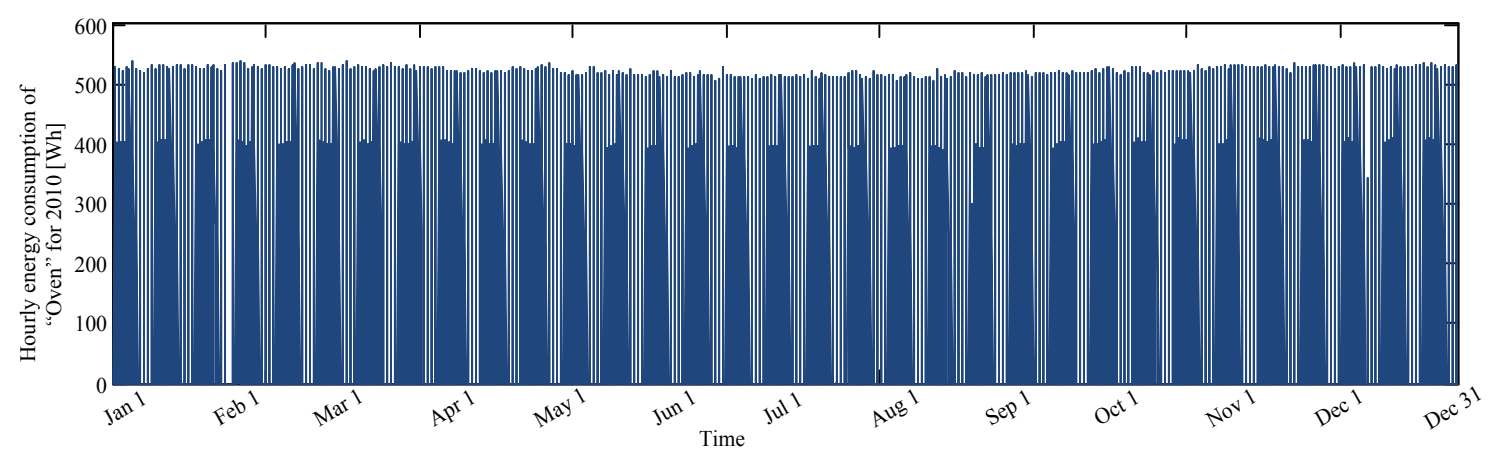

Figure 3.38. Range usage for CC1 type home for 2010 . 
Table 3.4. Range usage in millions of U.S. homes, EIA 2005 [40]

\begin{tabular}{|c|c|}
\hline More than once a day & 8.9 \\
\hline Once a day & 19.2 \\
\hline Once a day to once a week & 32.0 \\
\hline Once a week & 19.1 \\
\hline Less than once a week & 30.3 \\
\hline
\end{tabular}

Examining the range in detail shows that the oven undergoes cycling behavior as shown in Figure 3.39. For the oven, preheating to the correct temperature represents the first stage, with power levels exceeding $1200 \mathrm{~W}$. The second stage represents the cycling to hold the temperature in the oven within a specific range at $500 \mathrm{~W}$.

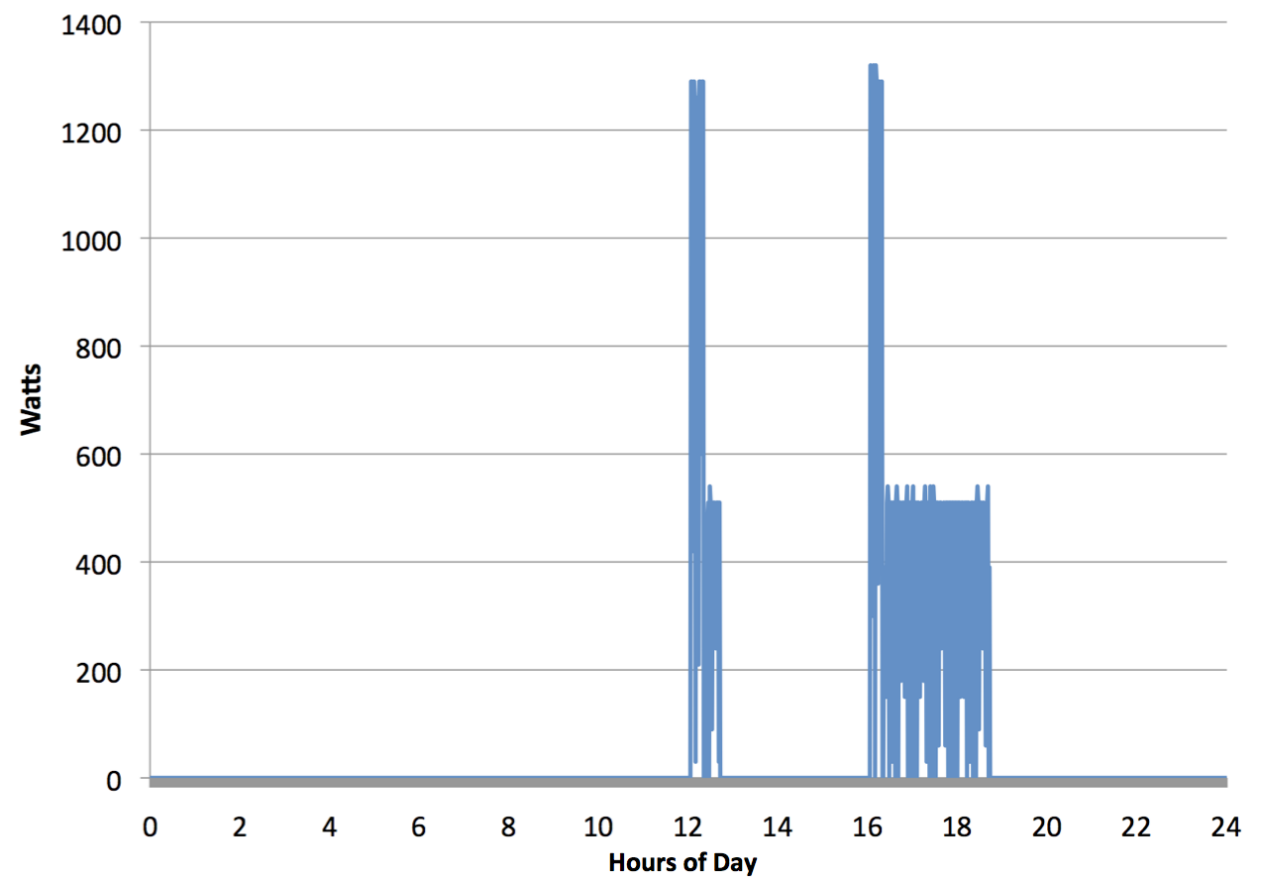

Figure 3.39 Oven characteristics

Typically the heat preference of the user is controlled by applying certain number of AC line cycles out of a fixed number of AC line cycles. This is achieved by turning a switch on and off to apply the line voltage or zero voltage across the heating element, and the number of applied AC line cycles in a certain period of time is controlled with an on/off switch. For example, for a low heating set point, the switch is turned on for a shorter period of time over the entire period of use. Similarly, for a higher heating set point, the 
switch stays in on mode for a longer period of time over the entire period. This can be considered as a duty cycle control.

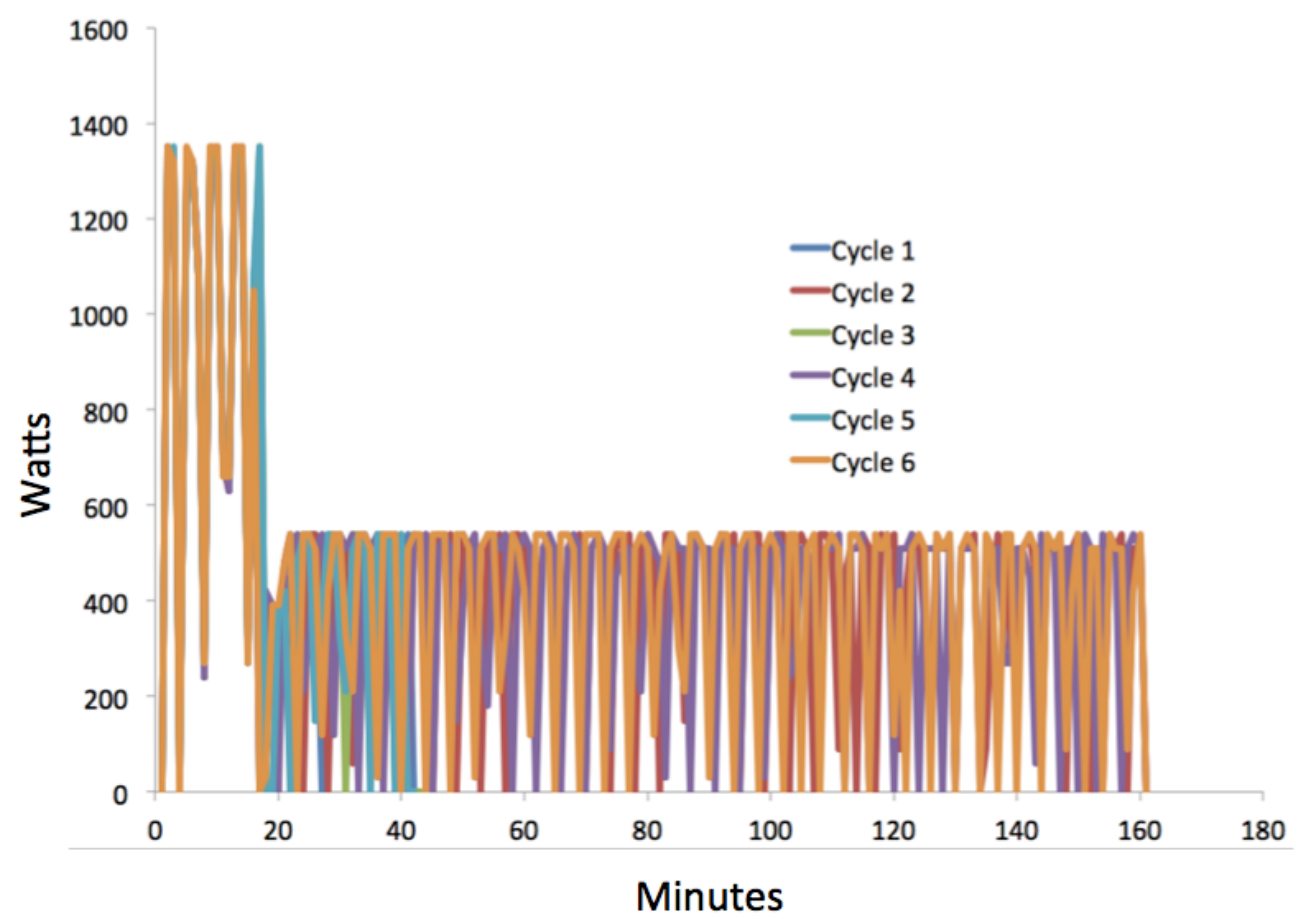

Figure 3.40 Oven load behavior.

The on/off states of the heater switch depending on the user setting are illustrated in Figure 3.41 and Figure 3.42. Alternatively, thyristor controlled AC chopper circuits can be employed for the control of heating coils. However, in this case, a portion of the each sinusoidal AC line cycle is applied to the heating element and this causes current and voltage harmonics. 


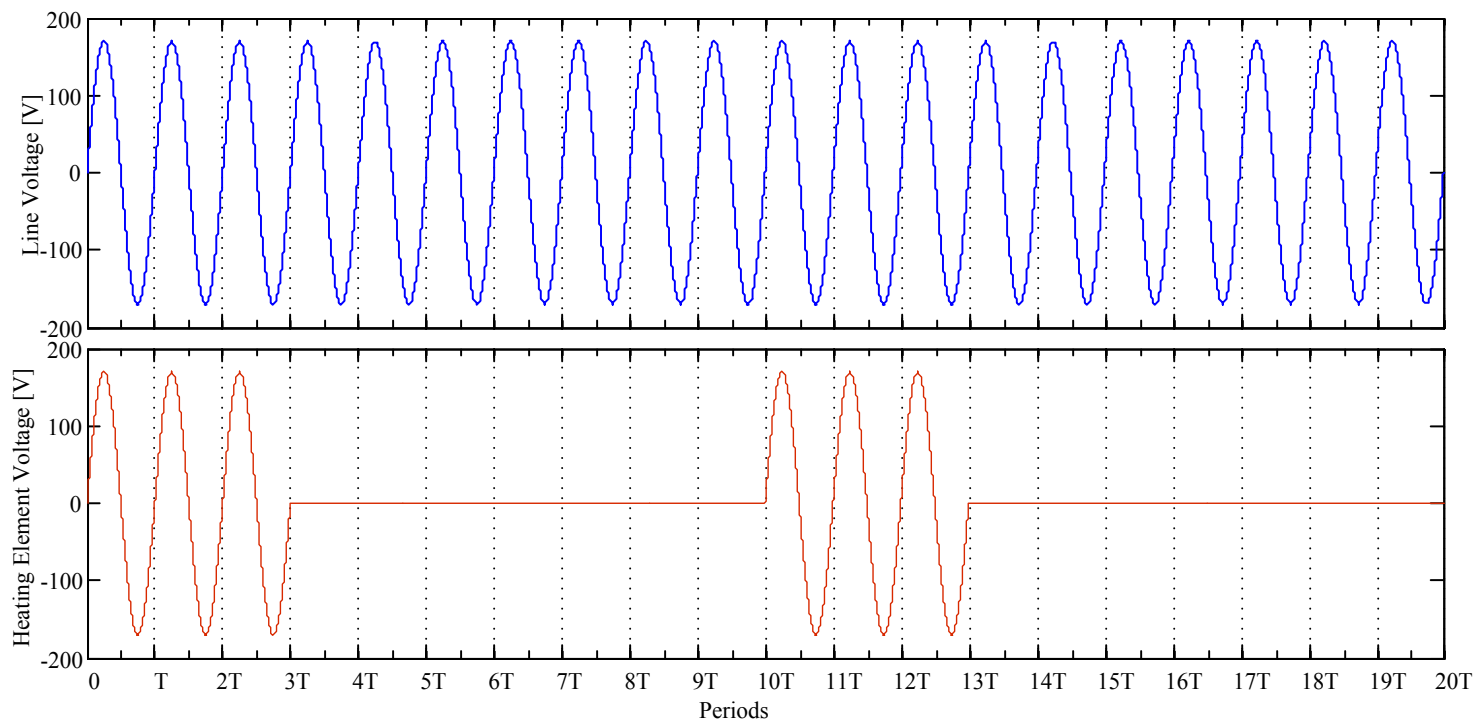

Figure 3.41 Cooktop heating element set to lower heating.

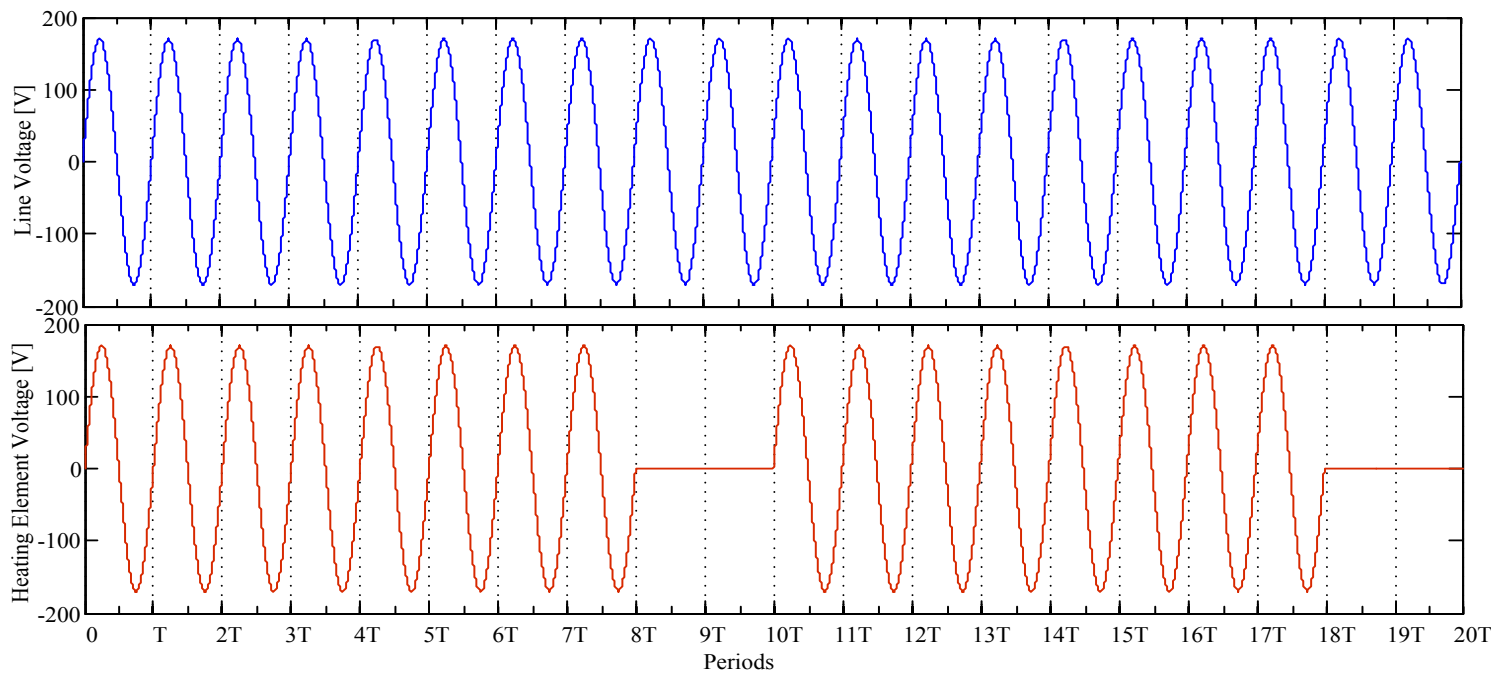

Figure 3.42 Cooktop heating element set to higher heating.

\subsection{Lighting}

The Energy Independence and Security Act of 2007 (the "Energy Bill"), signed by President Bush on December 18, 2007 requires all light bulbs use 30\% less energy than today's incandescent bulbs by 2012 to 2014 . The phase-out will start with 100 -watt bulbs sold starting in January 2012 and end with 40-watt bulbs sold starting in January 2014. By 2020, a Tier 2 would become effective which requires all bulbs to be at least $70 \%$ more efficient (effectively equal to today's CFLs)[22].

Lighting is approximately $12 \%$ of the average household's energy bill. DOE estimates this law could cut our nation's electric bill by nearly $\$ 6$ billion in 2015 alone. 
Available residential lighting technologies can be broken down into many categories but this report focuses on three: (1) incandescent, (2) compact fluorescent lighting (CFL), and (3) light emitting diode (LED).

The basic incandescent light built bulb technology is essentially a resistive element. The actual resistive element is known as a filament and is fixed with stiff wires surrounded inert gas. Application of electrical current causes atoms within the high resistance filament to excite, jumping to a higher state, and returning to the normal state while emitting light.

CFL technologies employ either magnetic or electronic ballasts. The electronic ballast technology is the most common and is composed of multiple electronic conversion stages and a fluorescent tube. A schematic of a CFL electronic ballast is shown in Figure 3.43 Stage 1 operation represents inductive and capacitive elements being used for filtering the harmonics from the load and peak limiting. Stage 2 is a full-wave rectifier bridge that converts the available AC input voltage to DC. A DC filter represents stage 3 and is utilized to separate the converter and tube. Stage 4 is composed of a filter and the tube itself. The filter is utilized to reduce the DC ripple created in stage 2 . The converter in stage 4 generates a high frequency $\mathrm{AC}$ voltage that is filtered and delivered to the fluorescent tube [45], [46]. These devices produce light on application of $120 \mathrm{~V} \mathrm{AC}$ and are not deactivated until disconnected or when the device fails. Lowering the delivered power or reducing the voltage lowers the amount of produced light.

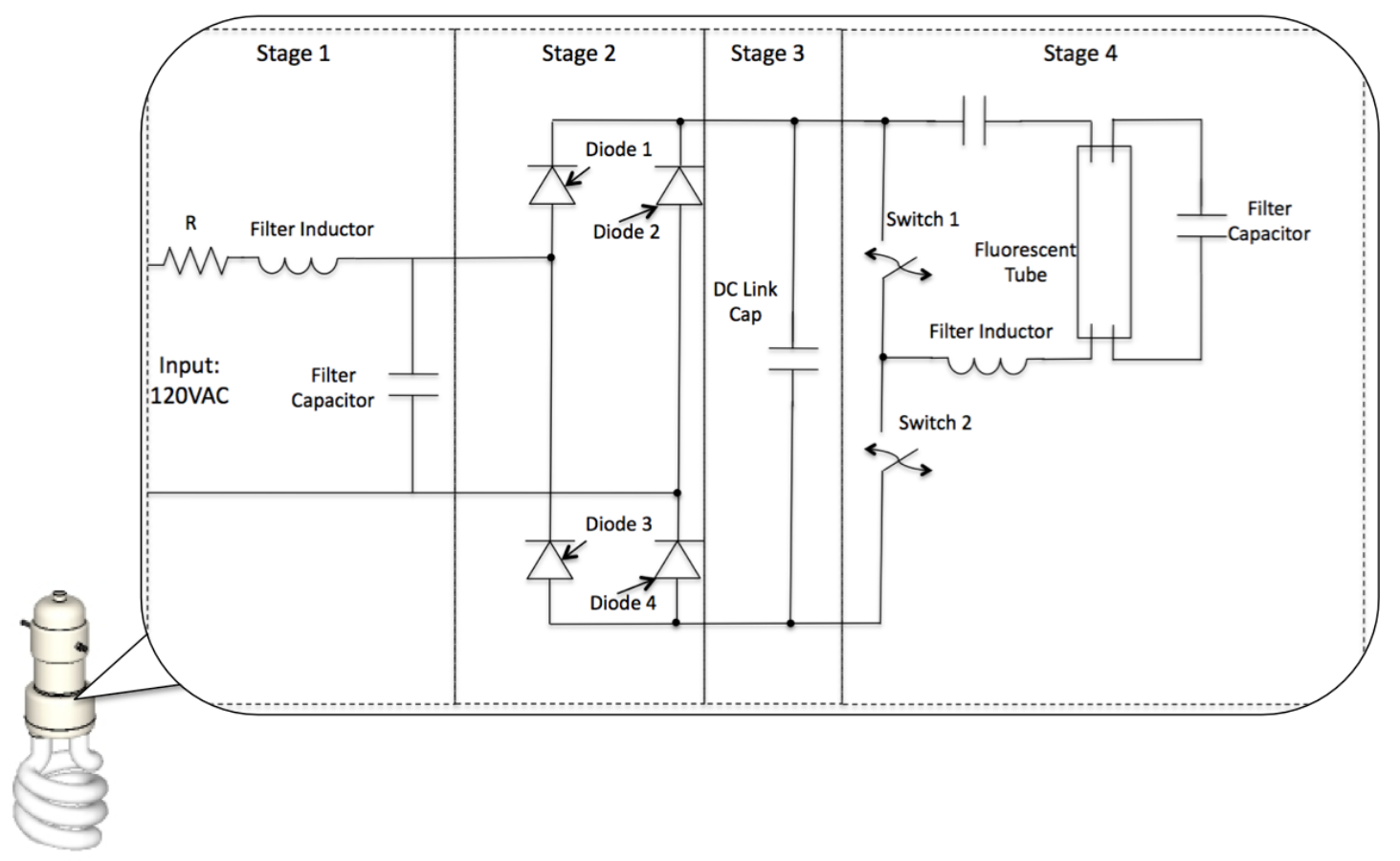

Figure 3.43 CFL ballast technology. 
LEDs are solid-state devices that convert electric energy directly into light at high efficiency. A typical LED is essentially a diode with a chip that is mounted in a reflective cup. On the application of current, electrons travel across the junction of two different materials creating light. For creating a commercially usable device, LEDs are often implemented in series and parallel so that the available illumination is adequate for the application, as shown in Figure 3.44. A filter and rectifier bridge (as for CFL technology) is employed to convert the power from AC to DC. A power factor corrector (PFC) circuit is often used to boost voltage, correct for any power factor issues, and conduct necessary switching for the LEDs at the end of the circuit. These devices produce light as long as $120 \mathrm{~V} \mathrm{AC}$ is applied and will not deactivate until disconnected from the supply power [47].

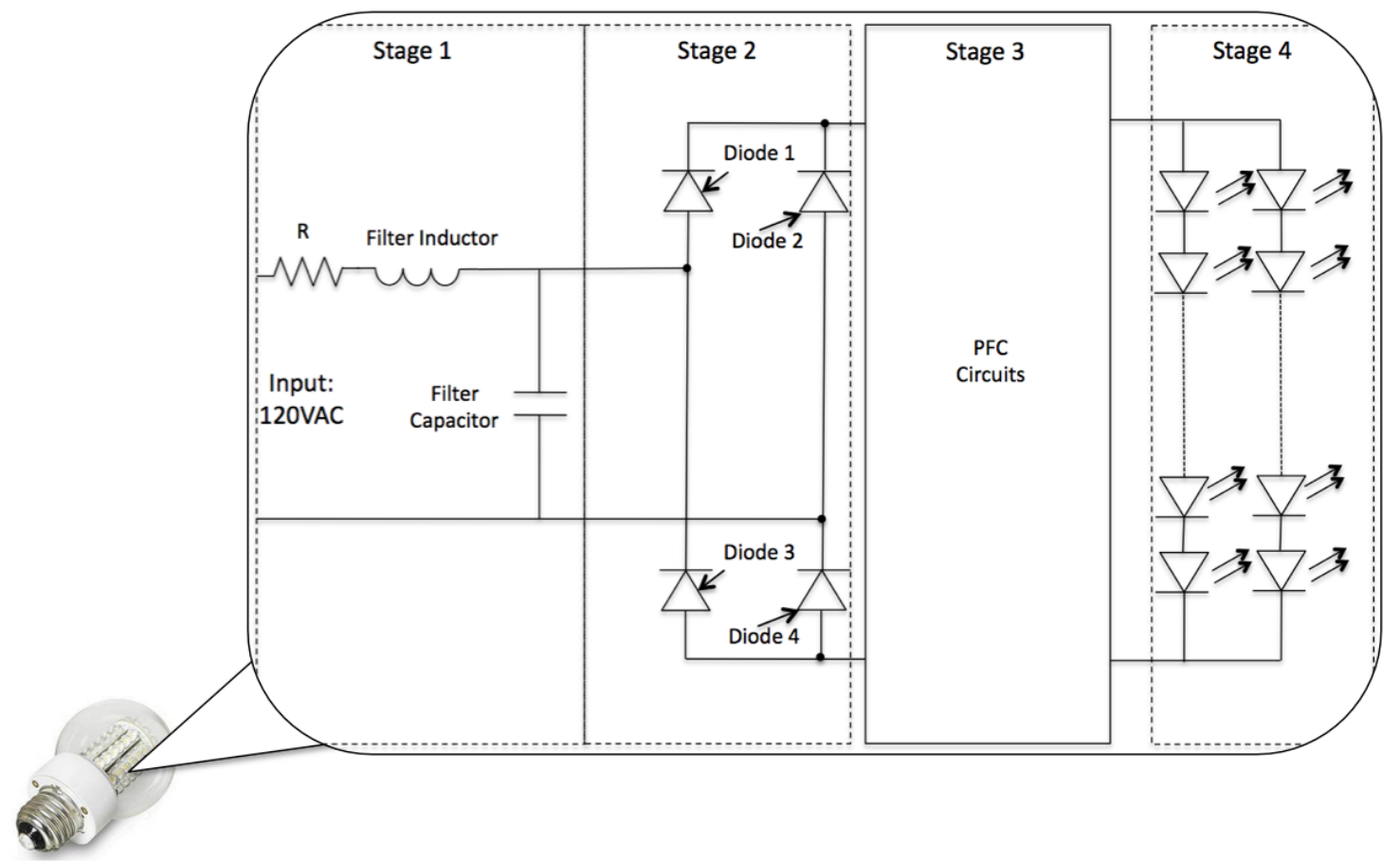

Figure 3.44 LED technology.

The lighting load at $\mathrm{CC} 1$ did not vary significantly from season to season, as shown in Figure 3.45. In $\mathrm{CC} 1$, the lighting is turned on during morning hours and evening hours when natural light is not available. Depending on the availability of natural light and residents' habits and preferences, this curve could shift in size and hour. Yearly statistics were not available for examination. The amount of lighting usage across the United States was statistically determined by EIA and is presented in Table 3.5. Most homes use 1 to 2 lights anywhere from 1 to 12 hours a day. 


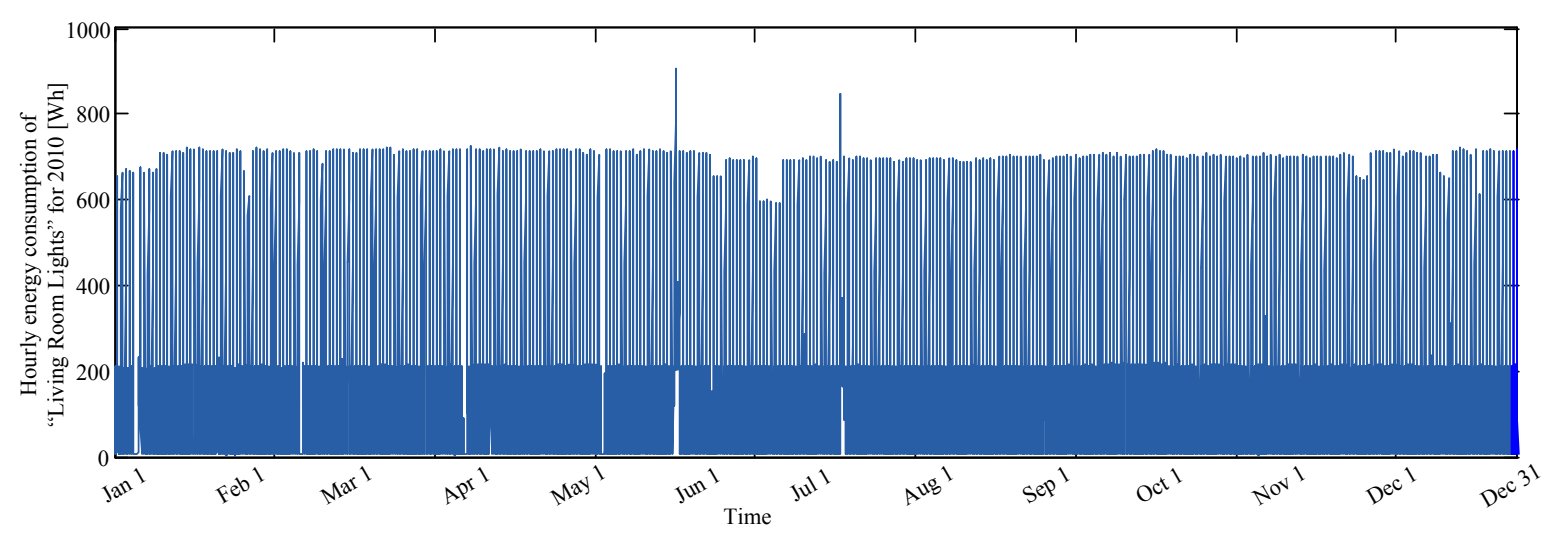

Figure 3.45. Lighting usage for CC1 type home for 2010.

Table 3.5 Millions of U.S. homes using lighting in summer; 2005 EIA data [65]

\begin{tabular}{|c|c|c|c|}
\hline & 1-4 Hours & 4-12 Hours & More than 12 Hours \\
\hline 1 light & 28.6 & 23.0 & 14.8 \\
\hline 2 lights & 29.5 & 24.9 & 7.8 \\
\hline 3 lights & 14.7 & 12.5 & 2 \\
\hline 4 lights & 9.3 & 6.4 & 1 \\
\hline 5 or more lights & 9.7 & 6.4 & 1.4 \\
\hline
\end{tabular}

Studies focused on demand response have largely focused on commercial application. A study by Lawrence Berkeley National Laboratory broke down lighting control for demand response into two categories: analog and digital [48]. With analog control, the ballasts are controlled individually. A router sends a separate signal to each ballast on the appropriate dimming level. The advantages noted include cost and the maturity of the technology.

Digital control approaches vary, but the dominant type is considered to be digital addressable lighting interface (DALI). This control approach sends a single signal to a number of ballasts for controlling light output. Consistency in communication methodologies between DALI manufacturers has prevented the incompatibility issues between manufactures.

Interestingly, the lighting output (illumination level) is directly related to input power, as shown in Figure 3.46. Hence, dimming technologies can in most cases be easily implemented for energy savings or demand response mechanisms. A signal provided by an ISO could be issued to an energy management system within a residential building and instruct the lighting to be temporarily reduced. This signal can be either sent directly to the controller of the switching devices (with the inverter feeding the fluorescent tube) and 
adjusting the switching duty cycle, or another device connected between the CFL and supply could adjust the voltage to a lower state.

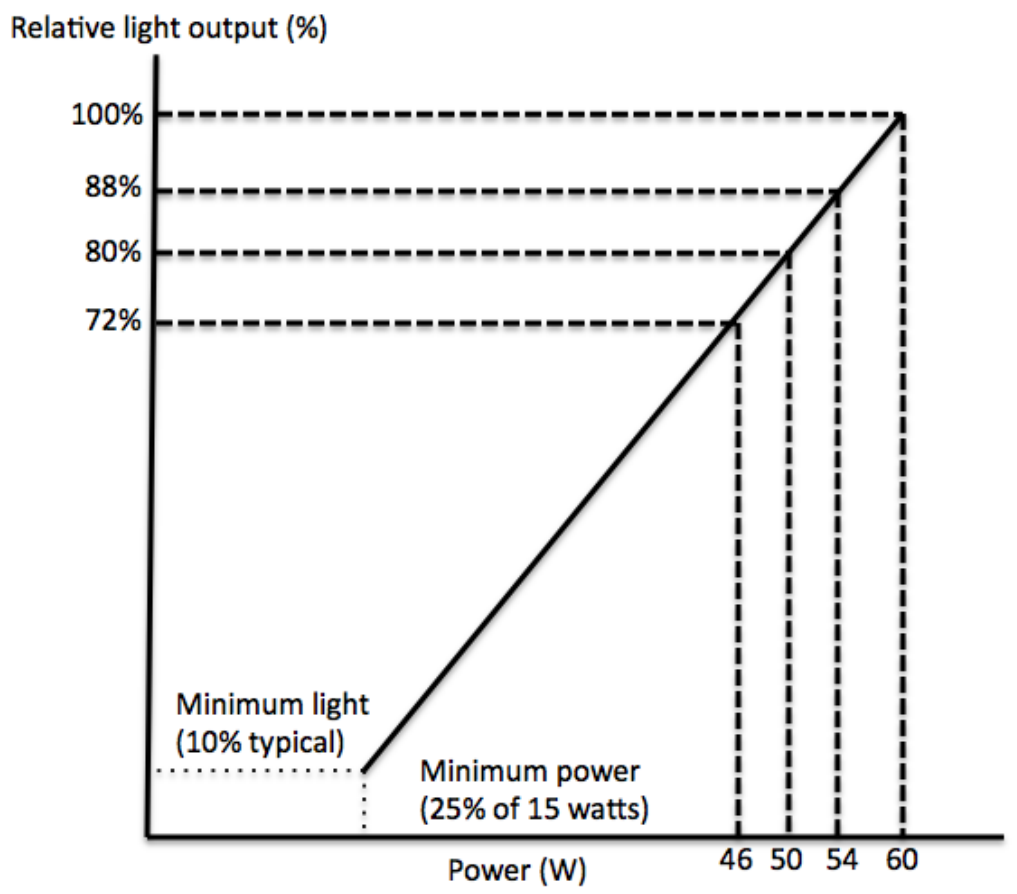

Figure 3.46 Power and Light Characteristics of Typical Dimming Ballast [48].

With LED lighting two approaches can be implemented for dimming the light produced: continuous current reduction and pulse width modulation (PWM). Reducing the continuous current has a simple, direct relationship to the light produced. Using this method provides a dimmable range of $100 \%$ to $10 \%$. The PWM method offers changes in switching duty cycle to change the light output by adjusting the average current provided to the LED. A high modulation frequency is often implemented to avoid a perceptible flicker [49].

A report by the National Research Council in Canada evaluated the perception and discomfort levels of adjustable lighting in both a building where available light from outside sources was present and with no available additional lighting. The findings are shown in Table 3.6. Under many conditions, customers are not significantly affected by a reduction in lighting and in some cases do not even notice. 
Table 3.6 Lighting impact on customers [50].

\begin{tabular}{|l|l|l|}
\hline Dimming Levels & Not Noticed by Customers & Noticed but Acceptable \\
\hline No Daylight & $20 \%$ change in light & $40 \%$ change in light \\
\hline Low Prevailing Light & $40 \%$ change in light & $40 \%$ change in light \\
\hline High Prevailing Light & $60 \%$ change in light & $80 \%$ change in light \\
\hline
\end{tabular}

\subsection{Computers/Electronics}

Household computers and most electronic appliances such as TV sets, alarm clocks, DVD/VCR players, and home theatre audio systems use DC voltage and thereby require an AC/DC converter. Most of these appliances use several DC voltage levels with different purposes. For example, in a computer power system, the processor (CPU) core voltage is $+3.3 \mathrm{~V} \mathrm{DC}$, controls and logic operations and hard disk need $\pm 5 \mathrm{~V}$ DC and $0 \mathrm{~V}$, and CD-ROM drives use $12 \mathrm{~V}$ DC supply voltage for their motors. Therefore, even after the rectification stage (AC/DC conversion), more $\mathrm{DC} / \mathrm{DC}$ conversion stages (sharing the same DC input but supplying different loads with different voltages) may be needed [51]. Typically, a fly-back type DC/DC converter is used for these DC/DC conversion stages, as this type of converter is highly efficient, provides isolation, and employs a high frequency transformer. A simplified diagram of a computer/electronics power supply is provided in Figure 3.47.

In laptop and cell phone chargers, only one level of voltage output is required. Further conversion stages (if any are required) are incorporated within the device. The DC voltage used in laptop computers is typically between 12 and $24 \mathrm{~V}$, whereas cell phone chargers convert the utility AC voltage to 3-7 V DC. In LCD TVs and other electronic devices, a rectification stage is used and is often followed by different DC/DC converters for appropriate DC voltage conversion.

Some electronic devices, such as laptops, have short-term back-up batteries. However, where batteries are not available, a disconnection of power requires internal clocks to be reset and an initial restart of software. This could be unacceptable to many consumers. 


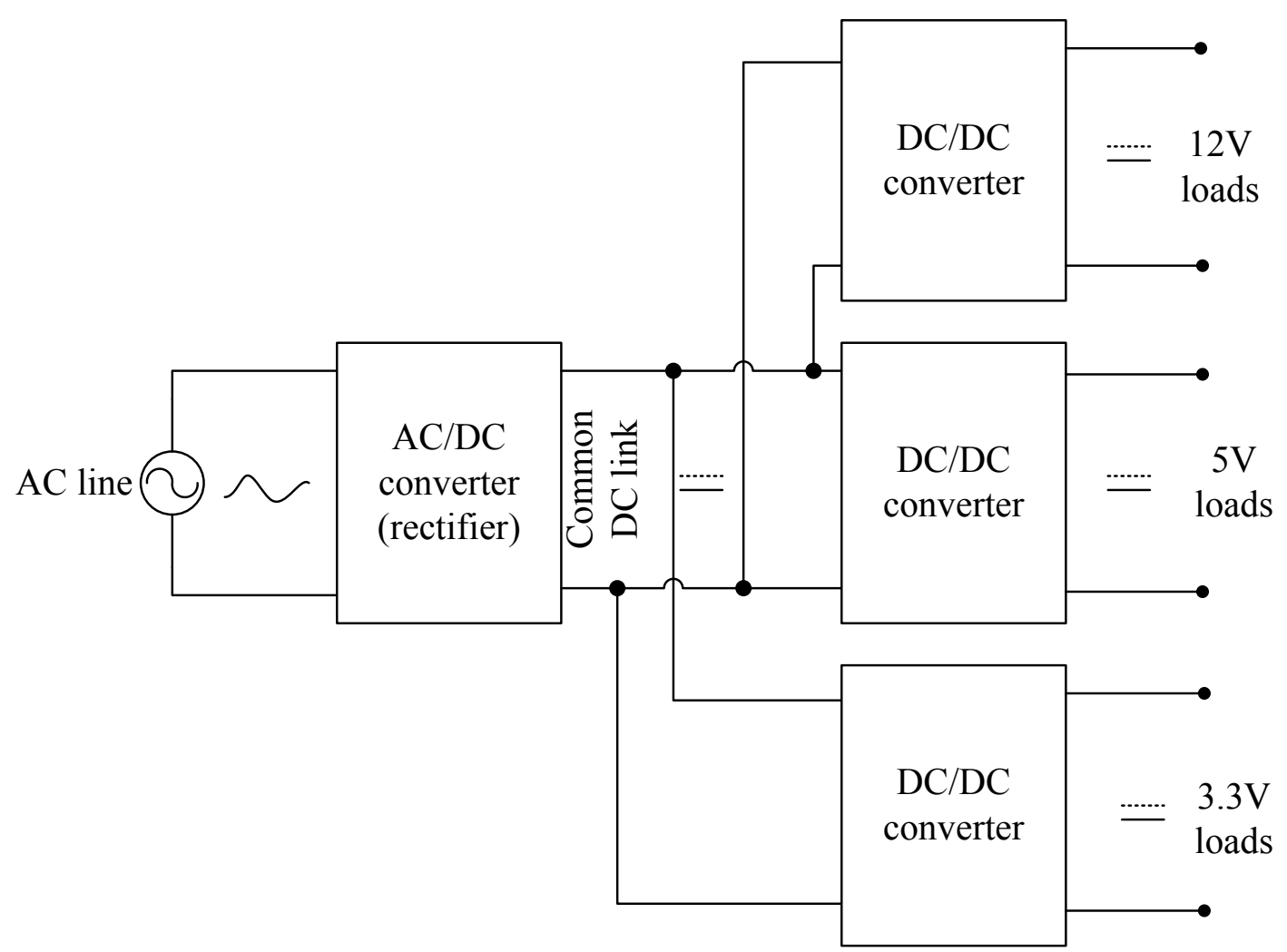

Figure 3.47 Simplified diagram of a computer power supply.

\subsection{PHEV Loads}

Currently vehicles are not considered to be a significant load in the residential sector. However, this is anticipated to change as President Obama announced in the State of the Union Address a goal to bring one million electric vehicles to U.S. roads by 2015 [52]. Fuel prices have also increased significantly in the last decade.

A number of plug-in hybrid electric vehicles (PHEVs) and electric vehicles (EVs) have reached the consumer market. As of January 2010, Tesla has sold 1,000 of its electric vehicle, the 2-seat Roadster sports car, with total sales of 2,500 planned.. The Model-S, a 4-door sedan electric vehicle developed by Tesla, has reached a reservation count exceeding 3000. An Extended Range Electric Vehicle (E-REV) by Fisker, the Karma, had received 3000 orders as of January 2011. Ford Motor Company also announced that an all-electric Ford Focus will reach the U.S. market in 2011. Nissan's EV Leaf and GM's PHEV, the Chevy Volt, started delivery to customers in December 2010. The first Nissan Leafs sold in the United States were produced in Japan, U.S. production is scheduled to begin in late 2012 at Nissan's manufacturing facility in Smyrna, Tennessee. The Smyrna plant is capable of producing up to 150,000 vehicles and 200,000 battery packs annually. GM increased production of the Volts with the number by the end of 2011 increasing from 10,000 to a range of "10,000 to 15,000", and for 2012, the company 
plans to build as many as 60,000 Volts. Toyota Prius, the top selling hybrid electric vehicle, is expected to have a plug-in vehicle available in the first half of 2012. Plug-in PHEV conversion kits for retrofit conversions of regular hybrid vehicles have also been available for several years.

From the electrical load perspective, PHEVs and EVs are a compromise of an AC/DC rectifier and a DC/DC converter in cascaded form, as shown in Figure 3.48. The AC from a wall outlet is converted to DC voltage through a rectifier. The DC/DC converts the rectified DC voltage to the appropriate DC voltage for charging. Typically these vehicles can plug into $120 \mathrm{~V} \mathrm{AC}$ and $240 \mathrm{~V}$ AC. However, the nominal battery voltage is much higher than the rectified DC voltage, requiring the DC/DC conversion stage. For example, nominal voltage of the battery pack of the Chevy Volt is $300 \mathrm{~V} \mathrm{DC}$, the Nissan Leaf's is $345 \mathrm{~V} \mathrm{DC}$, and the upcoming Toyota Prius's is $345.6 \mathrm{~V}$ DC. The compete specifications of these vehicle batteries are given in Table 3.7[53]-[58].

Although the maximum power ratings of the battery packs vary among models and manufacturers, the maximum charging power delivered to the battery may be limited by the circuit breaker and fuses in residential installations, or may be limited by the particular car manufacturers battery/on-vehicle charger design (Nissan Leaf is currently limited to maximum $3.3 \mathrm{~kW}$ for Level 2 charging $-6.6 \mathrm{~kW}$ planned for future development, much higher charging rate possible with Leaf's optional $440 \mathrm{~V}$ DC Level 3 charger - to be standard feature on 2012 Leaf). Typically, most $120 \mathrm{~V}$ outlets are rated to handle $15 \mathrm{Amps}$; however, 12A is the maximum continuous current rating. This is levelone charging for an EV/PHEV. Wall outlets used in delivering power to heavy-duty appliances such as an oven, dryer, water heater, or air conditioner are rated for $240 \mathrm{~V}$. For $240 \mathrm{~V}$ chargers, typical breaker size needs to be at least $40 \mathrm{~A}$ to ensure the continuous current rating of 30-32A (level-two charging) [59]. In, the specifications of Level-1 and Level-2 residential chargers are given [60].

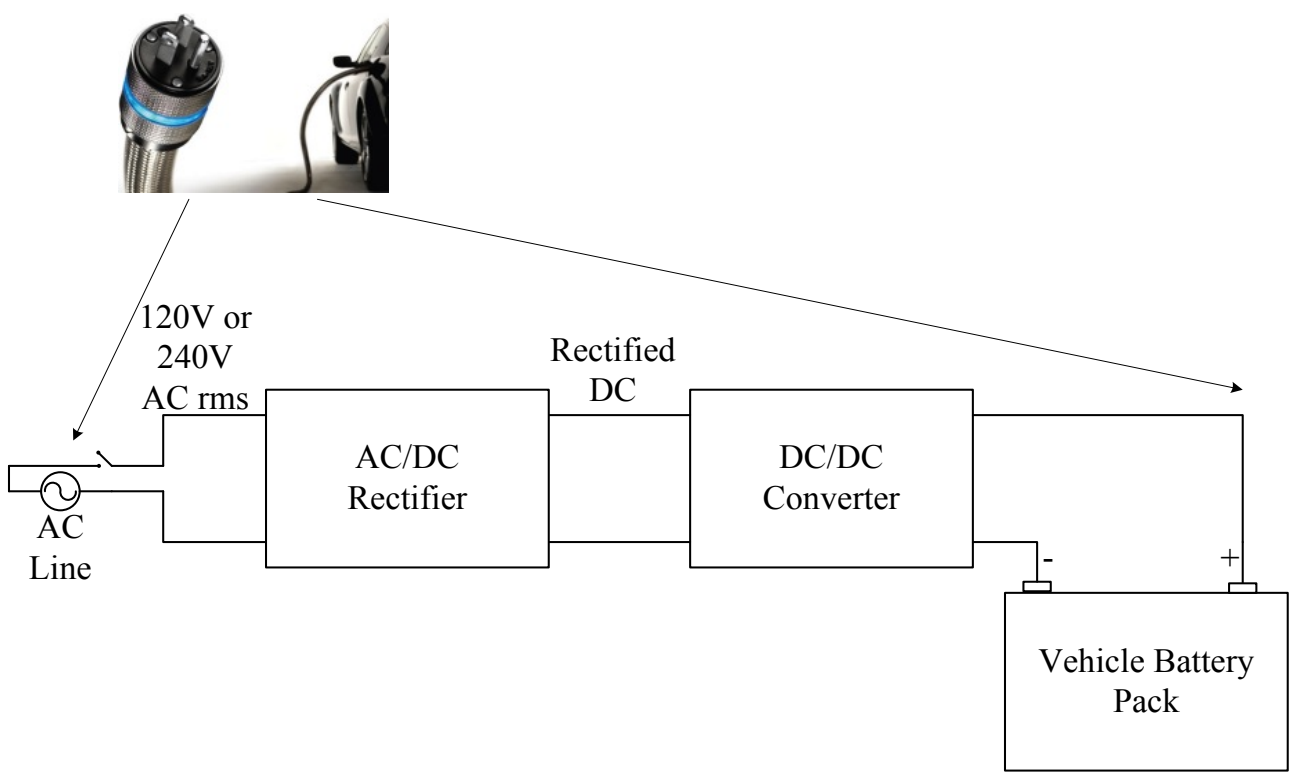

Figure 3.48 A PHEV or EV connected to the grid. 
Table 3.7 Battery specifications of Chevy Volt, Nissan Leaf, and Toyota Prius.

\begin{tabular}{|c|c|c|c|}
\hline Vehicle & Parameter & Value & Unit \\
\hline $\begin{array}{c}\text { Chevrolet Volt [53], } \\
\text { [54] }\end{array}$ & Nominal battery voltage & 300 & {$[\mathrm{~V}]$} \\
\cline { 2 - 4 } & Number of cells & 200 & {$[\mathrm{cnt}]$} \\
\cline { 2 - 4 } & Energy storage capacity & 16 & {$[\mathrm{kWh}]$} \\
\cline { 2 - 4 } & Nominal power (continuously) & 55 & {$[\mathrm{~kW}]$} \\
\cline { 2 - 4 } & Peak power & 111 & {$[\mathrm{~kW}]$} \\
\cline { 2 - 4 } Nissan Leaf [55], & (for a short period of time) & 370 & {$[\mathrm{~A}]$} \\
\cline { 2 - 4 } [56] & Maximum current & 345 & {$[\mathrm{~V}]$} \\
\cline { 2 - 4 } & Nominal battery voltage & 192 & {$[\mathrm{cnt}]$} \\
\cline { 2 - 4 } & Number of cells & 24 & {$[\mathrm{kWh}]$} \\
\cline { 2 - 4 } & Energy storage capacity & 62 & {$[\mathrm{~kW}]$} \\
\cline { 2 - 4 } & Nominal power (continuously) & 260.87 & {$[\mathrm{~kW}]$} \\
\hline Toyota Prius [57], & Peak power & 345.6 & {$[\mathrm{~A}]$} \\
\cline { 2 - 4 } & Maximum current & 288 & {$[\mathrm{cnt}]$} \\
\cline { 2 - 4 } & Nominal battery voltage & 5.2 & {$[\mathrm{kWh}]$} \\
\cline { 2 - 4 } & Number of cells & 60 & {$[\mathrm{~kW}]$} \\
\cline { 2 - 4 } & Energy storage capacity & {$[\mathrm{kW}]$} \\
\cline { 2 - 4 } & Nominal power (continuously) & 60 & {$[\mathrm{~A}]$} \\
\hline
\end{tabular}

Table 3.8 Specifications of the Coulomb Tech Vehicle Chargers [60]

\begin{tabular}{|c|c|c|c|}
\hline Model & Level & Power & Connector \\
\hline CT 500 & LEVEL II & 240 V-30A & SAE J1772 \\
\hline CT 1000 & LEVEL I & $120 \mathrm{~V}-16 \mathrm{~A}$ & Nema 5-20 \\
\hline CT 2000 & LEVEL II & $240 \mathrm{~V}-30 \mathrm{~A}$ & SAE J1772 \\
\hline \multirow{2}{*}{ CT 2100 } & LEVEL I & $120 \mathrm{~V}-30 \mathrm{~A}$ & Nema 5-20 \\
& LEVEL II & $240 \mathrm{~V}-30 \mathrm{~A}$ & SAE J1772 \\
\hline
\end{tabular}

\subsection{Other Large Loads}

Although only the primary loads identified by EIA are discussed in this report, other loads exist that can consume significant amounts of power and energy. Loads such as coffee machines, microwaves, dehumidifiers, spas, and pool pumps can play a large role 
in the overall consumption in a residence, as shown in Table 3.9. Many of these loads are fully capable of participating in demand response programs through load reduction.

\subsection{Summary of Loads}

The loads discussed in the preceding section can generally be characterized by four distinct characteristics, as shown in Table 3.10: loads use power electronics for conversion, loads employ motors to mechanically perform a function, loads use resistive elements for heating, and loads have thermal storage. Power electronic components in the loads are often utilized to convert the $60 \mathrm{~Hz}$ AC voltage in residential settings to DC for DC loads. Depending on the nature of the existing power electronics, control signals could be sent directly to the devices, as in the case of a controlled rectifier bridge, to reduce consumption. In most cases a simple non-controllable rectifier bridge is used (to keep costs low), and control cannot be conducted this way. Another approach is to insert an add-on system that is capable of adjusting the input voltage to the device. However, this approach may only be suitable for some DC loads.

Table 3.9 Operating consumption of home appliances [18].

\begin{tabular}{|c|c|c|c|}
\hline Appliances & $\begin{array}{c}\text { Power draw } \\
{[\mathrm{W}]}\end{array}$ & $\begin{array}{c}\text { Annual consumption } \\
{[\mathrm{kWh} / \text { year] }}\end{array}$ & $\begin{array}{c}\text { Annual cost } \\
{[\$]}\end{array}$ \\
\hline Coffee maker & 1000 & 58 & 5 \\
\hline Dishwasher & 1200 & 120 & 11 \\
\hline Microwave oven & 1500 & 131 & 12 \\
\hline Refrigerator & 380 & 660 & 62 \\
\hline Freezer & 350 & 470 & 44 \\
\hline 18-W Compact fluorescent & 18 & 20 & 2 \\
\hline 60-W Incandescent lamp & 60 & 40 & 4 \\
\hline 100-W Incandescent lamp & 100 & 70 & 7 \\
\hline Torchiere lamp-halogen & 300 & 440 & 41 \\
\hline Hair dryer & 710 & 40 & 4 \\
\hline Waterbed heater & 350 & 1070 & 101 \\
\hline Clothes dryer & 2790 & 1000 & 94 \\
\hline Clothes washer & 512 & 110 & 10 \\
\hline CPU / monitor & $182 / 30$ & 260 & 24 \\
\hline Stereo systems & 33 & 119 & 11 \\
\hline $\mathrm{TV}$ & 113 & 193 & 18 \\
\hline Analog, <40" & 86 & 184 & 17 \\
\hline Analog, $>40 "$ & 156 & 312 & 29 \\
\hline Digital, ED/HD TV,$<40 "$ & 150 & 301 & 28 \\
\hline Digital, ED/HD TV, $>40 "$ & 234 & 455 & 43 \\
\hline Set-top box & 20 & 178 & 17 \\
\hline DVD/VCR & 17 & 78 & 7 \\
\hline Dehumidifier & 600 & 970 & 91 \\
\hline Furnace fan & 295 & 400 & 38 \\
\hline Ceiling fan (only fan motor) & 35 & 81 & 8 \\
\hline Water heater (family of 4) & 4500 & 4770 & 448 \\
\hline Water heater (family of 2) & 4500 & 2340 & 220 \\
\hline Portable Spa & 4350 & 2525 & 237 \\
\hline Pool pump & 1000 & 790 & 74 \\
\hline Well pump & 725 & 80 & 8 \\
\hline
\end{tabular}


Motor loads with no power electronics interface often do not have significant controllability. In some cases, multiple winding sets are used and controlled through a switch to adjust speeds from one setting to another. Yet motors have the potential to be more actively controlled through the application of power electronics as drivers. Rectifying the conventionally supplied AC voltage to DC and using an inverter to control the power delivered to the motor can increase operational efficiency of the motor and provide accurate control of motor loads. Still, the additional cost for the driver may not be an acceptable tradeoff for the gains.

Many of the loads having resistive elements use two or more parallel and series configurations for adjusting heat. In other cases, switches adjust the amount of power delivered to the load based on a number of cycles. These control approaches provide varying degrees of flexibility.

Table 3.10 Load characteristic components

\begin{tabular}{|l|l|l|l|l|}
\hline & $\begin{array}{l}\text { Does the load } \\
\text { utilize power } \\
\text { electronic } \\
\text { stages? }\end{array}$ & $\begin{array}{l}\text { Does the } \\
\text { load utilize } \\
\text { motors? }\end{array}$ & $\begin{array}{l}\text { Does the } \\
\text { load utilize } \\
\text { purely } \\
\text { resistive } \\
\text { elements? }\end{array}$ & $\begin{array}{l}\text { Does the } \\
\text { load utilize } \\
\text { thermal } \\
\text { storage? }\end{array}$ \\
\hline Incandescent & No & No & Yes & No \\
\hline CFL & Yes & No & No & No \\
\hline LED & Yes & No & No & No \\
\hline HVAC & No & Yes & Yes* & Yes \\
\hline Water Heater & No & No & Yes & Yes \\
\hline Refrigerator & No & Yes & Yes** & Yes \\
\hline Washer & No & Yes & No & No \\
\hline Dryer & No & Yes & Yes & No \\
\hline Range & No & No & Yes & No \\
\hline Computers/Electronics & Yes & Yes & No & No \\
\hline PHEV & Yes & Yes & No & No \\
\hline * Strip heater \\
** Defrost & & & \\
\hline
\end{tabular}

\subsection{On-Site Solar}

Photovoltaic (PV) output power is dependent on solar radiation, temperature, and DC operating voltage. Solar radiation is often affected by cloud cover, which can result in significant variability, as shown in Figure 3.49 and Figure 3.50. Figure 3.49 represents data collected on February 5, 2010, showing significant variation from optimum in the available solar radiance. Figure 3.50 shows the data collected on a sunny day with optimum solar irradiance. 


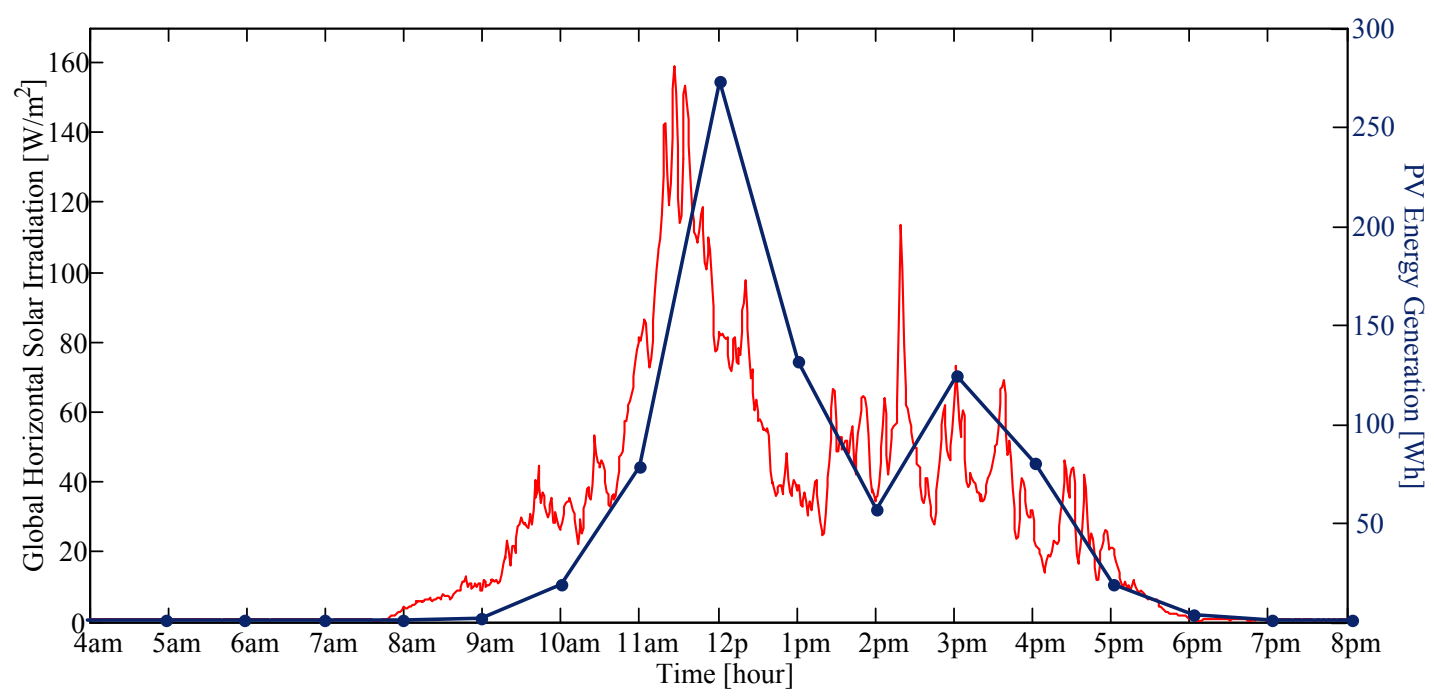

Figure 3.49 Hourly energy generation of PV panels at CC3 home and global solar irradiation profile on February 5, 2010.

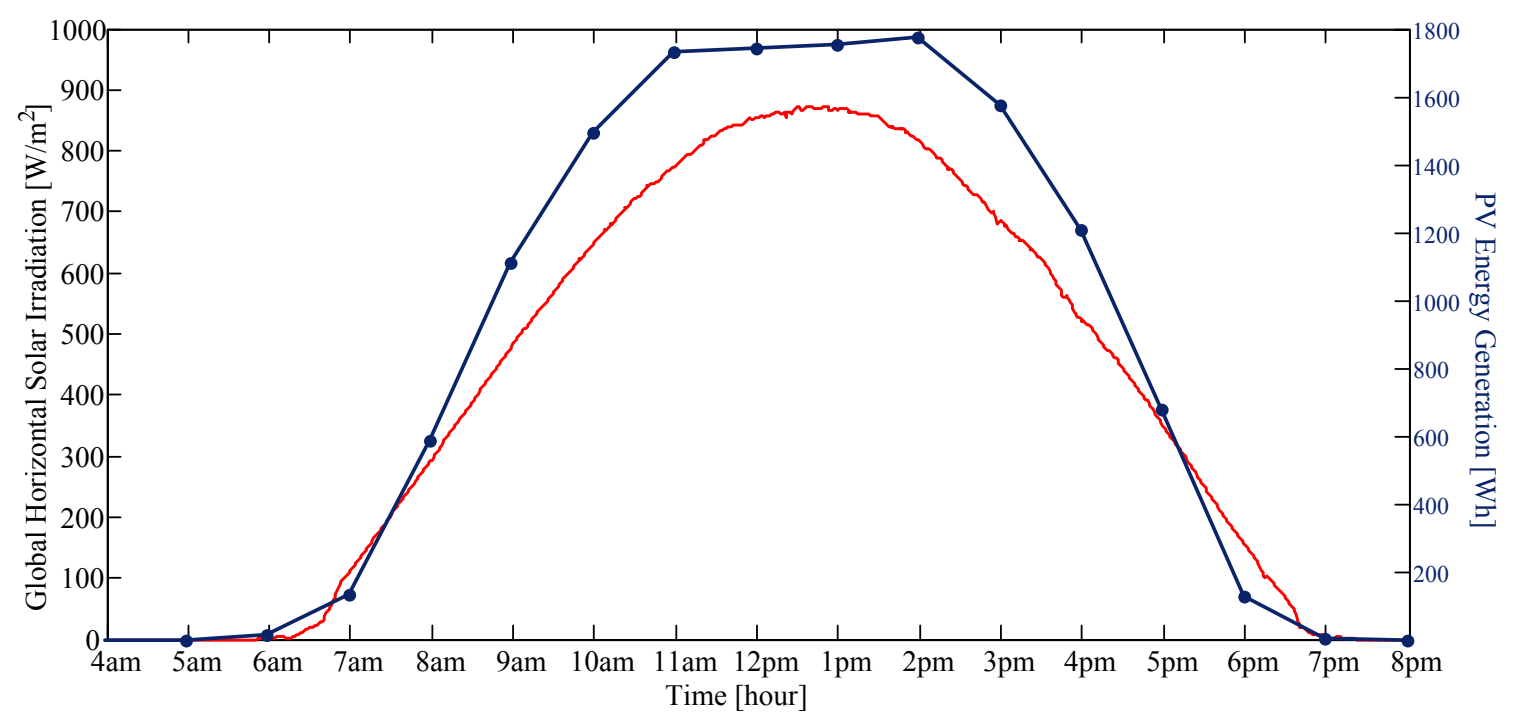

Figure 3.50 Hourly energy generation of PV panels at CC3 home and global solar irradiation on August 31, 2010.

The characteristic voltage, current, and power profiles for a specific PV panel are given in Figure 3.51. The curves represent characteristic behavior of PV panels. The output current is typically flat for much of the DC operating voltage range and only begins to fall when approaching the open circuit voltage rating of the PV panel. Since solar panels output DC, many homes use an inverter to create $60 \mathrm{~Hz}, 120 \mathrm{~V} \mathrm{AC}$, as shown in Figure 3.52. The inverter can be controlled by maximum power point tracking (MPPT), where the power delivered from the PV is maximum at a particular solar radiance level. This requires maintaining the $\mathrm{DC}$ voltage at the location where maximum power is delivered. 
A DC/DC converter can be employed at the PV panels' output in order to operate at the maximum power point based on the current-voltage (I-V) characteristics of the PV array [61], [62]. This DC/DC converter is controlled to operate at the desired current and voltage output of the PV array. However, in most residential applications, this DC/DC converter is not used to keep the initial system cost down.

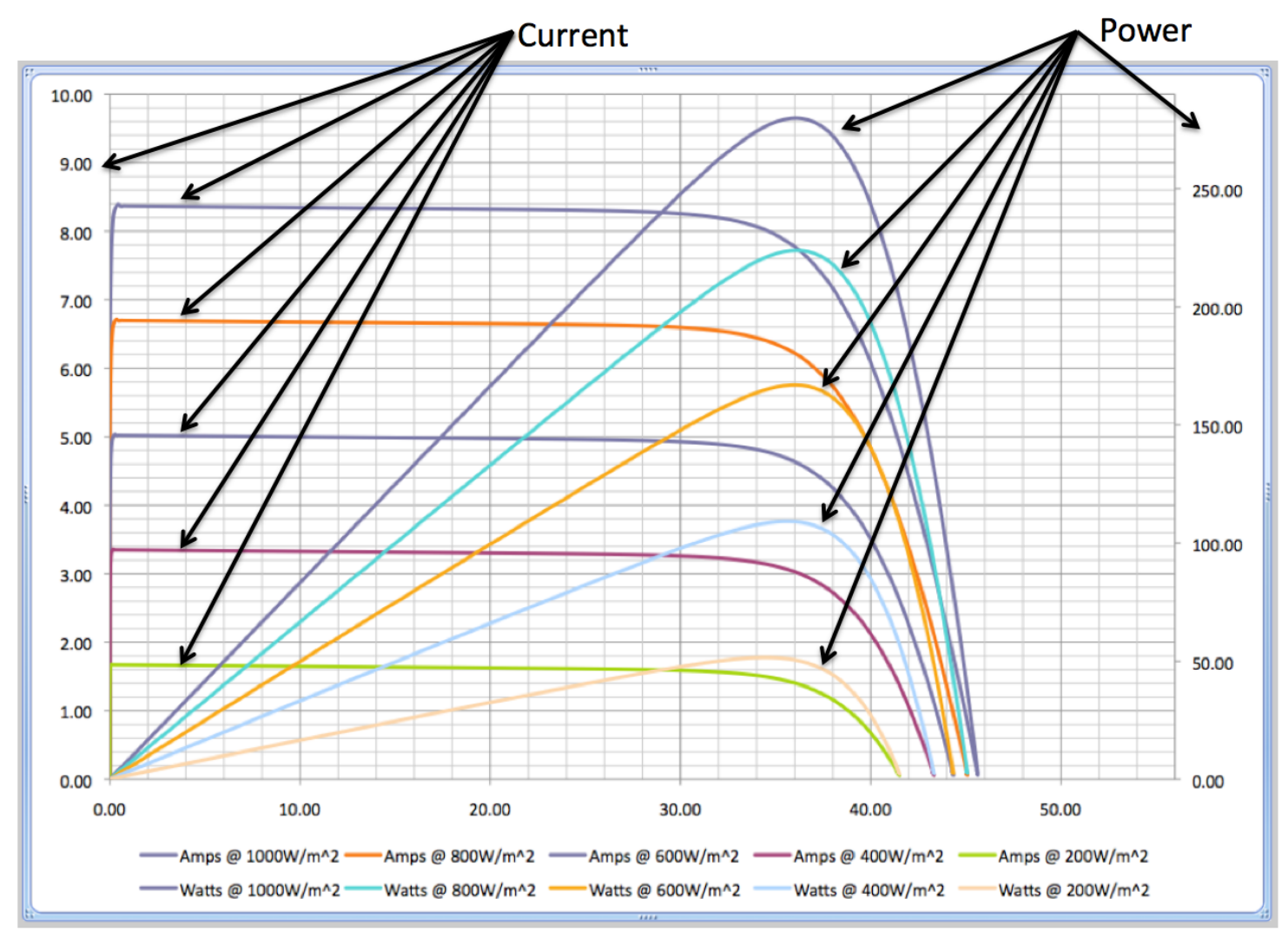

Figure 3.51 PV Characteristic curves. 


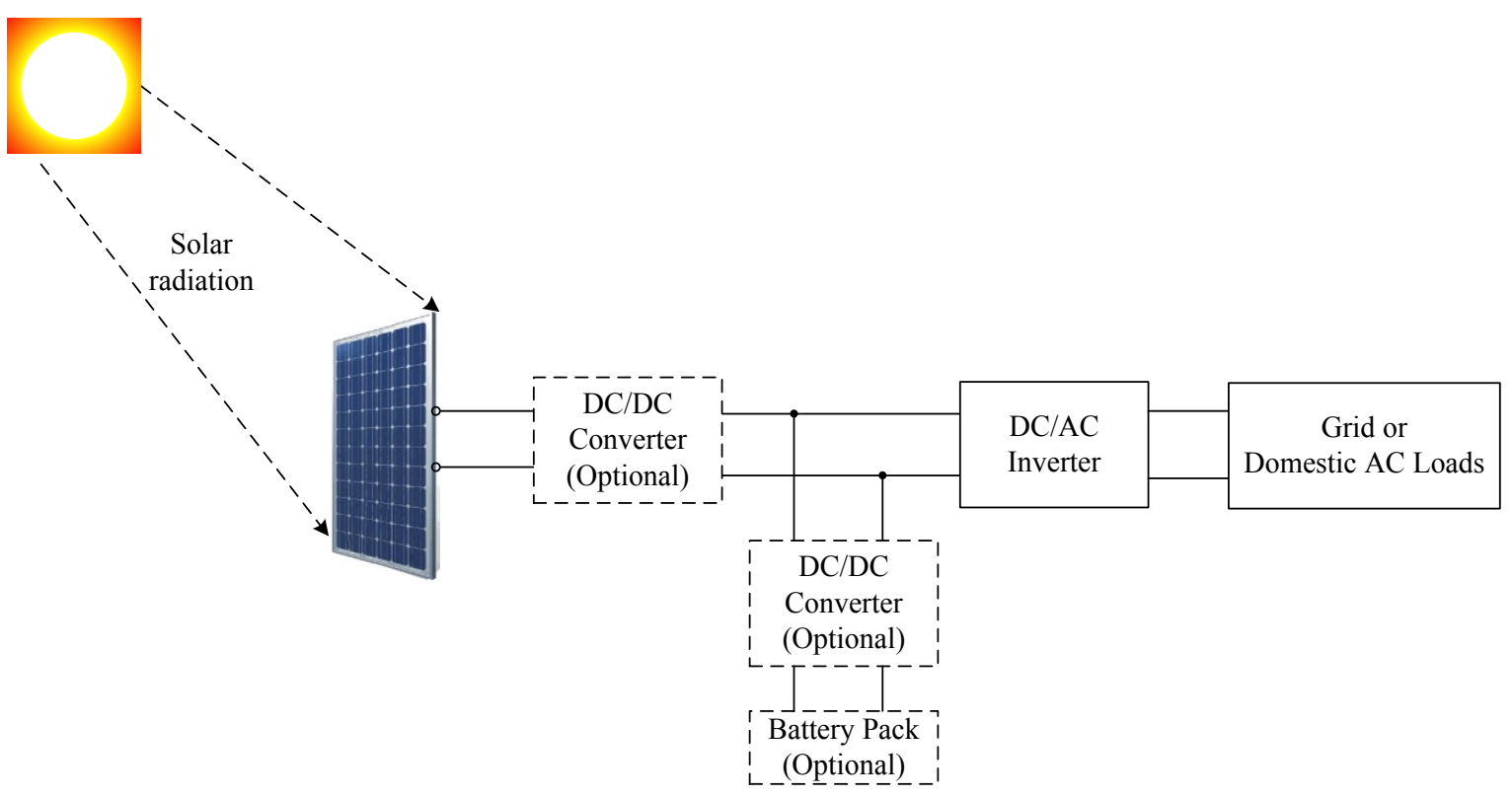

Figure 3.52 A solar energy system with maximum power point tracking.

A battery pack can be connected to the DC bus of the system to provide extra power that might not be available from the PV module during night and cloudy periods. The battery pack can also store energy when the PV module generates more power than demanded. A grid connection is also useful to draw or inject power from or to the utility network to take the advantage of excess power or to recharge the batteries using grid power during off-peak periods of the utility network.

\subsection{Demand Response Expectation}

The demand reduction potential is dependent on the loads currently active and the current state of operation of the load. Providing exact values of power that can be expected is difficult due to the varying designs and phases of operation.

The washer, dishwasher, dryer, and range are loads that are not significantly utilized over a 24 hour period or on a day-to-day basis. These loads, however, can provide demand response through delay of activation and/or reduction of consumption when using resistive heating elements. Still, demand response benefits from these loads will likely not be significant compared to the potential of water heaters, refrigerators, and HVAC units.

The water heater, refrigerator, and HVAC have the potential to provide the most demand reduction and even possibly regulation with control and implementation strategies in place. As a result of the cycling behavior of these loads due to temperature control and thermal storage, these loads could be switched on and off periodically. In an aggregated scale across a number of homes, this could represent a small step or almost linear ramp. 
A report written by the Brattle Group attempted to predict the amount of available demand response from various load types for 2019 through the analysis of four case scenarios: business as usual, expanded business as usual, achievable participation, and full participation [63]. Assumptions made in each case scenario are presented in Table 3.11 .

Table 3.11 Assumptions on demand response study by Brattle [63].

\begin{tabular}{|c|c|c|c|c|}
\hline Assumption & $\begin{array}{c}\text { Business as } \\
\text { usual }\end{array}$ & $\begin{array}{c}\text { Expanded } \\
\text { business as } \\
\text { usual }\end{array}$ & $\begin{array}{c}\text { Achievable } \\
\text { participation }\end{array}$ & Full participation \\
\hline $\begin{array}{c}\text { Dynamic pricing } \\
\text { participation }\end{array}$ & $\begin{array}{c}\text { Today's } \\
\text { level }\end{array}$ & Voluntary (5\%) & $\begin{array}{c}\text { Default (60 to } \\
75 \%)\end{array}$ & $\begin{array}{c}\text { Universal } \\
(100 \%)\end{array}$ \\
\hline $\begin{array}{c}\text { Eligible } \\
\text { customers } \\
\text { offered enabling } \\
\text { technology }\end{array}$ & None & None & $95 \%$ & $100 \%$ \\
\hline $\begin{array}{c}\text { Eligible } \\
\text { customers } \\
\text { accepting } \\
\text { enabling } \\
\text { technology }\end{array}$ & None & None & $60 \%$ & $100 \%$ \\
\hline $\begin{array}{c}\text { Basis for non- } \\
\text { pricing } \\
\text { participation rate }\end{array}$ & Today's & "Best practices" & "Best practices" & "Best practices" \\
\hline $\begin{array}{c}\text { Residential Peak } \\
\text { Reduction by } \\
2019\end{array}$ & $\sim 5 \mathrm{GW}$ & $\sim 20 \mathrm{GW}$ & $\sim 65 \mathrm{GW}$ & $\sim 100 \mathrm{GW}$ \\
\hline
\end{tabular}

In the analysis, residential, industrial, and commercial peak profiles for each state were examined and predicted for the next 10 years. Differing levels of metering technologies and other assumptions led to the results presented in Figure 3.53. Brattle noted that the residential sector had the most significant potential for demand response but also listed a number of barriers that had to be overcome. 


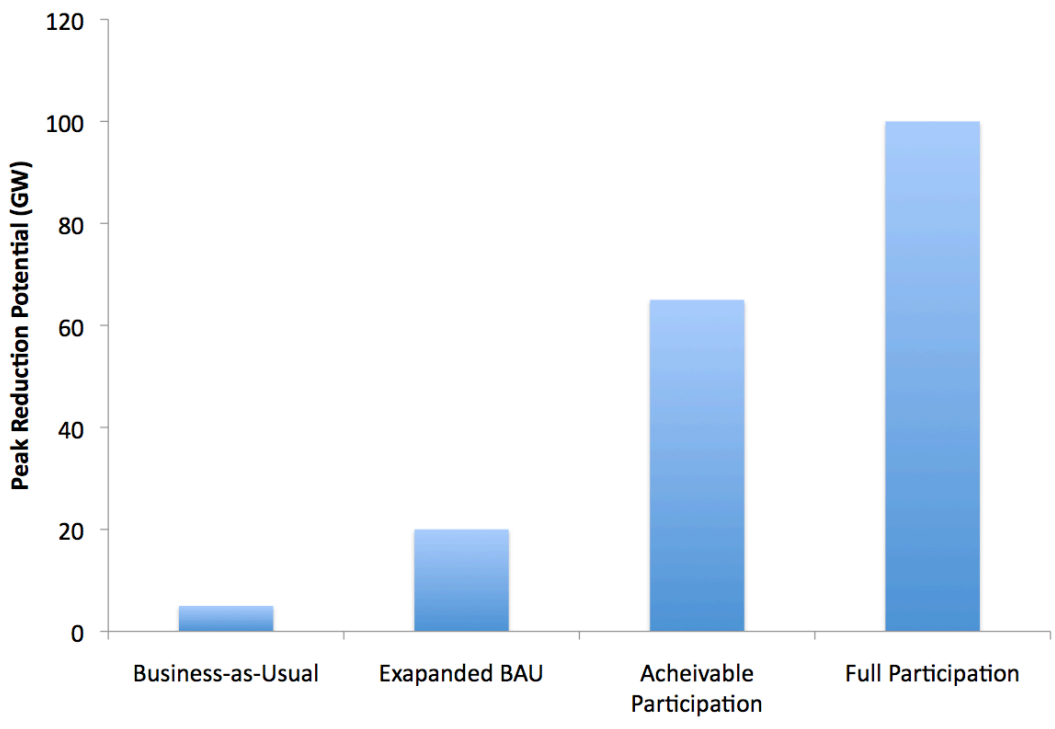

Figure 3.53 Peak demand reduction potential estimated by Brattle [63] 


\section{CONCLUSION}

The residential sector has significant resources for demand response. Brattle's exploratory study on predicting the future potential of demand reduction suggested that the residential sector would have the most potential demand reduction. Full participation could lead to a potential demand reduction as high as $100 \mathrm{GW}$ by 2019 . However, the study also noted that regulatory, economical, and technological barriers must be overcome.

A number of demand programs currently do exist and can be classified as either economic or emergency. Each ISO has distinct rules and regulations that must be met to participate in either. In terms of the grid service of regulation, residential loads currently do not participate. This is largely due to the complexity of the communication requirements and controls. However, future advancements in energy management systems, load control, and communications may alter the participation of residential loads.

Loads such as HVAC, refrigerators, water heaters, washers and dryers, dishwashers, ranges, and lighting provide the most opportunity for demand response participation, as these are the largest loads in the residential sector. These loads are primarily composed of power electronics, motors, and resistive elements. As a result, different control approaches and varying operational patterns of consumption exist for each load. Complexity is further increased with residential loads, as these loads may or may not be available for demand reduction at any given point. Load utilization for many loads is based on the occupant.

The most flexible loads are those that have inherent energy storage (thermal storage) as the actual cycling could be controlled to meet power system needs. These loads include water heaters, refrigerators, and HVAC units. In all cases, control of the loads is subject to the constraints of consumer health and comfort. Consumers that are severely impacted will likely discontinue participation in any demand response programs.

Further research is needed to investigate and demonstrate the needed control (communication) and sensor technologies that are available for control of residential loads. Sensor technologies need to identify the range of control of the various loads though information related to occupancy, temperature, moisture, lighting, and power consumption. Gaps that exist in sensor and control technology and rules and strict requirements on loads for participation are a few of the barriers in further participation of loads in demand response programs. These will be developed further in a roadmap. 


\section{ACKNOWLEDGEMENTS}

The authors of this report would like to thank Jeff Christian and Anthony Gehl for providing data on the Campbell Creek homes in support of this report. The authors would also like to thank Roderick Jackson for supplying additional information. 


\section{REFERENCES}

[1] D. Todd, M. Caufield, B. Helms, M. Starke, B. Kirby, J. Kueck, Providing Reliability Services through Demand Response: A Preliminary Evaluation of the Demand Response Capabilities of Alcoa Inc,” ORNL/TM-2008/233, January 2009.

[2] Markets Committee of the ISO/RTO Council, "Harnessing the Power of Demand Response: How ISOs and RTOs Are Integrating Demand Response into Wholesale Electricity Markets," October 2007.

Available online at http://www.isorto.org/atf/cf/\%7B5B4E85C6-7EAC-40A08DC3-003829518EBD\%7D/IRC DR Report 101607.pdf

[3] Brattle Group, "Quantifying Demand Response Benefits in PJM," January 2007. Available online: http://sites.energetics.com/MADRI/pdfs/brattlegroupreport.pdf

[4] U.S. Department of Energy, "Benefits of Demand Response in Electricity Markets and Recommendations for Achieving Them: A Report to the United States Congress Pursuant to Section 1252 of the Energy Policy Act of 2005," February 2006.

[5] P. Sotkiewicz, "Introduction to PJM Demand Response," Indiana Utility Regulatory Commission Workshop, October 2008.

[6] PJM Demand Response Program, Available online: http://pjm.com/markets-andoperations/demand-response.aspx, March 2011.

[7] Midwest ISO Demand Response Task Force, Emergency Demand Response in PJM and NYISO, March 2007.

Available online at: http://www.naesb.org/pdf2/dsmee061807w2.pdf

[8] H. Yoshimura, New England Demand Responses: Present Observations and Future Challenges, February 2008.

Available online at: http://www.naruc.org/Ferc/default.cfm?c=2

[9] CALISO, Demand Response \& Proxy Demand Resource - Frequently Asked Questions, September 2010.

Available online at: http://content.caiso.com/271e/271ee8df2c760.pdf

[10] F. Rahimi, "Overview of Demand Response Programs at Different ISOs/RTOs," IEEE Power Systems Conference and Exposition 2009.

[11] D. Pratt, "NYISO Demand Response Programs: Performance," Presentation at DREXPO in Chicago, IL, October 2007.

[12] NYISO, NYISO Emergency Demand Response Program Manual, Manual 7, December 2010. 
Available online at:

http://www.nyiso.com/public/webdocs/products/demand response/emergency dema nd_response/edrp_mnl.pdf

[13] NYISO, Day-Ahead Demand Response Program Manual, Manual 5, July 2003. Available online at:

http://www.nyiso.com/public/webdocs/products/demand_response/day_ahead/dadrp mnl.pdf

[14] IRC, "North American Wholesale Electricity Demand Response Program Comparison, 2010 Edition,"

Available online at:

http://www.isorto.org/site/c.jhKQIZPBImE/b.2604461/k.6151/Documents and Issu es.htm

[15] PJM, Operational Analysis, http://www.pjm.com/markets-and-operations/opsanalysis.aspx, January 2010.

[16] FERC 1996, Promoting Wholesale Competition Through Open Access Nondiscriminatory Transmission Services by Public Utilities; Recovery of Stranded Costs by Public Utilities and Transmitting Utilities, Order 888, Federal Energy Regulatory Commission, May

[17] ABB Power T\&D Company Inc., "Electrical Transmission and Distribution Reference Book," 1997, $5^{\text {th }}$ Edition, Raleigh, NC.

[18] 2010 Buildings Energy Data Book, Energy Efficiency and Renewable Energy, U.S. Department of Energy, March 2011.

[19] J. Christian, T. Gehl, P. Boudreaux, J. New, and R. Dockery, “Tennessee Valley Authority's Campbell Creek Energy Efficient Homes Project: 2010 First Year Performance Report, July 1, 2009 - August 31, 2010,” ORNL/TM-2010/206, November 2010.

[20] R. Hendron and C. Engebrecth, Building America House Simulation Protocols, "Building America House Simulation Protocols," Building Technologies Program, Energy Efficiency and Renewable Energy, U.S. Department of Energy, October 2010 .

[21] J. F. Kreider, "Handbook of Heating, Ventilation, and Air Conditioning," Boca Raton, FL: CRC Press, ISBN: 978-0849395840, December 2000.

[22] US Environmental Agency and US Department of Energy; Energy Star; Frequently Asked Questions; Lighting; Availble online at: http://energystar.supportportal.com/link/portal/23002/23018/Article/24835/Why-are- 
incandescent-light-bulbs-being-phased-out-I-hear-CFLs-will-be-required-by-2012Is-that-true

[23] F. C. McQuiston, J. D. Parker, and J. D. Spitler, "Heating, Ventilating, and Air Conditioning Analysis and Design," Wiley, $6^{\text {th }}$ Ed., August 2004.

[24] American Society of Heating, Refrigerating and Air-Conditioning Engineers, Inc, "Thermal Environmental Conditions for Human Occupancy," ANSI/ASHRAE Standard 55-2010

[25] M. Goldstein and I. F. Goldstein, “Understanding the Laws of Energy,” Harvard University Press, 1995.

[26] Y. Ikegami, V. K. Nanayakkara, M. Nakashima, and H. Uehara, "Refrigerator system modeling and validation," in Proc., IEEE International Symposium on Industrial Electronics, vol. 3, pp. 2001-2006, June 2001, South Korea.

[27] H. H. Masjuki, R. Saidur, I. A. Choudhury, and T. M. I. Mahlia, "Factors effecting energy consumption of household refrigerator-freezers," in Proc., IEEE TENCON Conference, vol. 2, pp. 92-96, September 2000, Malaysia.

[28] M. D. Felice, L. Piroddi, A. Leva, and A. Boer, "Adaptive temperature control of a household refrigerator," in Proc., American Control Conference, pp. 889-894, June 2009, St. Louis, MO.

[29] United Sates Department of Agriculture, Food Safety and Inspection Service Website, Safe Food Handling, April 2011. Availabe online at: http://www.fsis.usda.gov/factsheets/refrigeration_\%26_food_safety/

[30] D. Najewicz, "Demand Response Enabled Appliances/Home Energy Management System," Presentation at NREL, Golden, CO, October 2009.

[31] J. Kondoh, N. Lu, and D. J. Hammerstrom, "An evaluation of the water heater load potential for providing regulation service," IEEE Transactions on Power Systems, vol. X, no. Y, pp. 1-8, 2010.

[32] J. Fernandez-Seara, F. J. Uhia, and J. Siere, "Experimental analysis of a domestic electric hot water storage tank. Part II: Dynamic mode of operation," Applied Thermal Engineering, vol. 27, pp. 137-144, 2007.

[33] J. Kondoh, H. Aki, H. Yamaguchi, A. Murata, and I. Ishii, "Future consumed power estimation of time deferrable loads for frequency regulation," in Proc., $18^{\text {th }}$ International Conference and Exhibition on Electricity Distribution, June 2005, Turin, Italy.

[34] GE Appliances, GeoSpring Hybrid Electric Residential Water Heaters. 
Available online: at:

http://products.geappliances.com/MarketingObjectRetrieval/Dispatcher?RequestTyp $\underline{\mathrm{e}=\mathrm{PDF} \& N a m e=49-50254-2 . \mathrm{pdf}}$

[35] R. Jia, M. H. Nehrir, and D. A. Pierre, "Voltage control of aggregate electric water heater load for distribution system peak load shaving using field data," in Proc., $39^{\text {th }}$ North American Power Symposium (NAPS), pp. 492-497, September-October 2007, Las Cruces, NM.

[36] A. Sepulveda, L. Paull, W. G. Morsi, H. Li, C. P. Diduch, and L. Chang, "A novel demand side management program using water heaters and particle swarm optimization," in Proc., IEEE Electric Power and Energy Conference (EPEC), pp. 1-5, August 2010, Halifax, Canada.

[37] M. S. Zolpirani, W. G. Morsi, H. Li, C. P. Diduch, and L. Chang, “A centralized controller to control power demands of electric water heaters for peak shaving of total house-hold power demands," in Proc., IEEE Electric Power and Energy Conference (EPEC), August 2010, Halifax, Canada.

[38] B. Levesque, M. Lavioe, J. Joly, "Residential water heater temperature: 49 or 60 degrees Celsius?" The Canadian Journal of Infectious Diseases, January 2004.

[39 ] United States Deparment of Labor, Occupational Safety \& Health Administration website. Link: http://www.osha.gov/dts/osta/otm/legionnaires/faq.html

[40] U.S. Department of Energy, "Home Appliances Usage Indicators by Type of Housing Unit, 2005," Table HC2.10.

Availabe online at: http://www.eia.gov/emeu/recs/recs2005/hc2005_tables/hc10homeappliaceindicators/ pdf/alltables.pdf

[41] Demand Response Module Reference Instructions for Washer Model WPDH8910 Available online at: http://www.geservicenet.com/cc/prodtrng/DRMEnergyMan_b/Washer-49-90371.pdf

[42] Demand Response Module Reference Instructions for Dryer Model DPHV891 Available online at: http://www.geservicenet.com/cc/prodtrng/DRMEnergyMan/Dryer-49-90372.pdf

[43] M. Steinke, "Implementation of the standard for safety-related solid-state controls for household electric ranges, UL 858A," IEEE Transactions on Industry Applications, vol. 28, no. 1, pp. 239-250, January/February 1992.

[44] Omega Engineering Technical Reference, "Introduction to Temperature Controllers," Available online at: http://www.omega.com/prodinfo/temperaturecontrollers.html 
[45] Z. Wei, N. Watson, L. Frater, "Modeling of Compact Fluorescent Lamps," IEEE International Conference on Harmonics and Quality of Power, 2008.

[46] R. Saski, "The Impact of Electronic Ballast Compact Fluorescent Lighting on Power Distribution Systems," Purdue e-Pubs, TR-EE 94-28, September 1994.

[47] B. Wang, X. Ruan, "A Method of Reducing the Peak-to-Average Ratio of LED Current for Electrolytic Capacitor-Less AC-DC Drivers," IEEE Transactions on Power Electronics, Vol. 25, March 2010.

[48] F. Rubinstein, L. Xiaolei, D. Watson, "Using Dimmable Lighting for Regulation Capacity and Contingency Reserves in the Ancillary Services Market: A Feasibility Study" Lawrence Berkeley National Laboratory, December 2010

[49] M. Dyble, N. Narendran, A. Bierman, and T. Klein. 2005. "Impact of dimming white LEDs: Chromaticity shifts due to different dimming methods." Fifth International Conference on Solid State Lighting, Proceedings of SPIE 5941, 291299. Bellingham, WA: International Society of Optical Engineers.

[50] G. Newman, S. Mancini, R. Marchand, "Detection and acceptance of demandresponsive lighting in offices with and without daylight," National Research Council Canada, January 2008.

[51] Computer Power Supply - Schematics, Reviews, and Repair Guides, Available online: http://www.smps.us/computer-power-supply.html

[52] White House Press Release "Vice President Biden Announces Plan to Put One Million Advanced Technology Vehicles on the Road by 2015," January 26, 2010.

[53] 2011 Chevrolet Volt Owner Manual, Available online: http://www.chevrolet.com/assets/pdf/owners/manuals/2011/2011_chevrolet_volt_ow ners.pdf

[54] Chevrolet Volt Specifications, Available online: http://gm-volt.com/full-specifications/ and http://www.roperld.com/science/ChevyVolt.htm

[55] Nissan Zero Emission, Nissan Leaf Specs, Available online: http://www.nissan-zeroemission.com/EN/LEAF/specs.html

[56] David Coldewey, "Nissan releases final specs on the Leaf," CrunchGear, Available online: http://www.crunchgear.com/2010/11/02/nissan-releases-final-specson-the-leaf/ 
[57] Autoblog Green, "Toyota officially launches plug-in Prius program, retail sales in 2011,"

Available online: http://green.autoblog.com/2009/12/14/toyota-officially-launchesplug-in-prius-program-retail-sales-i/

[58] Yoshikazu Tanaka, "Prius Plug-in Hybrid Vehicle Overview," Toyota Passenger Vehicle Development Center, Toyota Motor Corporation, December 2009.

[59] "SAE electric vehicle and plug-in hybrid electric vehicle conductive charge coupler," SAE Standard J-1772, 2010.

[60] A. Bedir, M. Kisacikoglu, and B. Ozpineci, "PHEV Assessment," ORNL/TM2010/221, September 2010.

[61] M.A.S. Masoum, H. Dehbonei, and E.F. Fuchs, "Theoretical and experimental analyses of photovoltaic systems with voltage and current-based maximum powerpoint tracking," IEEE Trans. Energy Conversion, vol. 17, no. 4, 2002, pp. 514-522.

[62] A. Khaligh and O. C. Onar, "Energy Harvesting: Solar, Wind, and Ocean Energy Conversion Systems," Boca Raton, FL: Taylor\&Francis CRC Press, ISBN: 978-14398-0069-0, November 2009.

[63] Brattle Group, "A National Assessment of Demand Response Potential," Federal Energy Regulatory Commission Staff Report, June 2009. 